NIST Technical Note 1896

\title{
High-Speed Monitoring of Multiple Grid-Connected Photovoltaic Array Configurations
}

\author{
Matthew T. Boyd
}

This publication is available free of charge from: http://dx.doi.org/10.6028/NIST.TN.1896
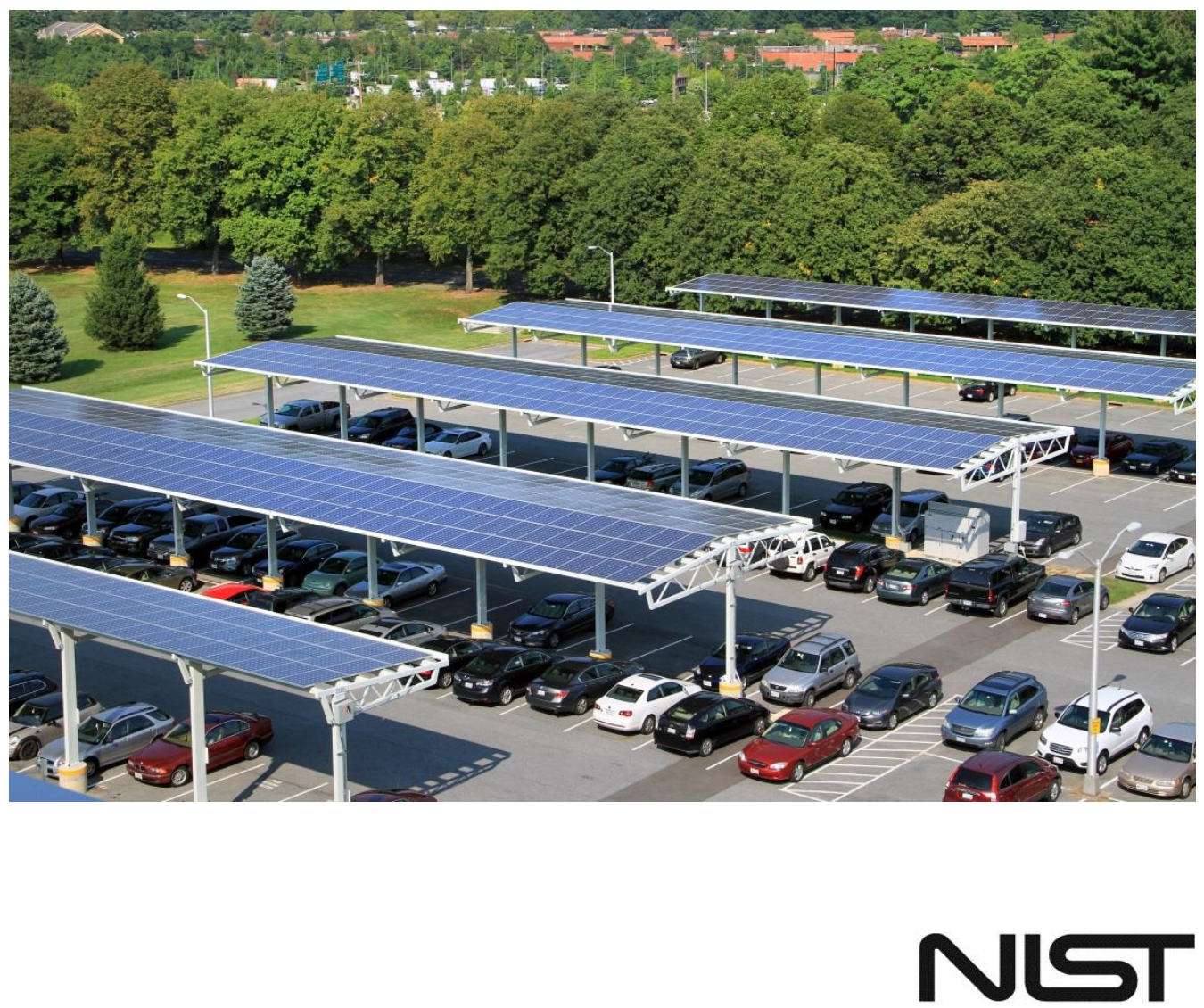

National Institute of Standards and Technology U.S. Department of Commerce 

NIST Technical Note 1896

\title{
High-Speed Monitoring of Multiple Grid-Connected Photovoltaic Array Configurations
}

\author{
Matthew T. Boyd \\ Energy and Environment Division \\ Engineering Laboratory
}

This publication is available free of charge from:

http://dx.doi.org/10.6028/NIST.TN.1896

October 2015

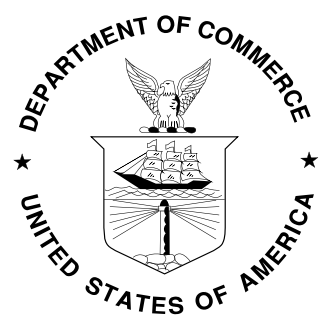

U.S. Department of Commerce Penny Pritzker, Secretary

National Institute of Standards and Technology Willie May, Under Secretary of Commerce for Standards and Technology and Director 
Certain commercial entities, equipment, or materials may be identified in this document in order to describe an experimental procedure or concept adequately. Such identification is not intended to imply recommendation or endorsement by the National Institute of Standards and Technology, nor is it intended to imply that the entities, materials, or equipment are necessarily the best available for the purpose.

National Institute of Standards and Technology Technical Note 1896

Natl. Inst. Stand. Technol. Tech. Note 1896, 60 pages (October 2015) CODEN: NTNOEF

This publication is available free of charge from: http://dx.doi.org/10.6028/NIST.TN.1896 


\section{Preface}

This effort was conducted by the Energy and Environment Division in the Engineering Laboratory at the National Institute of Standards and Technology (NIST). This document describes the data acquisition systems (DASs) for three photovoltaic (PV) arrays on the NIST campus in Gaithersburg, Maryland, USA, and includes the rationale behind choices made for the sensors, data loggers, control software, and supplementary devices that comprise the DASs. The intended audiences are modelers who wish to use the data gathered from these specific systems and researchers who build and utilize similar DASs. Modelers and analysts who are interested in using the data in collaboration on new research before a public data portal is made available can contact the author.

\section{Author Information}

Matthew T. Boyd

Mechanical Engineer

National Institute of Standards and Technology

Engineering Laboratory

100 Bureau Drive, Mailstop 8632

Gaithersburg, MD 20899-8632

Tel.: 301-975-6444

Email: matthew.boyd@nist.gov 


\begin{abstract}
Three grid-connected monocrystalline silicon photovoltaic arrays have been instrumented with research-grade sensors on the Maryland campus of the National Institute of Standards and Technology (NIST). These arrays range from $73 \mathrm{~kW}$ to $271 \mathrm{~kW}$ and are of different tilts, orientations, and configurations. Irradiance, temperature, wind, and electrical measurements at the arrays are recorded, and images are taken of the arrays to monitor any shading or anomalies. Nearly all measurements are sampled and saved every 1 second, with monitoring having started August 1, 2014. This report describes the instrumentation approach to capture the performance of these photovoltaic systems for use in computer model validation or performance monitoring.
\end{abstract}

\title{
Keywords
}

data acquisition, solar energy, photovoltaic array, inverter, meteorology 


\section{Table of Contents}

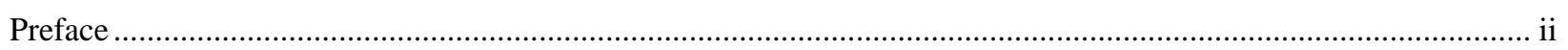

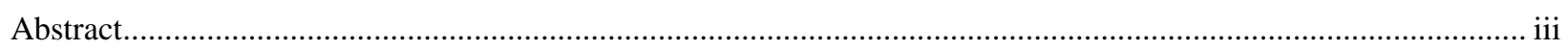

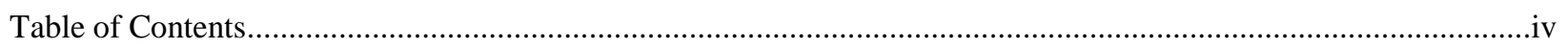

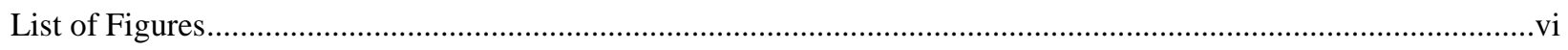

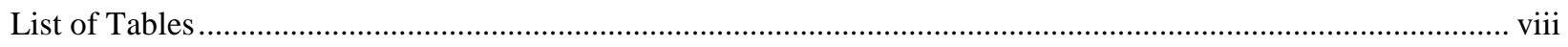

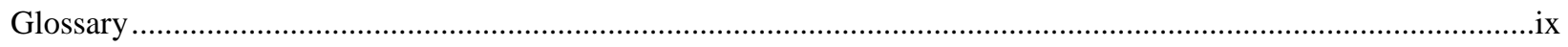

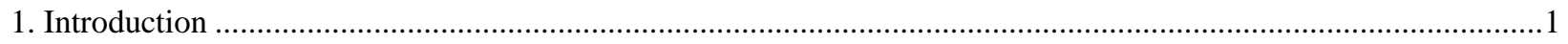

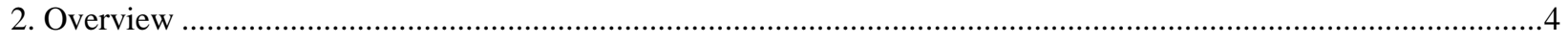

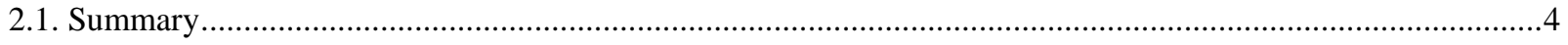

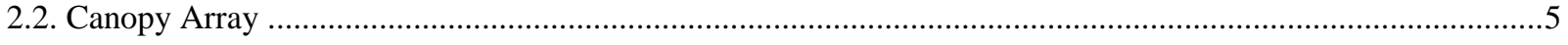

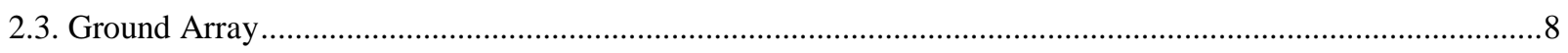

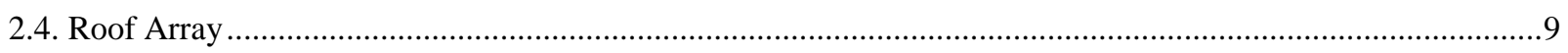

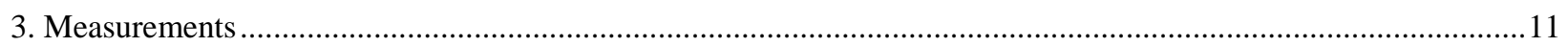

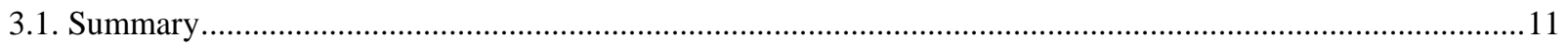

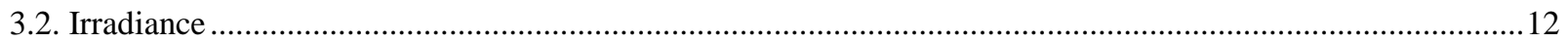

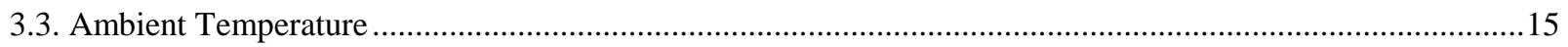

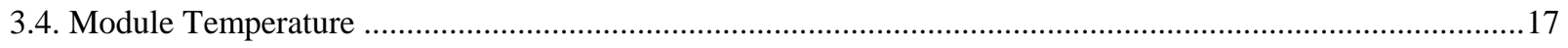

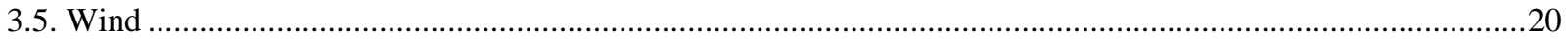

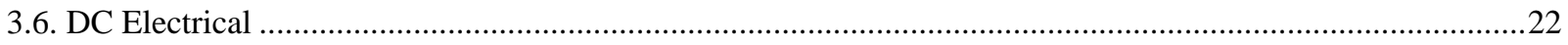

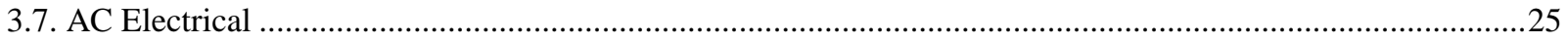

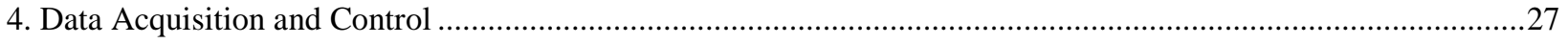

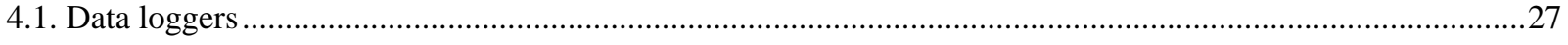

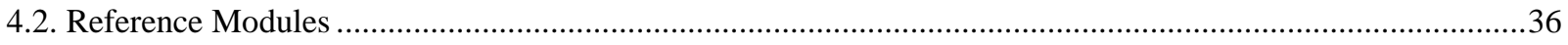

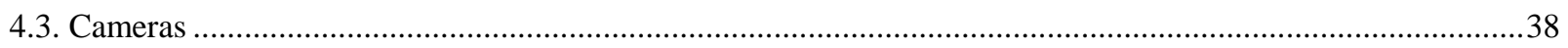

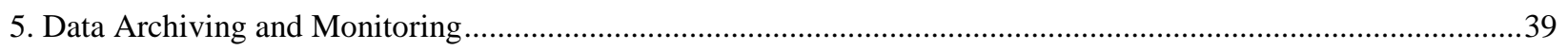

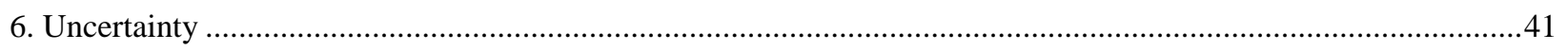

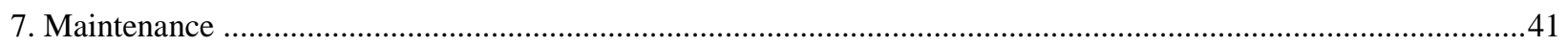

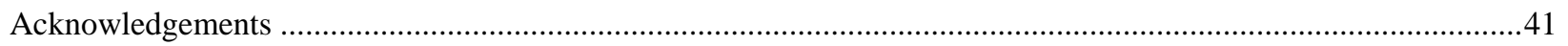

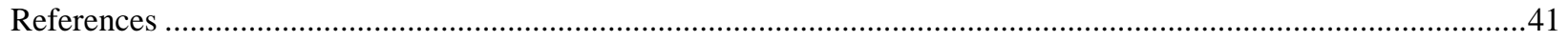

Appendix A. Oblique Images of the Arrays ............................................................................................... A-1

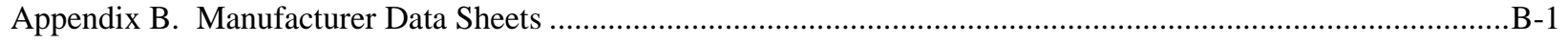

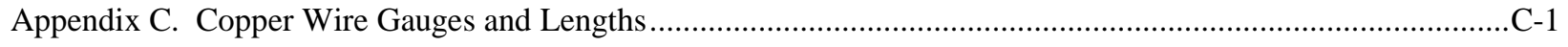

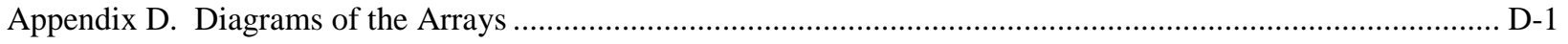


Appendix E. The Saved Data Values From Each Array ……............................................................................. E-1

Appendix F. Anonymized Diagram of the Data Acquisition Systems' Communications Network .......................... F-1 


\section{List of Figures}

Figure 1-1 A map of the instrumented PV arrays and weather station on the NIST campus in Gaithersburg, Maryland. The horizontal roof array shown will be instrumented as part of a future project. The vertical

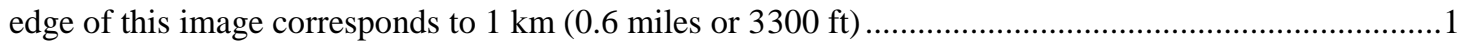

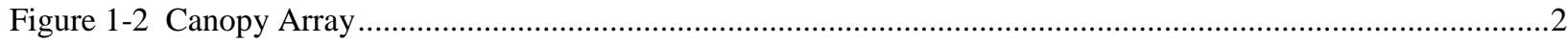

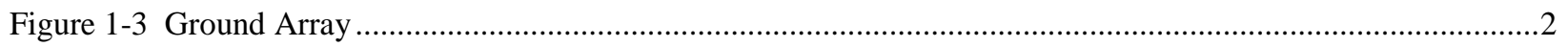

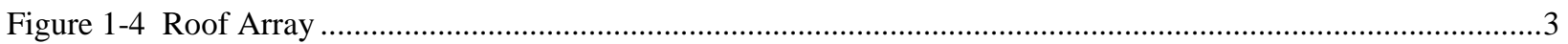

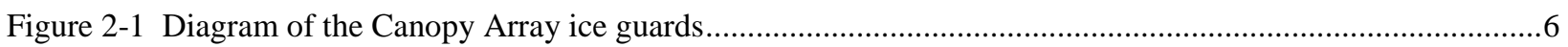

Figure 2-2 Canopy Array electrical layout and measurement locations. The numbered squares are the combiner boxes and the hatched regions are the source circuits. Note that "POA Pyra." stands for a pyranometer in the plane of the array, "GHI" stands for a pyranometer measuring the global horizontal irradiance, and "RTD" stands for resistance temperature detector, which are mounted on the backsides of the respective modules. The integrator also has an RTD mounted on the back of a cell on the module north of combiner box 3, the same module with a NIST RTD.

Figure 2-3 The Canopy Array inverter, identical to the Ground Array inverter .....................................................

Figure 2-4 Ground Array electrical layout and measurement locations. The numbered squares are the combiner boxes and the hatched regions are the source circuits. The gray regions on the front, back, and east sides of the array are bioretention areas. Note that "POA Pyra." stands for a pyranometer in the plane of the array, "GHI" stands for a pyranometer measuring the global horizontal irradiance, and "RTD" stands for resistance temperature detector, which are mounted on the backsides of the respective modules. The integrator also has an RTD mounted on the back of a cell on the module east of combiner box 3 , the

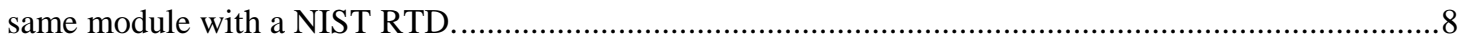

Figure 2-5 Wind deflectors on the rear of the Roof Array module racks ..........................................................

Figure 2-6 Roof Array electrical layout and measurement locations. The numbered squares are the combiner boxes and the hatched regions are the source circuits. Note that "POA Pyra." stands for a pyranometer in the plane of the array, "GHI" stands for a pyranometer measuring the global horizontal irradiance, and "RTD" stands for resistance temperature detector, which are mounted on the backsides of the respective modules

Figure 2-7 The Roof Array inverter.

Figure 3-1 The Canopy Array weather instruments at the north end of the center canopy, showing the irradiance sensors and mounts as well as the ambient temperature sensor, wind sensor, and wind sensor surge protector.

Figure 3-2 The Ground Array irradiance sensors at the center of the array, showing the sensors and mounts ..........13

Figure 3-3 The Roof Array irradiance sensors at the southeast corner of the array, showing the sensors and mounts

Figure 3-4 The irradiance sensors at the center of the older horizontal PV array, showing the sensors and mounts .14

Figure 3-5 The temperature probe and radiation shield used to measure the outdoor ambient air temperature at each array

Figure 3-6 The temperature probe and enclosure used to measure the ambient air temperature in the inverters at the Canopy and Ground Arrays

Figure 3-7 A visual comparison of the three types of module temperature sensors used at the arrays and for the reference modules: the RTD used at the arrays (left), the RTD used for the reference modules (center), and the thermocouple used for the reference modules (right)......

Figure 3-8 An RTD mounted on the back of a module using thermally conductive epoxy and an adhesive film overlay

Figure 3-9 The integrator's module temperature sensor mounted on the back of a module at the Ground Array ......20

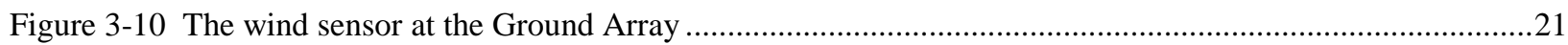

Figure 3-11 The wind sensor and outdoor ambient temperature sensor at the Roof Array ....................................21 
Figure 3-12 The custom voltage divider circuit for measuring the array DC voltage

Figure 3-13 The inverter DC combiner compartment at the Ground Array with the installed DC measurement components, including the current shunts, and left-to-right on the upper DIN rail: the ambient temperature sensor, shunt RTU, analog transmitter, voltage divider, and fuse holder. .24

Figure 3-14 The outdoor DC measurement enclosure at the Roof Array, which includes the current shunts, and leftto-right on the upper DIN rail: the fuse holder, voltage divider, analog transmitter, and shunt RTU ....24

Figure 3-15 The AC power meter at the Ground Array (formerly branded by Square D), also showing the separate dedicated enclosure for the voltage tap fuses

Figure 4-1 The data acquisition enclosure at the Canopy Array showing the data logger, measurement and communication peripherals, battery backup, and power converters and distribution blocks ................27

Figure 4-2 The integrator's RTU and a terminal block in their outdoor enclosure at the Ground Array ...................29

Figure 4-3 Breakdown of the DAS energy draws and UPS backups.....................................................................30

Figure 4-4 The indoor communication hubs at the Ground Array for the NIST (top) and integrator (bottom)

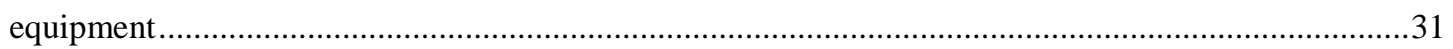

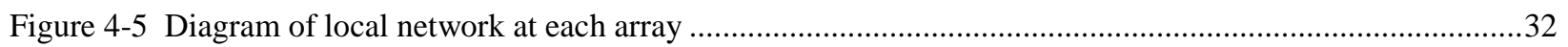

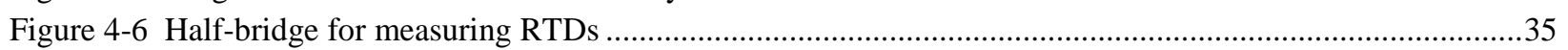

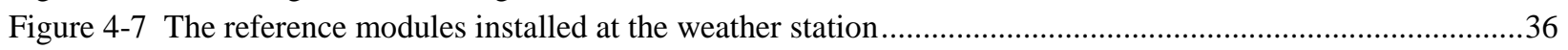

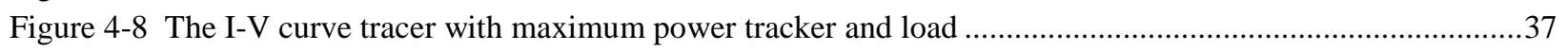

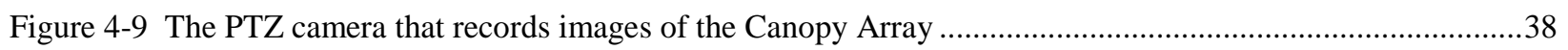

Figure 4-10 The enclosure for the Canopy and Roof Array camera midspans and network switch ..........................39

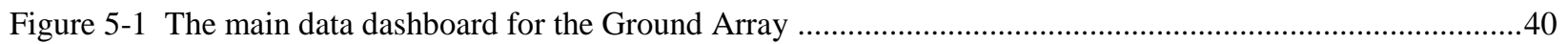

Figure A-1 Oblique Aerial View of the Canopy Array Site …….......................................................................

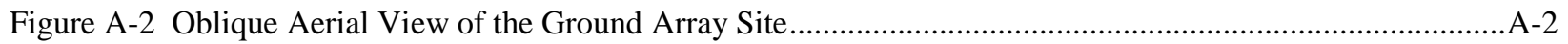

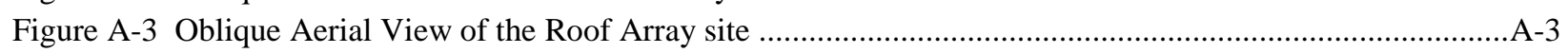

Figure B-1 Manufacturer Datasheet for the PV Module at All Three Arrays ........................................................... B-1

Figure B-2 Manufacturer Datasheet for the Inverter at the Canopy and Ground Arrays ........................................ B-2

Figure B-3 Manufacturer Datasheet for the Inverter at the Roof Array ............................................................... B-3

Figure D-1 Diagram of the Canopy Array Strings and Pertinent Array Dimensions ............................................D-1

Figure D-2 Diagram of the Ground Array Strings and Pertinent Array and Fence Dimensions ............................D-2

Figure D-3 Diagram of the Roof Array Strings and Pertinent Array Dimensions ..................................................

Figure F-1 Anonymized Diagram of the Data Acquisition Systems' Communications Network .......................... F-1 


\section{List of Tables}

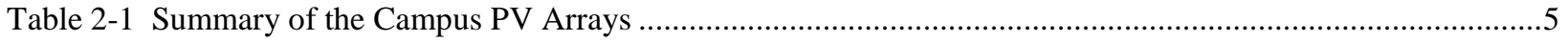

Table 3-1 Summary of the Measurements and Respective Instruments Installed at the Campus PV Arrays ............11

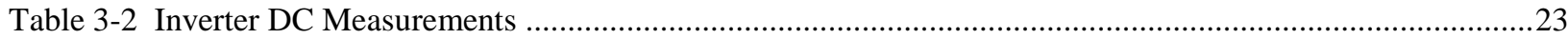

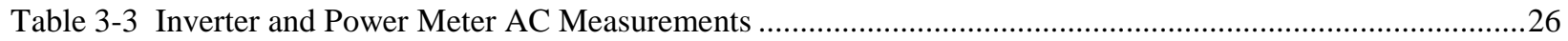

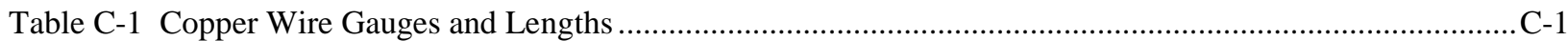

Table E-1 The Saved Data Values From Each Array ........................................................................................ E-1 


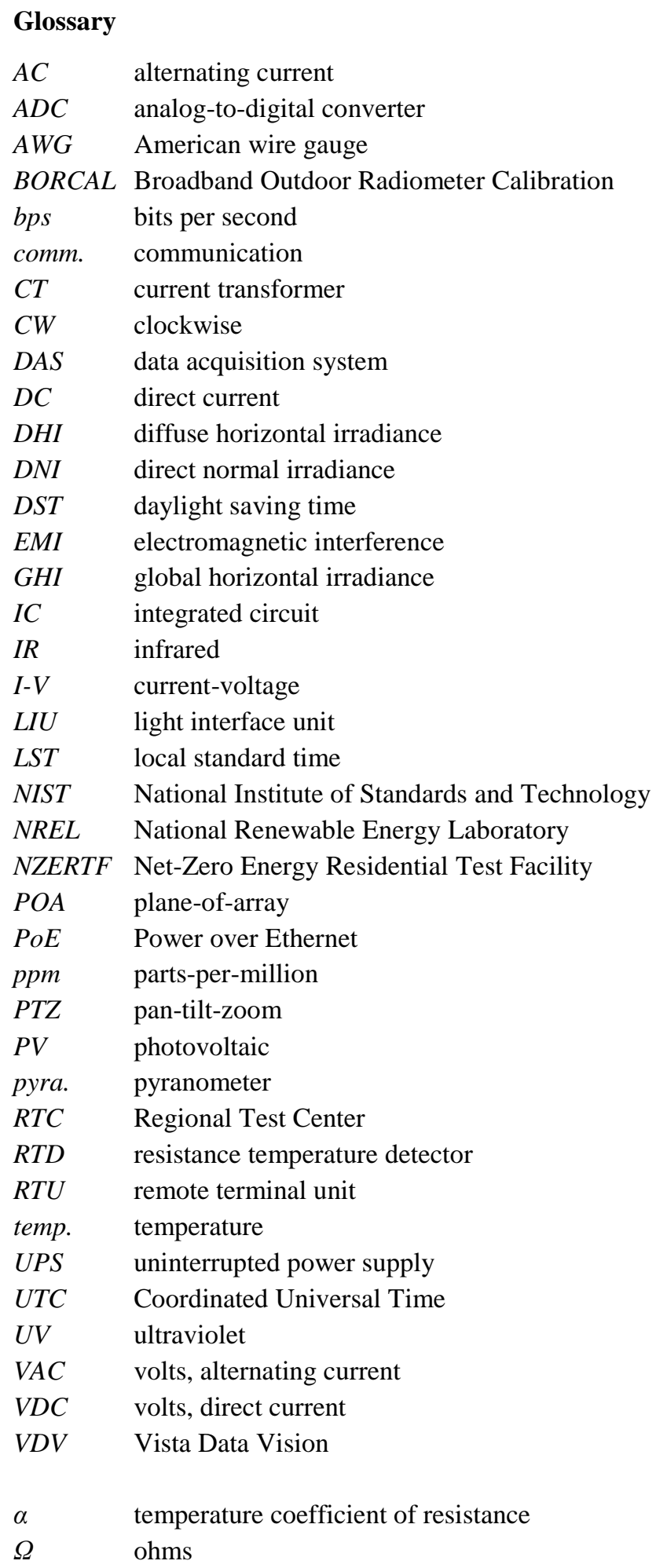




\section{Introduction}

Three grid-connected solar photovoltaic (PV) arrays were constructed on the National Institute of Standards and Technology (NIST) campus in Gaithersburg Maryland, with construction finishing around July of 2012. A map of the sites is shown in Figure 1-1. Oblique aerial views of the three array sites are provided in Appendix A.

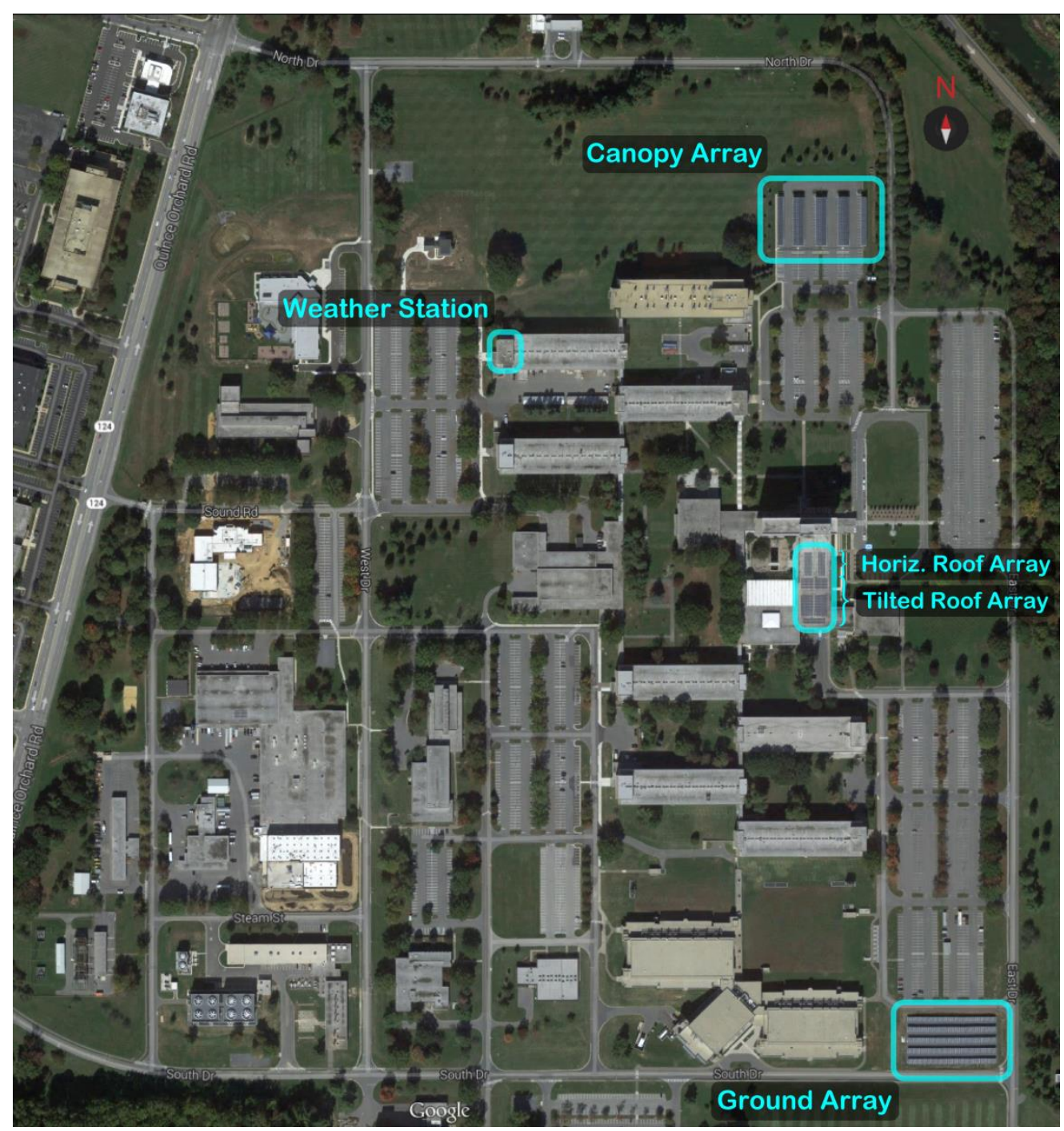

Figure 1-1 A map of the instrumented PV arrays and weather station on the NIST campus in Gaithersburg, Maryland. The horizontal roof array shown will be instrumented as part of a future project. The vertical edge of this image corresponds to $1 \mathrm{~km}(0.6$ miles or $3300 \mathrm{ft})$

The three arrays use the same monocrystalline silicon module, but all are mounted in different configurations: the Canopy Array (Figure 1-2) is mounted on east/west facing canopies over a parking lot, the Ground Array (Figure 1-3) is mounted on tilted ground supports in an open field, and the Roof Array (Figure 1-4) is mounted on tilted, weighted racks on a flat building roof. 


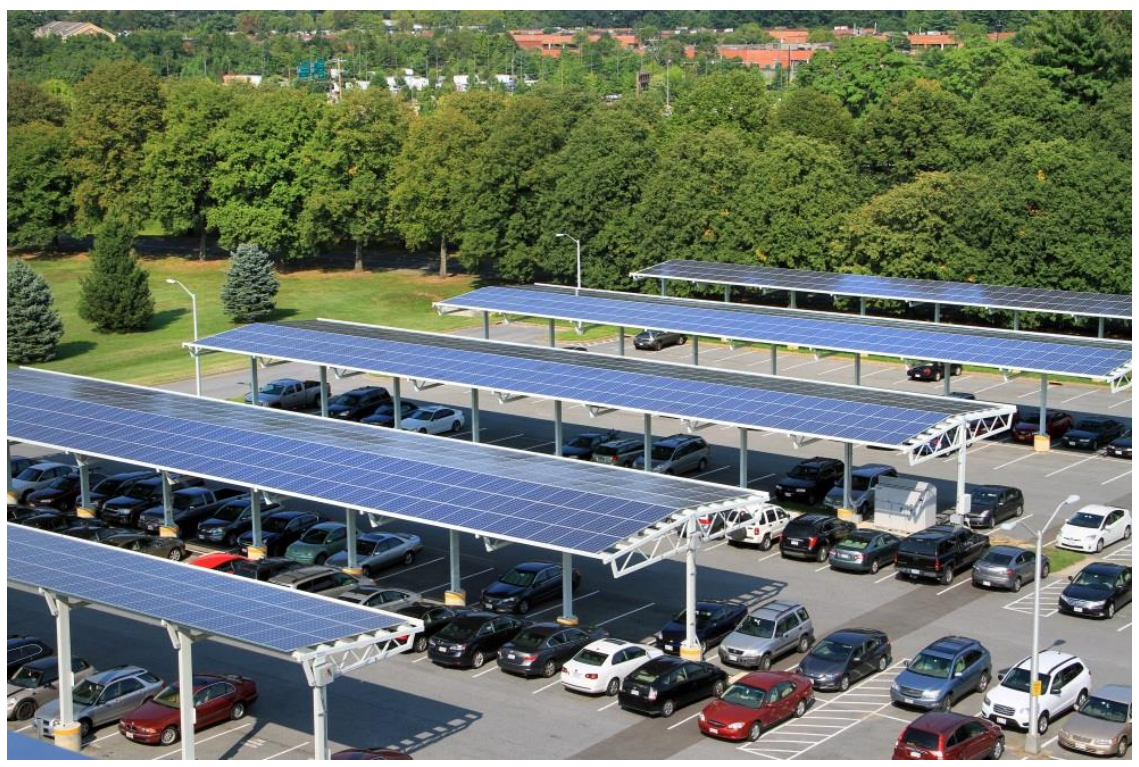

Figure 1-2 Canopy Array

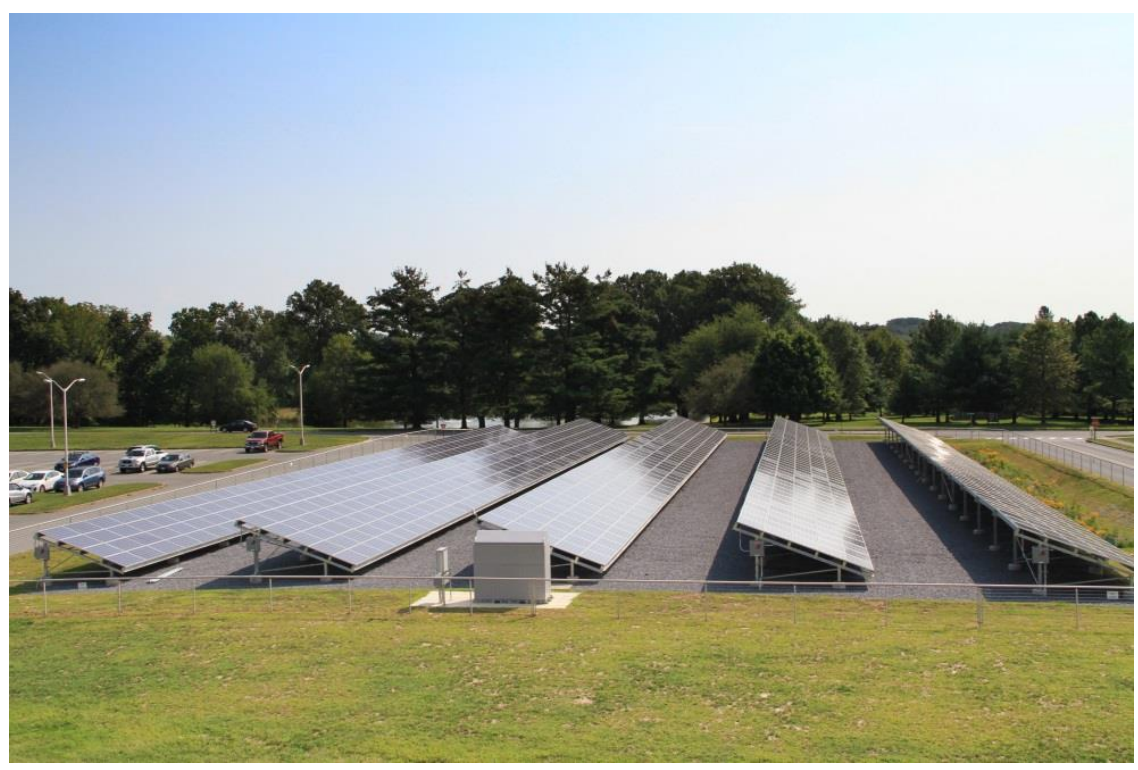

Figure 1-3 Ground Array 


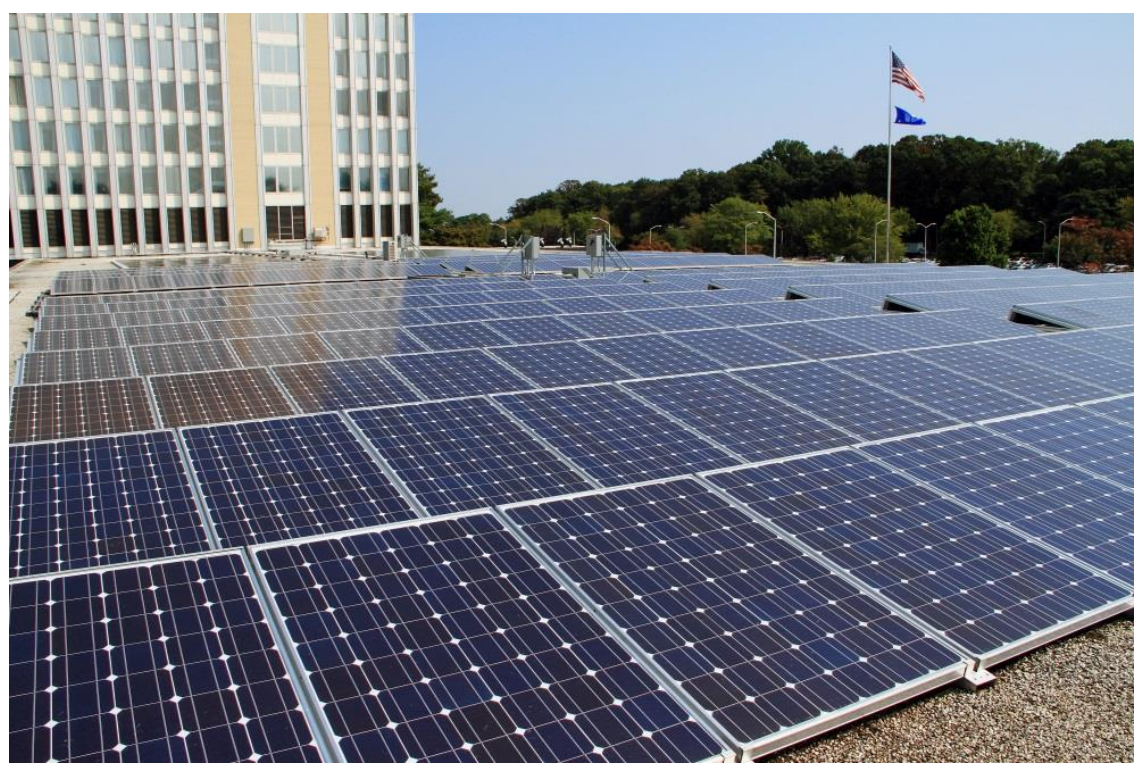

Figure 1-4 Roof Array

Research-grade sensors have been installed at each array and at the onsite weather station to measure various electrical, temperature, and meteorological values. These data acquisition systems (DASs) were created to address the needs for long-term, high accuracy, sub-minute data sets from large scale, calibrated, well-maintained and documented systems in a variable environment, as expressed in [1], [2], [3], and [4]. The only other known arrays instrumented to a comparable level with public to semi-public data sets in the northeast of the United States are the $65 \mathrm{~kW}$ to $907 \mathrm{~kW}$ arrays at the Northeast Solar Energy Research Center (NSERC) [5] and the $32 \mathrm{MW}$ Long Island Solar Farm [6], both installed at Brookhaven National Laboratory in Upton, New York, on Long Island, and the $6 \mathrm{~kW}$ and $60 \mathrm{~kW}$ Regional Test Center (RTC) arrays installed at an IBM facility in Williston, Vermont [7].

The weather station, at the location shown in Figure 1-1, measures various other meteorological quantities, providing supplementary data to the PV data sets. These measurements include:

- $\quad$ direct normal irradiance (DNI)

- diffuse horizontal irradiance (DHI)

- global horizontal irradiance (GHI)

- infrared (IR) irradiance (net and total)

- ultraviolet (UV) irradiance (A, B, and total)

- spectral irradiance curves

- snow depth

- $\quad$ wind speed and direction

- humidity

- precipitation

- barometric pressure

- hail count

- ambient temperature

- whole sky images

The weather station DAS will be described in a forthcoming technical report. 
The PV integrator who constructed the arrays has also installed a separate DAS at each PV array, monitoring a much smaller scope of parameters. Hereafter, if a differentiation is not made between the systems, then the NIST system is the one being referred to. At each array, both systems share communications with the inverter and AC power meter, with the NIST system also recording all other measurements made by the integrator's system.

The NIST systems save measurement values, including those from the integrator's systems, every 1 second along with the status of select components. Cameras near each array capture still images every 5 minutes, and a currentvoltage (I-V) tracer with a maximum power tracker and load saves curve traces from reference modules installed at the weather station in the orientations of each array every 1 minute, along with one-minute averaged maximum power measurements from one-second samples.

\section{Overview}

\subsection{Summary}

The arrays are located in Gaithersburg, Maryland in the United States, which is in the Eastern Time Zone (-5 hours from Coordinated Universal Time (UTC)). A summary of the arrays is given in Table 2-1. Location information is for the center of the array, elevation is for the base of the array support (e.g., ground, roof) above sea level, and height is the distance from the base of the array support to the bottom edge of the bottom module. Manufacturer data sheets for the module and inverters are provided in Appendix B and the average lengths and gauges of the wires are provided in Appendix C. 
Table 2-1 Summary of the Campus PV Arrays

\begin{tabular}{|c|c|c|c|}
\hline & Canopy & Ground & Roof \\
\hline Array Rated DC Power [kW] & 243 & 271 & 73 \\
\hline Latitude $\left[{ }^{\circ} \mathrm{N}\right]$ & 39.1385 & 39.1319 & 39.1354 \\
\hline Longitude $\left[{ }^{\circ} \mathrm{E}\right]$ & -77.2155 & -77.2141 & -77.2156 \\
\hline Elevation $^{*}[\mathrm{~m}]$ & 137 & 138 & 149 \\
\hline Height $^{* *}[\mathrm{~m}]$ & 5.11 & 0.67 & 0.08 \\
\hline Tilt $\left[{ }^{\circ}\right]$ & 5 & 20 & 10 \\
\hline Azimuth [ ${ }^{\circ} \mathrm{CW}$ from N.] & 90,270 & 180 & 180 \\
\hline Number of Modules & 1032 & 1152 & 312 \\
\hline Module Manufacturer & & Sharp $^{1}$ & \\
\hline Module Model & & NU-U235F2 & \\
\hline Module Technology & \multicolumn{3}{|c|}{ monocrystalline silicon - front contact } \\
\hline Module Rated Power [W] & \multicolumn{3}{|c|}{235} \\
\hline Modules Per String & \multicolumn{3}{|c|}{12} \\
\hline Number of Source Circuits & 86 & 96 & 26 \\
\hline Number of Combiner Boxes & 7 & 7 & 4 \\
\hline Number of Inverters & 1 & 1 & 1 \\
\hline Inverter Manufacturer & \multicolumn{2}{|c|}{ PV Powered (now Advanced Energy) } & Satcon \\
\hline Inverter Model & \multicolumn{2}{|c|}{ PVP260kW } & PVS-75 480 \\
\hline Inverter Rated Power [kW] & \multicolumn{2}{|c|}{260} & 75 \\
\hline
\end{tabular}

* Elevation of the array support (e.g., ground, roof) above sea level

${ }^{* *}$ Height of bottom edge of the bottom module above the array support (e.g., ground, roof)

\subsection{Canopy Array}

The Canopy Array in the parking lot northeast of NIST Building 227 is composed of five canopies running northsouth. The middle canopies have modules tilted nominally $5^{\circ}$ east and west and the two end canopies have modules tilted $5^{\circ}$ toward the center of the array. Periodic local shading on the array is caused by the five-story Building 227 southwest of the array, a line of trees east of the array, and several trees south and southwest of the array. Some local shading is also caused by ice guards along the outer longitudinal edges of the canopies that were designed to stop large sheets of ice from falling off the array. A diagram of the ice guards is shown in Figure 2-1.

${ }^{1}$ Certain commercial equipment, instruments, or materials are identified in this paper to foster understanding. Such identification does not imply recommendation or endorsement by the National Institute of Standards and Technology, nor does it imply that the materials or equipment identified are necessarily the best available for the purpose. 


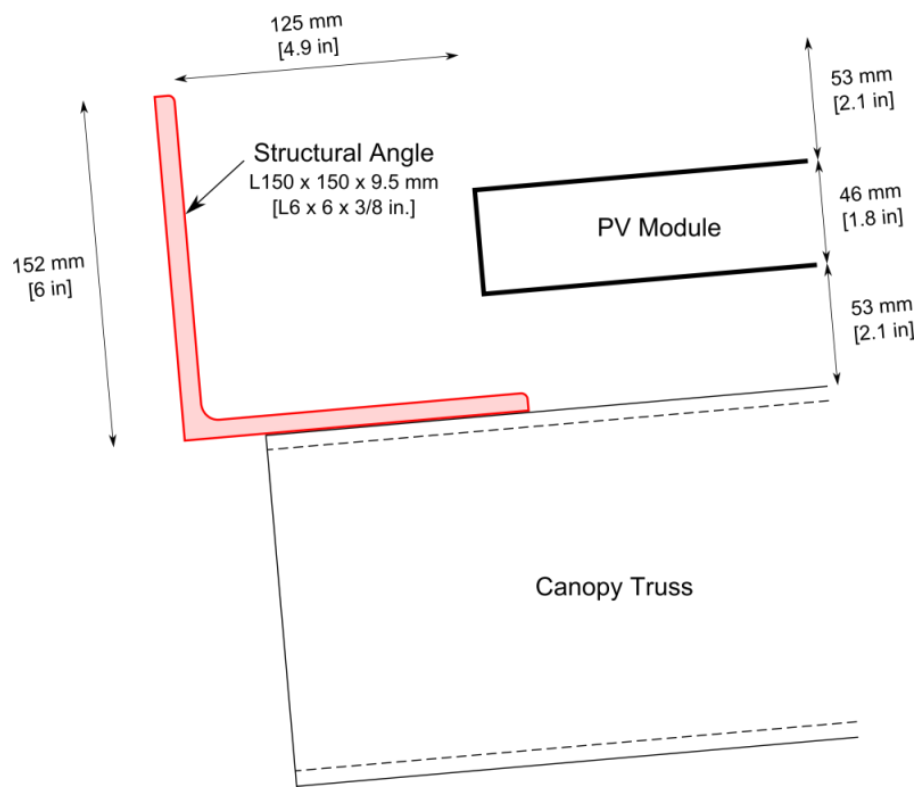

Figure 2-1 Diagram of the Canopy Array ice guards

The module strings in the array run predominantly north to south longitudinally in the five canopies. Individual strings contain modules that are either all east facing or all west facing. These strings combine in parallel at seven combiner boxes, at module height, to form seven output circuits that run to the inverter. Two of these output circuits contain strings in the same canopies and orientations, three contain strings in the same canopies but in both orientations, and two contain strings from four different canopies and in both orientations. This layout was designed to keep modules that are in the same strings at the same tilts to avoid limiting their power output due to current mismatch. This layout does, however, result in relatively longer source circuit wire lengths to the respective combiner box DC disconnects, as the wires have to run down the $5.35 \mathrm{~m}(17.5 \mathrm{ft})$ high canopies and through $0.9 \mathrm{~m}$ ( $3 \mathrm{ft}$ ) deep trenches and back up the other canopies. A diagram of the Canopy Array wiring layouts and the locations of the combiner boxes, inverter, and all instruments and sensors is shown in Figure 2-2. An image of the inverter is shown in Figure 2-3. A diagram of the string layouts and pertinent dimensions of the array is provided in Appendix D. 


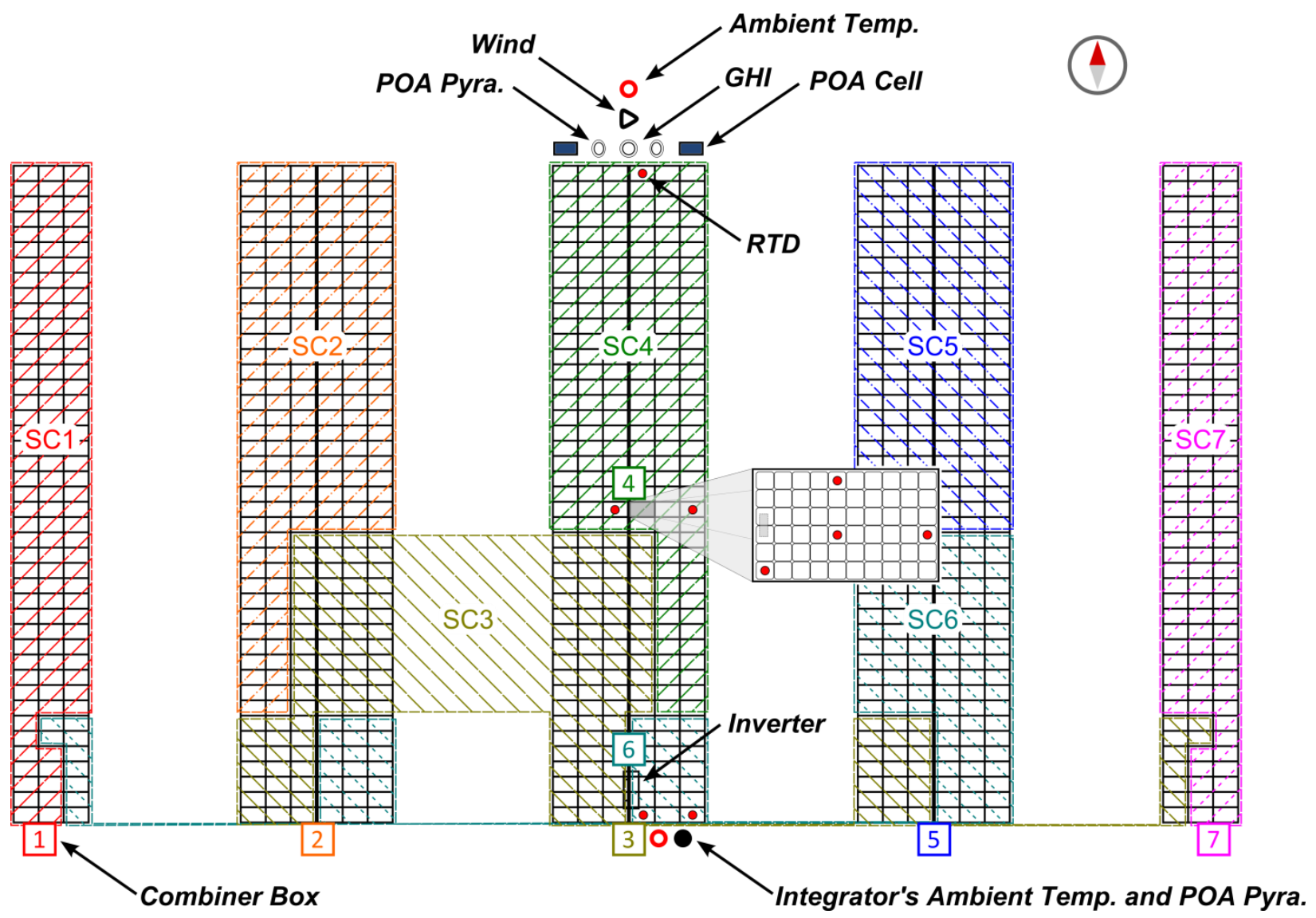

Figure 2-2 Canopy Array electrical layout and measurement locations. The numbered squares are the combiner boxes and the hatched regions are the source circuits. Note that "POA Pyra." stands for a pyranometer in the plane of the array, "GHI" stands for a pyranometer measuring the global horizontal irradiance, and "RTD" stands for resistance temperature detector, which are mounted on the backsides of the respective modules. The integrator also has an RTD mounted on the back of a cell on the module north of combiner box 3 , the same module with a NIST RTD.

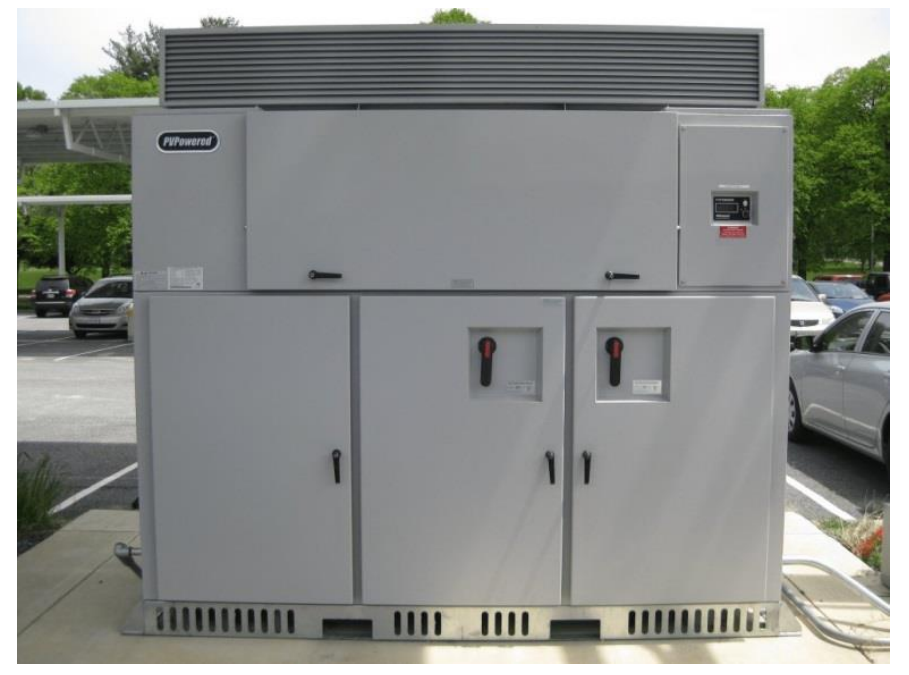

Figure 2-3 The Canopy Array inverter, identical to the Ground Array inverter 


\subsection{Ground Array}

The Ground Array in the field east of Building 216 is composed of five tilted rows, or sheds, running east-west. All sheds are tilted at nominally $20^{\circ}$ due south. The four front southernmost sheds are five modules wide while the back north shed is four modules wide. Periodic local shading on the array is caused by inter-row shading, the three-story Building 216 directly west of the array, vegetation in the bioretention area south of the array before it is periodically trimmed, and a $1.2 \mathrm{~m}$ (48 in.) high cable rail fence surrounding the array. This fence, shown in Figure 1-3, has a 6.4 $\mathrm{cm}(2.5$ in.) diameter horizontal top rail and $4.8 \mathrm{~cm}(1.9 \mathrm{in}$.) diameter vertical posts spaced $2.7 \mathrm{~m}(9 \mathrm{ft})$ apart.

The module strings in the array run east to west longitudinally in the five sheds. These strings combine in parallel at seven combiner boxes approximately $1.5 \mathrm{~m}(5 \mathrm{ft})$ above the ground to form seven output circuits that run to the inverter. Four of these output circuits contain strings in the same shed and the remaining three contain strings from two different sheds. This layout does result in relatively longer source circuit wire lengths to the respective combiner box DC disconnects, like the Canopy Array, as the wires have to run down the $2.06 \mathrm{~m}$ to $2.40 \mathrm{~m}$ ( $6.8 \mathrm{ft}$ to $7.9 \mathrm{ft}$ ) high ground supports and through $0.9 \mathrm{~m}(3 \mathrm{ft})$ deep trenches and back up the other sheds. A diagram of the Ground Array wiring layouts and the locations of the combiner boxes, inverter, and all of the instrument and sensor locations is shown in Figure 2-4. The inverter is identical to the one at the Canopy Arrays, as shown in Figure 2-3. A diagram of the string layouts and pertinent dimensions of the array as well as dimensions of the fence are provided in Appendix D.

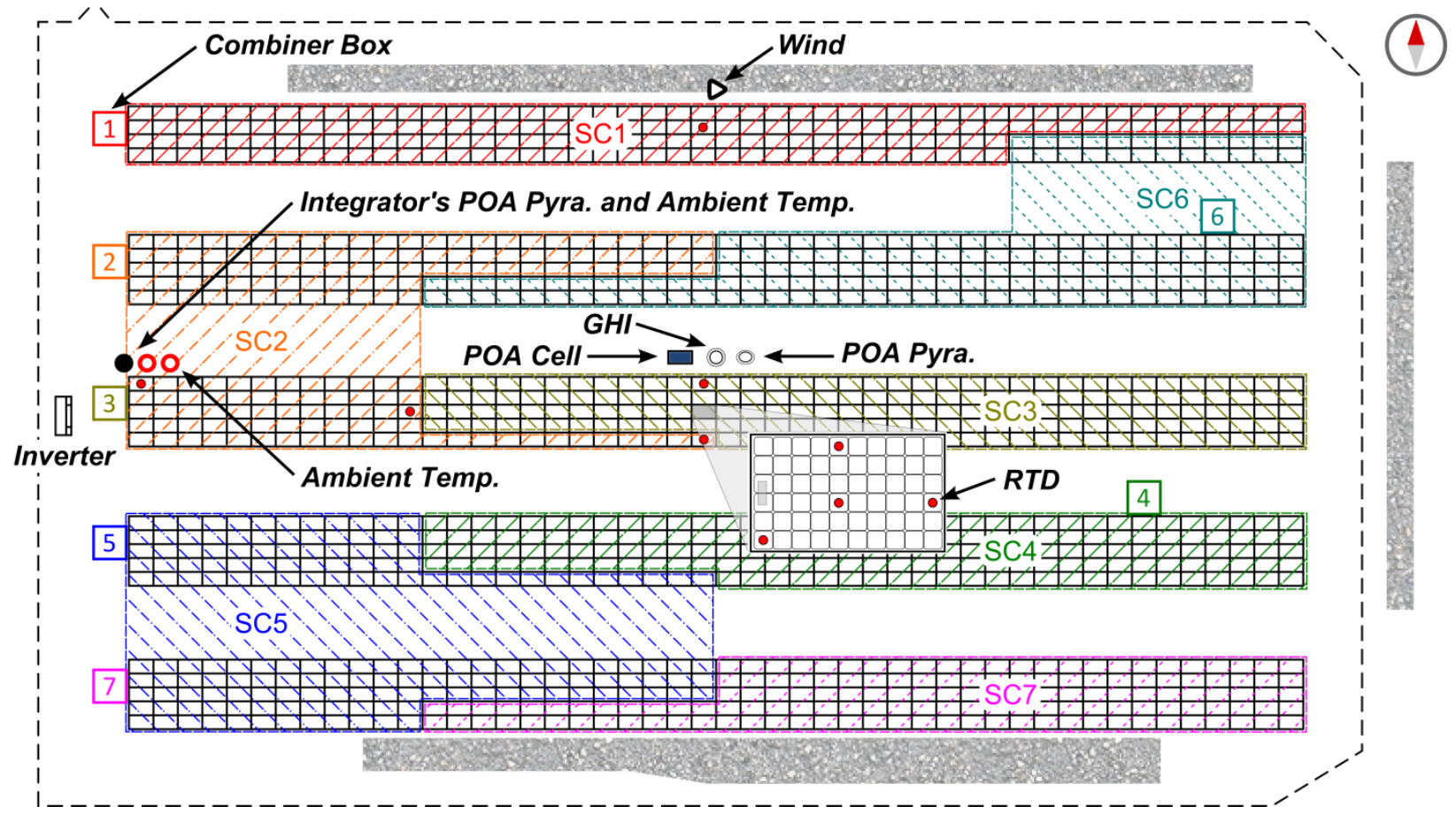

Figure 2-4 Ground Array electrical layout and measurement locations. The numbered squares are the combiner boxes and the hatched regions are the source circuits. The gray regions on the front, back, and east sides of the array are bioretention areas. Note that "POA Pyra." stands for a pyranometer in the plane of the array, "GHI" stands for a pyranometer measuring the global horizontal irradiance, and "RTD" stands for resistance temperature detector, which are mounted on the backsides of the respective modules. The integrator also has an RTD mounted on the back of a cell on the module east of combiner box 3, the same module with a NIST RTD. 


\subsection{Roof Array}

The Roof Array is located on a one-story roof of Building 101 just south of the 14 story tower section of the building. The array is composed of three sections arranged around various vents and other roof elements. The modules are tilted nominally $10^{\circ}$ due south; however, the north section of modules has a slight $0.5^{\circ}$ clockwise azimuthal offset. All of the module racks have an integrated sheet metal wind deflector at the back of the modules to inhibit wind forces, as shown in Figure 2-5; however, these deflectors also inhibit convective cooling of the modules from the wind.

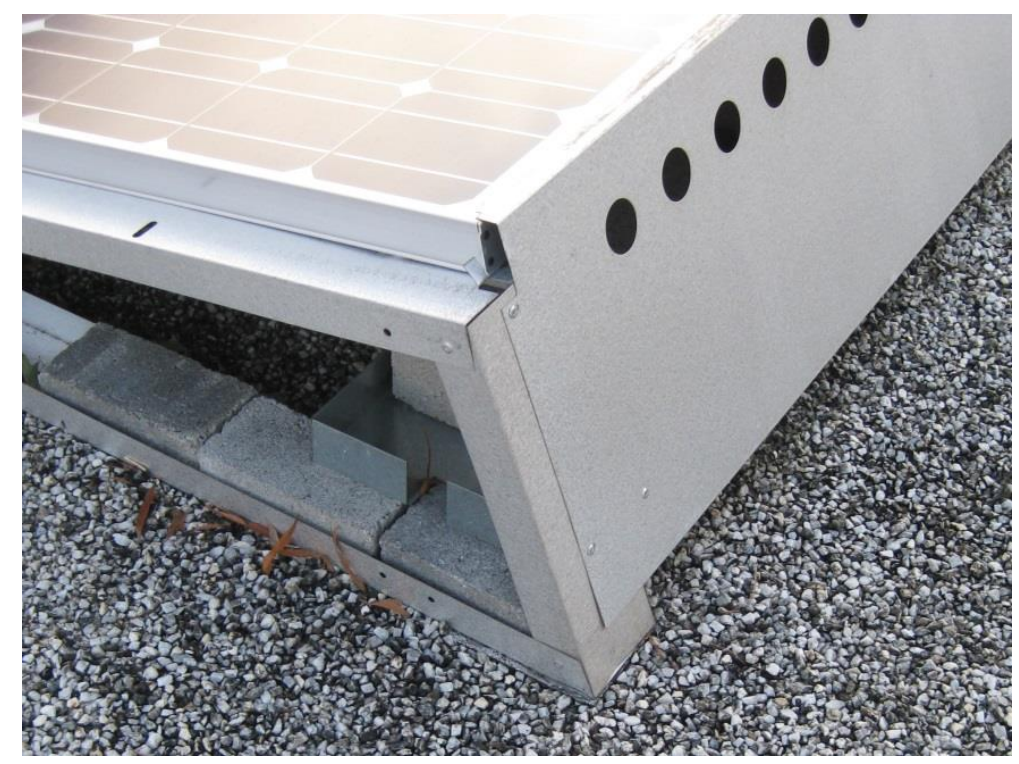

Figure 2-5 Wind deflectors on the rear of the Roof Array module racks

Periodic local shading on the array is caused by inter-row shading, $1.4 \mathrm{~m}$ to $4 \mathrm{~m}$ ( $4.6 \mathrm{ft}$ to $13 \mathrm{ft}$ ) high building elements to the east and west of the array, the combiner boxes, and roof vents. The 14 story (13 stories above array) building tower directly north of the array blocks a fraction of the diffuse irradiance but reflects and augments the irradiance incident on the array during sunny conditions [8].

The module strings in the array run predominantly east to west. The two farthest east modules in the most southern two rows are not connected to the array and will serve as replacements for any future broken modules in the three arrays. The module strings combine in parallel at four combiner boxes $0.5 \mathrm{~m}(1.6 \mathrm{ft})$ above the roof to form four output circuits that run to the inverter. Two of these output circuits contain strings in the same sections and the remaining two contain strings from different sections. The sections in this array layout are relatively close together, so there is significantly less additional wire needed to span the sections than that at the Canopy and Ground Arrays. The inverter, however, is farther from the array than at the other two arrays, located approximately $60 \mathrm{~m} \mathrm{(200} \mathrm{ft)}$ north of the array in the tower section of the building at the same height of the array. A diagram of the Roof Array wiring layouts and the locations of the combiner boxes and all of the instrument and sensor locations is shown in Figure 2-6. An image of the inverter is shown in Figure 2-7. A diagram of the string layouts and pertinent dimensions of the array is provided in Appendix D. 


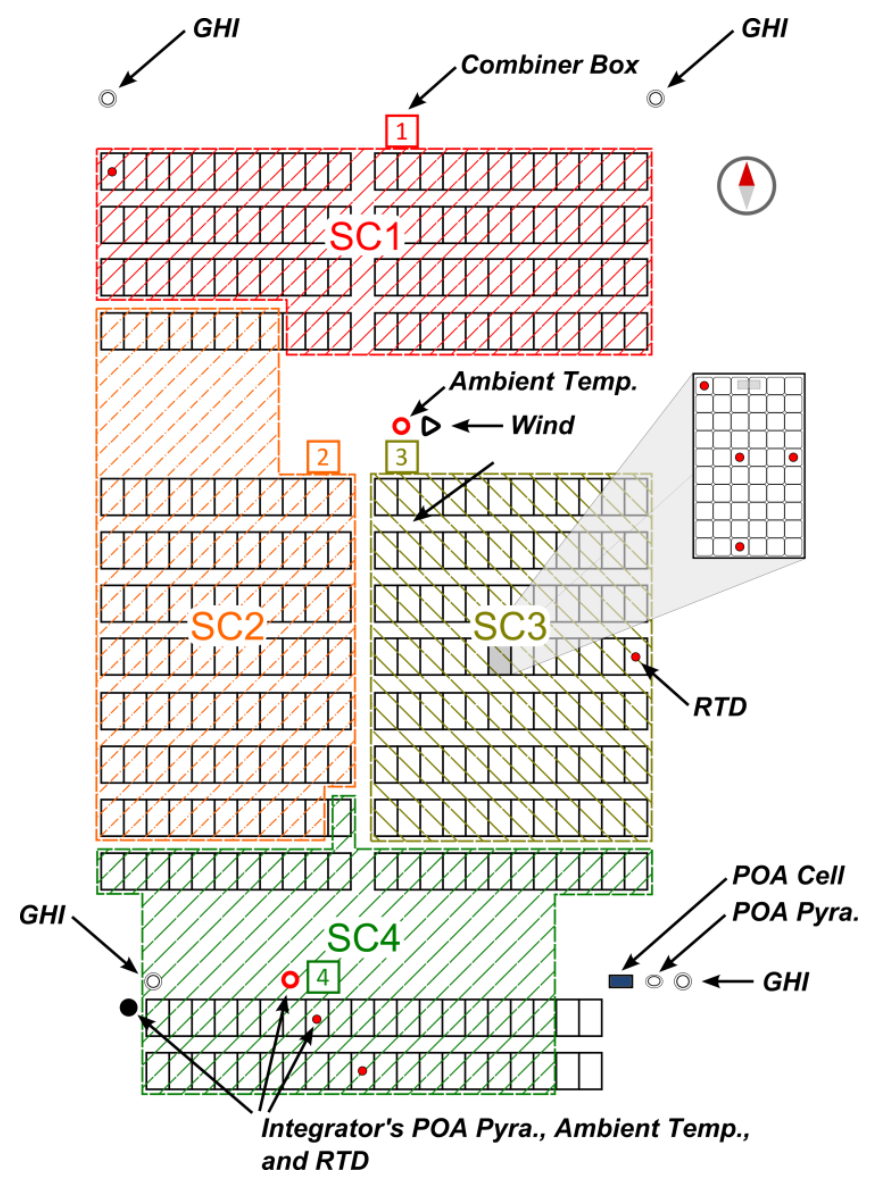

Figure 2-6 Roof Array electrical layout and measurement locations. The numbered squares are the combiner boxes and the hatched regions are the source circuits. Note that "POA Pyra." stands for a pyranometer in the plane of the array, "GHI" stands for a pyranometer measuring the global horizontal irradiance, and "RTD" stands for resistance temperature detector, which are mounted on the backsides of the respective modules.

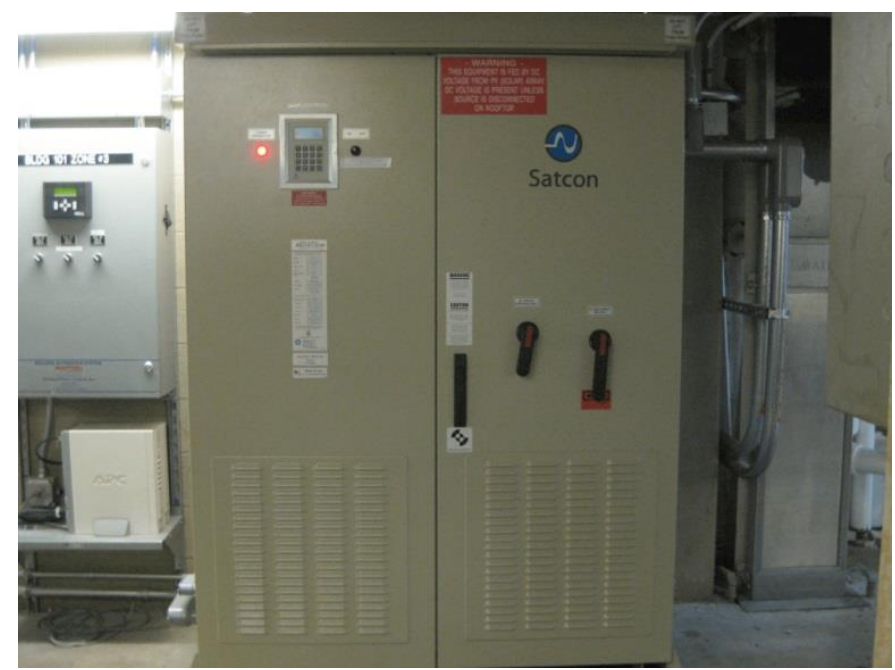

Figure 2-7 The Roof Array inverter 


\section{Measurements}

\subsection{Summary}

The measurements at each array and their corresponding sensor or instrument are summarized in Table 3-1. A complete listing of the saved data values from each array is provided in Appendix E.

Table 3-1 Summary of the Measurements and Respective Instruments Installed at the Campus PV Arrays

\begin{tabular}{|c|c|c|}
\hline Measurement & Instrument & Make/Model \\
\hline AC Voltage, Current, Freq., Power, Energy & $\begin{array}{l}\text { AC Power Meter with Current } \\
\text { Transformers (CTs) }\end{array}$ & $\begin{array}{l}\text { Schneider Electric } \\
\text { Powerlogic ION8600 with } \\
\text { Unknown Make CTs }\end{array}$ \\
\hline Ambient Temperature (inside inverter) & $\begin{array}{l}\text { RTD Air Probe in Custom } \\
\text { Ventilated Enclosure }\end{array}$ & Omega RTD-806 \\
\hline Ambient Temperature (outdoors) (1) & $\begin{array}{l}\text { RTD Probe in a Multi-Plate } \\
\text { Passively Ventilated Radiation } \\
\text { Shield }\end{array}$ & $\begin{array}{l}\text { R. M. Young 41342LC } \\
\text { in an } \\
\text { R. M. Young } 41003\end{array}$ \\
\hline Ambient Temperature (outdoors) (2) & $\begin{array}{l}\text { RTD Probe in a Multi-Plate } \\
\text { Passively Ventilated Radiation } \\
\text { Shield }\end{array}$ & $\begin{array}{l}\text { Unknown Make Pt1000 } \\
\text { in an } \\
\text { Unknown Make Shield }\end{array}$ \\
\hline Current Signal & Shunt Resistor & $\begin{array}{l}\text { Campbell Scientific } \\
\text { CURS100 }\end{array}$ \\
\hline DC Voltage & $\begin{array}{l}\text { Voltage Divider in a Custom } \\
\text { Circuit and Enclosure }\end{array}$ & Caddock 1776-C6815 \\
\hline DC Current (1) & Shunt Resistor & Empro W-200-100 \\
\hline DC Current (2) & Shunt Resistor & $\begin{array}{l}\text { Empro HA/LAB-120-100 } \\
\text { Empro HA/LAB-90-100 }\end{array}$ \\
\hline Digital Image (1) & PTZ Camera & Axis Q6032-E \\
\hline Digital Image (2) & Campbell Scientific & CC5MPX \\
\hline Global Horizontal Irradiance (GHI) & Thermopile Pyranometer & Eppley PSP \\
\hline Module Backsheet Surface Temperature (1) & RTD & Omega RTD-3-F3102-72-T \\
\hline Module Backsheet Surface Temperature (2) & RTD & Omega SA1-RTD-4W-80 \\
\hline Module Backsheet Surface Temperature (3) & Thermocouple & Omega CO1-T-72 \\
\hline Module Backsheet Surface Temperature (4) & RTD & Unknown Make Pt1000 \\
\hline Plane-of-Array (POA) Irradiance (1) & Thermopile Pyranometer & Kipp \& Zonen CMP 11 \\
\hline Plane-of-Array (POA) Irradiance (2) & $\begin{array}{l}\text { Flat-Plate Silicon Irradiance } \\
\text { Sensor }\end{array}$ & IMT Solar Si-420TC \\
\hline Plane-of-Array (POA) Irradiance (3) & $\begin{array}{l}\text { Domed Diffused Silicon-Cell } \\
\text { Pyranometer }\end{array}$ & Apogee SP-110 \\
\hline $\begin{array}{l}\text { Reference Module I-V Curve and Maximum } \\
\text { Power Point }\end{array}$ & $\begin{array}{l}\text { I-V Curve Tracer with } \\
\text { Maximum Power Tracker and } \\
\text { Load }\end{array}$ & Daystar Multi-Tracer 5 \\
\hline RTD Current & Shunt Resistor & $\begin{array}{l}\text { Campbell Scientific } \\
\text { 4WPB100 }\end{array}$ \\
\hline
\end{tabular}




\begin{tabular}{lll}
\hline Shunt Voltage & Remote Terminal Unit & Gantner Q.bloxx A104 \\
\hline Voltage Signal & Data Logger & $\begin{array}{l}\text { Campbell Scientific Inc. } \\
\text { CR1000-ST }\end{array}$ \\
\hline Voltage Signal and RTD & Remote Terminal Unit & $\begin{array}{l}\text { Advantech ADAM-4015 } \\
\text { (custom) }\end{array}$ \\
\hline Voltage Divider Output Voltage & Analog Transmitter & Acromag TT337 \\
Wind Speed and Direction & Ultrasonic Wind Sensor & Vaisala WMT52 \\
\hline
\end{tabular}

\subsection{Irradiance}

\subsubsection{Sensors}

The global horizontal irradiance (GHI) and the plane-of-array (POA) irradiance are measured at each array. The GHIs are measured using Eppley Precision Spectral Pyranometers (PSPs) and the POA irradiances are measured using both Kipp \& Zonen CMP 11 pyranometers and IMT Solar Si-420TC flat-plate silicon irradiance sensors. Both pyranometers are all-black thermopile, secondary-standard pyranometers, while the silicon sensor is a shunted monocrystalline silicon cell under a thin glass cover with a cell temperature-compensated output signal.

Pyranometers were installed to most accurately measure the irradiance incident on the array in the two standard orientations (horizontal and POA). Flat-plate silicon irradiance sensors were also installed to capture the irradiance under fast changing conditions at nearly instantaneous speeds, unlike the pyranometers which have multiple-second response times. The flat-plate irradiance sensors also better approximate the array's effective irradiance, or that absorbed by the PV cells (compared to the pyranometers which measure the incident irradiance,) because they have similar reflective properties due to the flat glass covers and similar spectral responses since both utilize monocrystalline silicon cells.

The PV integrator has also installed Apogee SP-110 domed diffused silicon-cell pyranometers at each array. These instruments are measuring the POA irradiance, with the single pyranometer at the Canopy Array measuring the irradiance in the east-tilted plane. These sensors function very similarly to the flat-plate irradiance sensors but have a dome-shaped diffuser over the cell that minimizes reflective losses, which better approximates the incident, rather than the absorbed, irradiance.

\subsubsection{Calibrations}

All of the thermopile pyranometers are calibrated at the National Renewable Energy Laboratory (NREL) according to their Broadband Outdoor Radiometer Calibration (BORCAL) procedure [9]. This calibration provides net-IR corrected responsivities $\left(\mu \mathrm{V} / \mathrm{W} / \mathrm{m}^{2}\right)$ at every $2^{\circ}$ in the measured solar zenith angle range. The POA pyranometers are recalibrated every year while the GHI measuring pyranometers are calibrated approximately every (18 to 24) months. The silicon sensors were calibrated in a solar simulator at the factory and verified to be within specifications. The flat-plate irradiance sensors have a stated yearly drift of $0.5 \%$, and the domed diffused silicon pyranometers have a yearly drift of less than $2 \%$.

\subsubsection{Locations and Orientations}

The locations of the irradiance sensors including those from the PV integrator are shown in the previous array diagrams. The sensors are positioned in the actual module plane as near to the modules as possible without shading them. As shown in the diagrams, none of the integrator's pyranometers are co-located with other irradiance sensors at the same tilt.

At the Canopy Array (Figure 2-2) there are two sets of POA irradiance sensors in both the east and west tilted module planes. These sensors, along with the pyranometer measuring the GHI, are co-located at the north end of the 
center canopy, as shown in Figure 3-1. This location is near the center of the array to measure the most representative array irradiance but is on the north end of the array opposite the sun to avoid any shading on the modules from the instruments. The integrator's pyranometer is located at the south end of the center canopy in close proximity to their outdoor data acquisition enclosure and positioned in the east-tilted module plane.

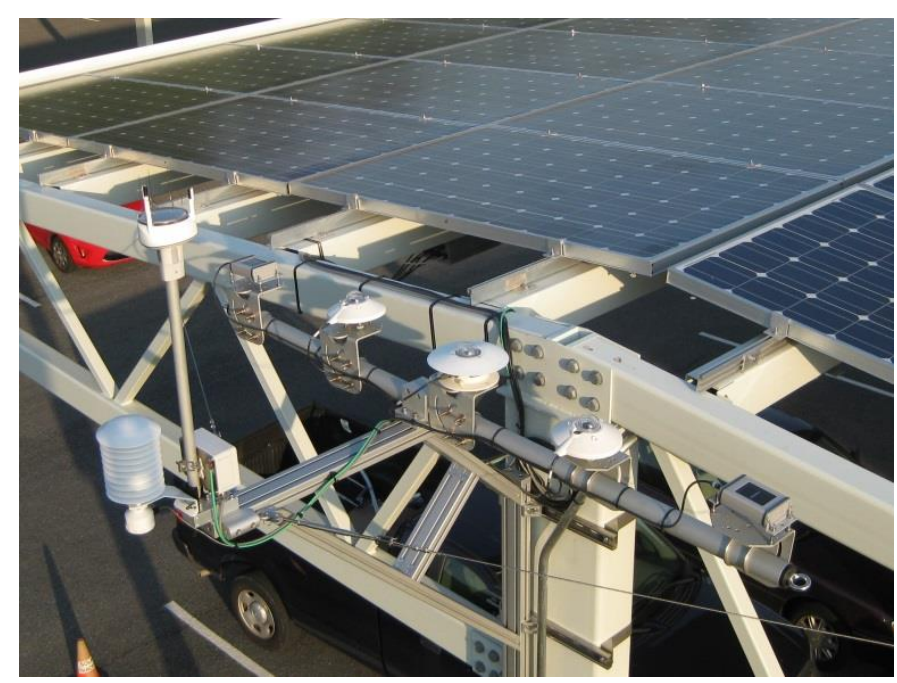

Figure 3-1 The Canopy Array weather instruments at the north end of the center canopy, showing the irradiance sensors and mounts as well as the ambient temperature sensor, wind sensor, and wind sensor surge protector

At the Ground Array (Figure 2-4) there is a single set of irradiance sensors located in the middle of the array to measure the most representative array irradiance, as shown in Figure 3-2. The integrator's pyranometer is located at the west end of the center shed in close proximity to their outdoor data acquisition enclosure and positioned in the plane of the array.

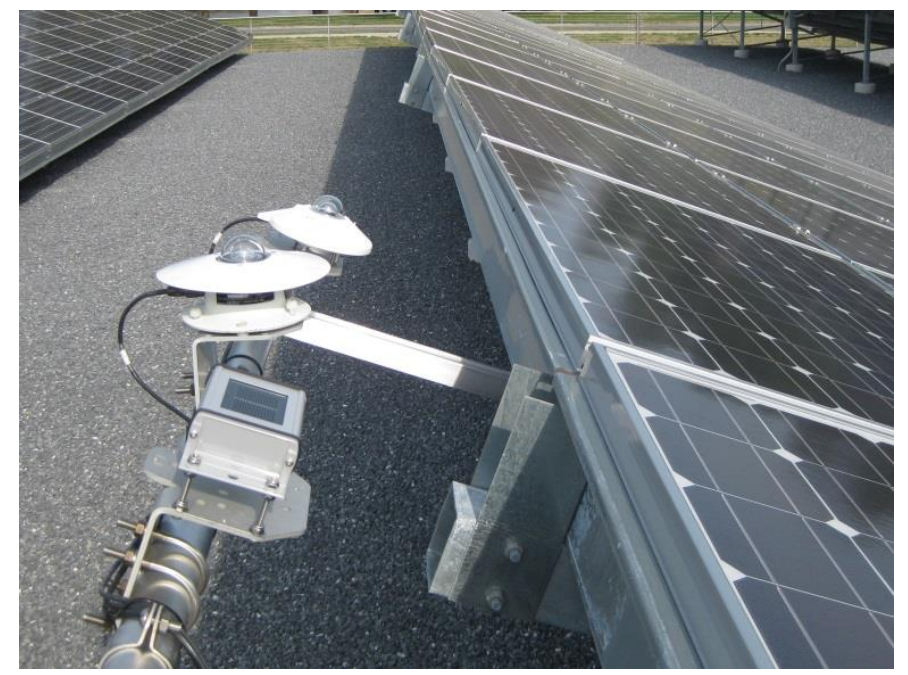

Figure 3-2 The Ground Array irradiance sensors at the center of the array, showing the sensors and mounts

At the Roof Array (Figure 2-6) there is a set of GHI and POA irradiance measuring sensors in the southeast corner of the array, as shown in Figure 3-3, located in an area that is least shaded by surrounding building and array elements. Pyranometers measuring the GHI are also installed at the other three corners of the array to capture the spatial variability of the irradiance caused by the 14 story (13 stories above array) building tower directly north of 
the array. The building has a large number of windows and a light-colored brick façade with reflective aluminum mullions (see Figure 1-4). The integrator's pyranometer is located at the southwest corner of the array in relatively close proximity to their outdoor data acquisition enclosure and positioned in the plane of the array.

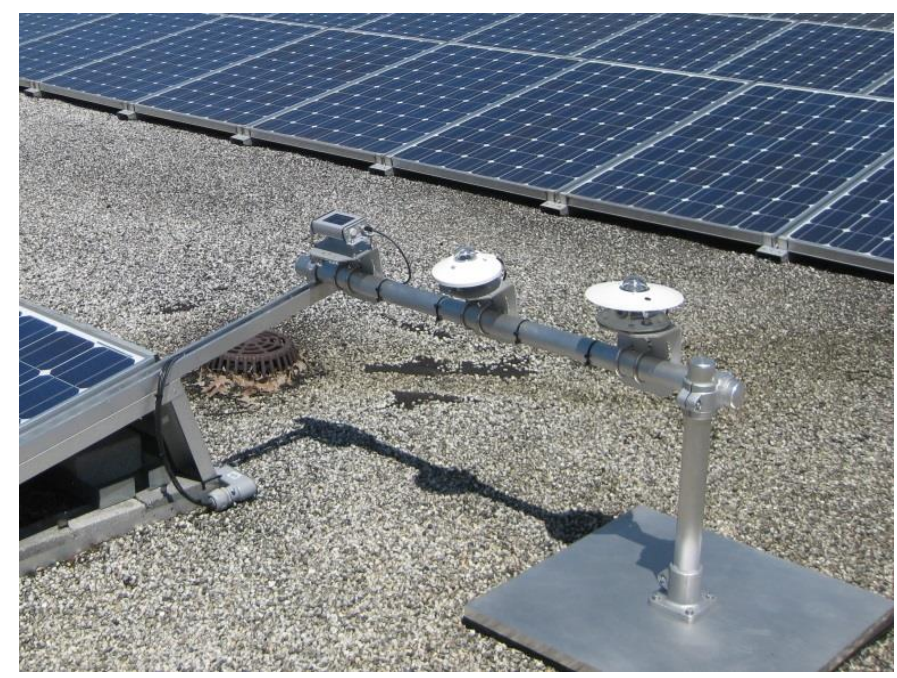

Figure 3-3 The Roof Array irradiance sensors at the southeast corner of the array, showing the sensors and mounts

There are three more locations not pictured in the Roof Array diagram that are nearer to the building where the GHI is also measured with pyranometers and flat-plate irradiance sensors. These additional sensors are situated around and at the center of an older horizontal PV array, which is the subject of a study on aging that will be discussed in later publications. The sensors at the center of this array are shown in Figure 3-4 and include two side-by-side flatplate irradiance sensors to quantify the level of soiling: the east one is regularly cleaned and the west one is not. The irradiance measurements from these additional sensors are included in this dataset.

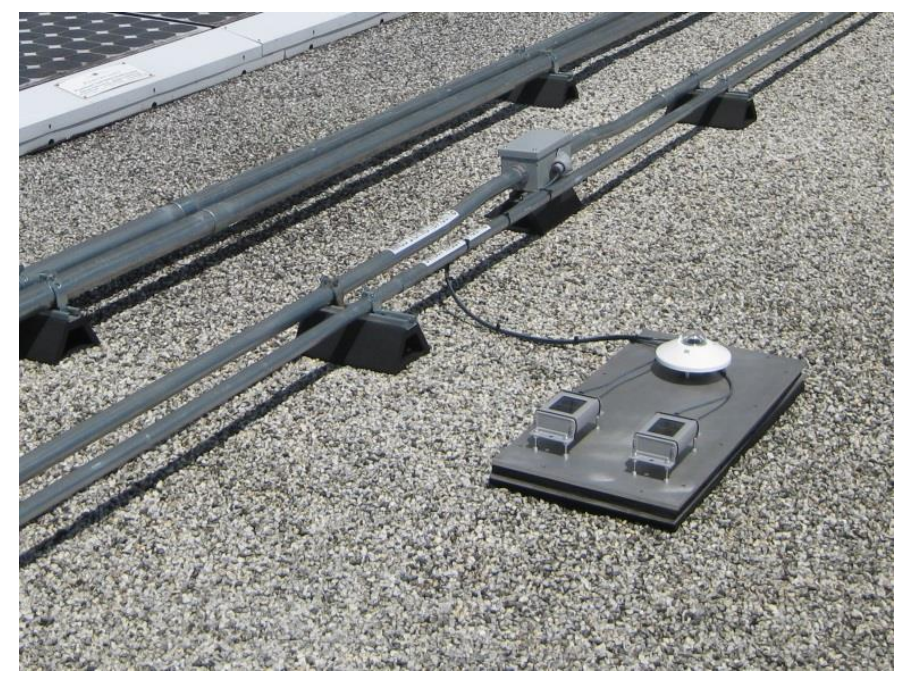

Figure 3-4 The irradiance sensors at the center of the older horizontal PV array, showing the sensors and mounts

\subsubsection{Mounting and Alignment}

The GHI and POA sensors are mounted using Campbell Scientific Inc. (CSI) CM245 Adjustable-Angle Mounting Stands, as shown in previous figures, or mounted directly to an aluminum plate for the single location at the center of the older horizontal roof array (Figure 3-4). The Eppley PSPs are mounted using nylon leveling and fastening 
screws to avoid creating ground loops and the associated signal noise they can induce because the body of a PSP is electrically connected to the ground pin on their cable connector. The GHI pyranometers are leveled using the integrated bubble levels, ensuring that the bubble is in the middle of the center circle, with the bubble anywhere in the circle corresponding to a leveling accuracy of approximately $\pm 0.1^{\circ}$ for the CMP 11 's and $\pm 0.2^{\circ}$ for the PSPs. The GHI and POA flat-plate irradiance sensors are aligned to horizontal and the array nominal tilt, respectively, using a Mitutoyo Pro 360 inclinometer to a reading within $\pm 0.1^{\circ}$.

The alignments of the POA pyranometers are more challenging because there is no accessible flat surface on a CMP 11 that is parallel to its sensor on which to rest an inclinometer. To align these instruments, a laboratory-grade granite surface plate is first leveled to within a reading of $\pm 0.1^{\circ}$ using the inclinometer. Then, the pyranometers are leveled on the surface plate using the pyranometers' leveling feet and integrated bubble levels. The mounts for the pyranometers are then aligned to a reading $\pm 0.1^{\circ}$ from the nominal array tilts using the inclinometer, and lastly the pyranometers are fastened to them.

\subsubsection{Wiring}

The irradiance sensors are wired directly to the data logger multiplexers using UV and moisture protected cables run through metal dedicated data conduit, separating them from power conductors that may generate high EMI. The cables enter the conduit through cable glands at pull boxes or conduit access ports. The sensors at the Roof Array, however, initially pass through shorter sections of nonmetallic conduit. The pyranometers are wired using shielded twisted-pair cable grounded at one end on the data logger side to reduce and allow the electromagnetic interference (EMI) to be later rejected when differentially measured, which is especially important for their $\sim 10 \mu \mathrm{V}$ resolution analog voltage output. The flat-plate irradiance sensors are similarly wired using shielded twisted three-wire cable. These silicon sensors communicate over an unpowered $4 \mathrm{~mA}$ to $20 \mathrm{~mA}$ current loop, which has a low sensitivity to electrical noise, and runs on one pair, with the third wire supplying power to the temperature compensation and loop transmitter circuits.

The integrator's pyranometers are wired directly to their nearby outdoor data acquisition enclosures using the cable pigtail connected to each sensor, entering through cable glands. These sensors communicate using an analog voltage signal.

\subsection{Ambient Temperature}

\subsubsection{Outdoor}

The outdoor ambient air temperature is measured at each array using one R. M. Young 41342LC $1000 \Omega$ platinum RTD probe and transducer in an R. M. Young 41003 multi-plate passively-ventilated radiation shield, shown disassembled in Figure 3-5. The radiation shields are used to shield the temperature probes from radiative heat transfer from the sun and surroundings, which would affect the temperature of the probe, while still allowing ambient airflow around the probe. Aspirated, or fan ventilated, radiation shields were not used due to backup power considerations. The PV integrator has also installed a similar style two-wire, $1000 \Omega$ RTD probe (without a transducer) and radiation shield at each array of otherwise unknown specifications. Both sets of sensors were calibrated at the factory and verified to be within specifications, and they have an unspecified yearly drift. 


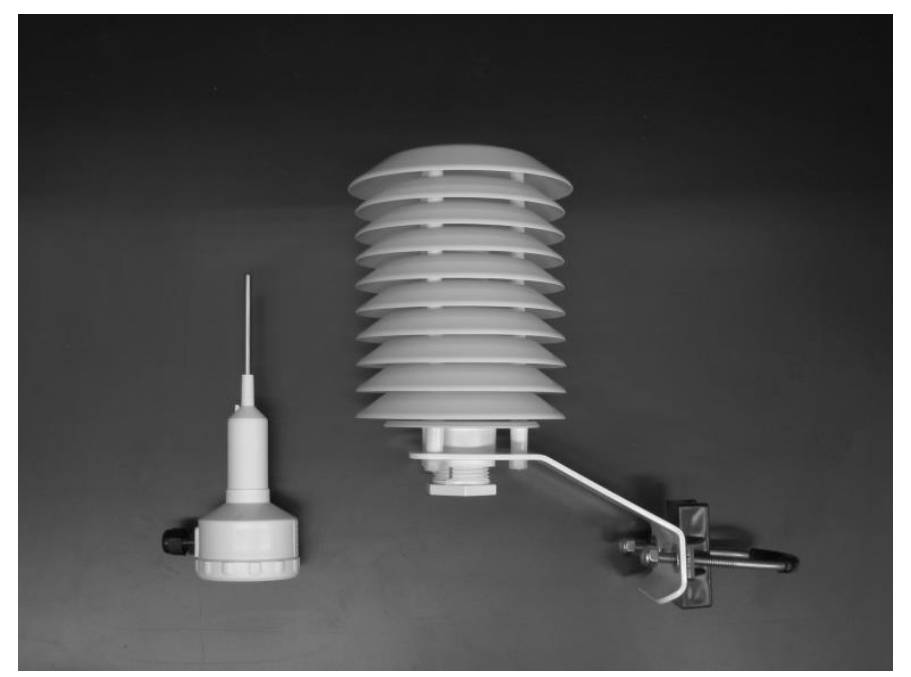

Figure 3-5 The temperature probe and radiation shield used to measure the outdoor ambient air temperature at each array

The sensors are located next to the arrays in locations that do not shade the modules, are not in stagnant air, and are not near potentially heat-releasing sources like roof vents, with the specific locations of both sets of sensors shown in the previous array diagrams. Only at the Ground Array are the NIST and integrator sensors co-located. Both sets of sensors are mounted to poles and vertically aligned.

The ambient temperature sensors are wired directly to the data logger multiplexers using UV and moisture protected cables, and at the Canopy and Ground Arrays these cables run through metal dedicated data conduit, separating them from power conductors that may generate EMI. The cables enter the conduit through cable glands at pull boxes. The sensor at the Roof Array is located immediately adjacent to the data acquisition enclosure, and its cable enters a short nonmetallic conduit through a conduit access port. The sensors at all arrays are wired using shielded cable grounded at one end on the data logger side to reduce EMI. These sensors communicate via a transducer over a powered $4 \mathrm{~mA}$ to $20 \mathrm{~mA}$ current loop, which has a low sensitivity to electrical noise and also supplies power to the sensor. The integrator's ambient temperature sensing two-wire RTDs do not have transducers and are wired directly to their nearby outdoor data acquisition enclosures, with the cables entering through cable glands.

\subsubsection{Inverter}

The ambient air temperatures inside the inverters at the Canopy Array and the Ground Array are each measured using one Omega RTD-806 exposed, three-wire, class "A", $100 \Omega$ platinum RTD air probe with an $\alpha=0.00385$. The exposed sensing element of these RTDs results in a fast response time. The RTDs are mounted inside a custom perforated enclosure, as shown in Figure 3-6, with a fourth terminal split off from the three-wire RTD at the enclosure to allow for more accurate four-wire measurements. The perforated enclosure mounts on a DIN rail and physically protects the sensor and limits any radiative heat transfer from the surroundings, which would affect the temperature of the probe, while still allowing ambient airflow around the probe. The sensors were calibrated at the factory and verified to be within specifications, and they have an unspecified yearly drift. The ambient temperature inside of the inverter at the Roof Array is measured by the inverter itself and is one of the measurements polled by the data acquisition system, as discussed in a later section. 


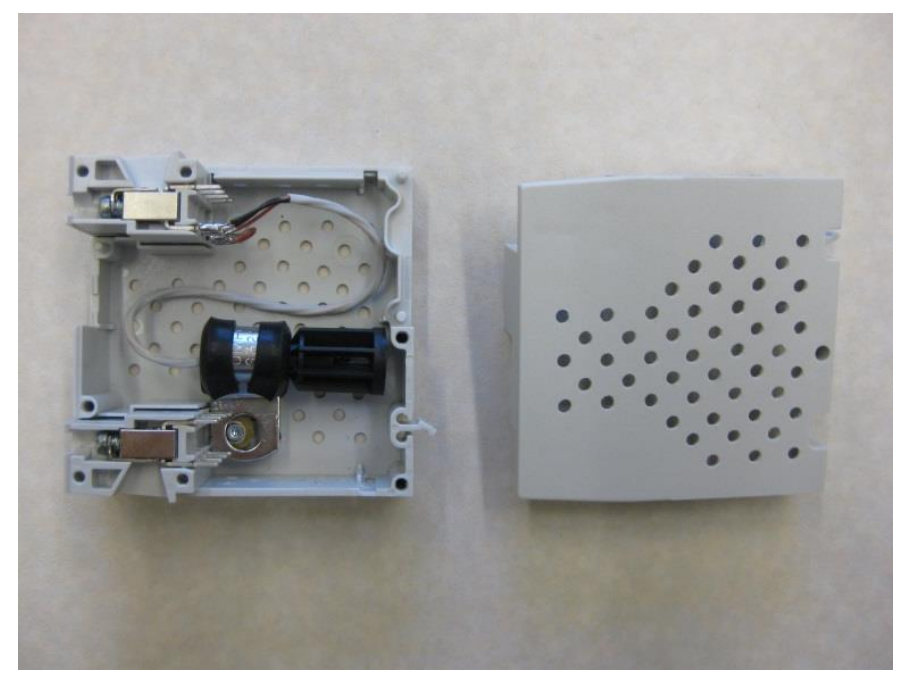

Figure 3-6 The temperature probe and enclosure used to measure the ambient air temperature in the inverters at the Canopy and Ground Arrays

The sensors are located in the top center of the DC combiner compartment, with generally unseparated airflow to the other inverter compartments including the $\mathrm{AC}$ and power module assembly compartments. The temperature sensors are wired directly to the data logger multiplexers using UV and moisture protected cables run through metal dedicated data conduit, separating them from power conductors that may generate EMI. The cables are also shielded and grounded at one end on the data logger side to reduce EMI. The RTD cable has four wires and has the inner wire insulation (and outer jacket) made of PTFE (Teflon). PTFE has a much lower permittivity and subsequent capacitance than PVC and nearly all other wire insulation materials, resulting in faster settling times after excitation.

\subsection{Module Temperature}

\subsubsection{Sensors}

The module backsheet surface temperatures are measured at each array using Omega RTD-3-F3102-72-T exposed, thin-film, four-wire, class "A", $100 \Omega$ platinum RTDs with an $\alpha=0.00385$. The sensing elements are flat, with only a thin ceramic base material covering the resistive element, thereby reducing the thermal gradient in the sensor, bringing it closer to the module surface temperature. The RTDs have relatively small sensing areas of $3.7 \mathrm{~mm} \mathrm{x}$ $4.7 \mathrm{~mm}(0.147 \mathrm{in.} \times 0.185 \mathrm{in}$.) that reduce the insulating effect on the module, which affects its temperature local to the RTD, while still providing enough area for adhesion and thermal contact. The relatively small size of the RTD also results in faster response times due to the smaller thermal mass. A four-wire RTD was chosen instead of a two or three-wire RTD because the long cable leads, the large changes in temperature and subsequent resistance of the sensing element, and using a static, unbalanced resistance bridge would have resulted in significant measurement errors.

The backsheet temperatures of the reference modules at the weather station are measured using a different RTD, the Omega SA1-RTD-4W-80, which is very similar to the aforementioned RTD, but has a large $19 \mathrm{~mm} \times 26 \mathrm{~mm}(0.75$ in. $x 1.0$ in.) adhesive backing to the sensing element. This different RTD was chosen because the other model is relatively delicate and rather difficult to install due to its small size. Thermocouples were also installed on the reference modules, Omega model CO1-T-72. These thermocouples are ungrounded, flat, low mass, type T, ANSI "Special Limits of Error" grade foil sensors with fast response times and high accuracy. These sensors were installed to connect to the built-in thermocouple temperature channels on the I-V tracer with maximum power tracker and load and provide a temperature measurement more easily correlated with the module measurements. A visual comparison of the three temperature sensors is shown in Figure 3-7. 


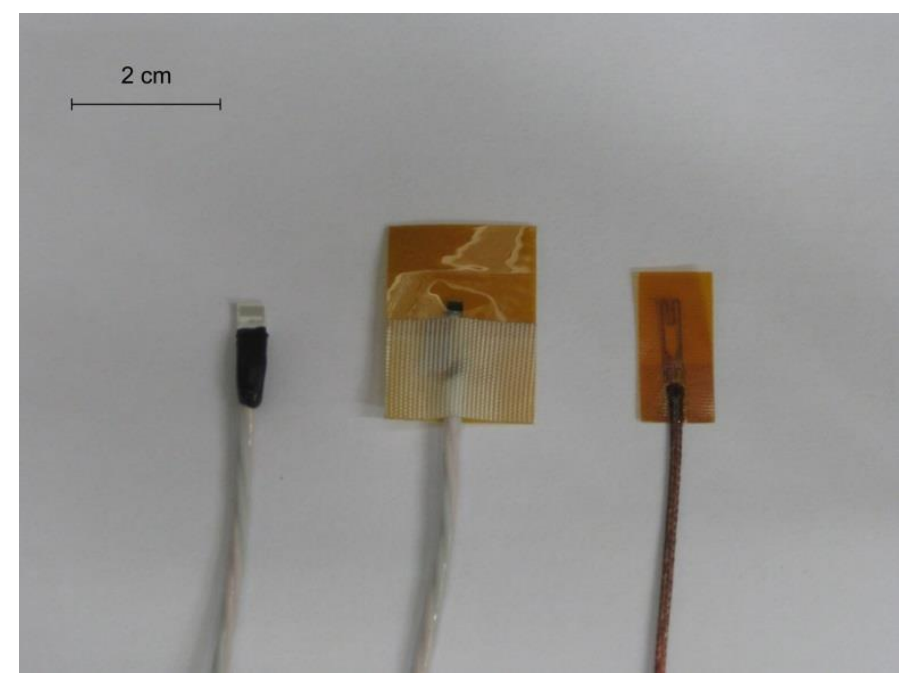

Figure 3-7 A visual comparison of the three types of module temperature sensors used at the arrays and for the reference modules: the RTD used at the arrays (left), the RTD used for the reference modules (center), and the thermocouple used for the reference modules (right).

RTDs were chosen instead of thermocouples or other temperature sensors for the primary module temperature measurements because they are the most stable and accurate temperature sensing technology [10]. RTDs also do not require a temperature reference as do thermocouples, which for the higher accuracy and many channel units can be rather large, and in the case of ice point references require significant amounts of power. RTDs do, however, need excitation, which requires a current source, increases the sampling time, and causes self-heating of the resistance sensor that affects the measurement. These issues were addressed and minimized, as later described in the Data Acquisition and Control section.

The PV integrator has also installed two-wire, $1000 \Omega$ adhesive backed RTDs of otherwise unknown specifications at each array that appear similar to the NIST adhesive backed RTDs.

\subsubsection{Calibrations}

All of the module temperature sensors were calibrated in the laboratory according to ASTM E220 [11]. According to the standard, dry calibrations were performed, with the test and reference temperature sensors packed in brass test tubes with thermally conductive aluminum oxide powder and immersed in a circulating temperature bath. With the exception of one defective RTD, all RTDs and thermocouples were within specifications, and the proportional and offset calibration coefficients and associated uncertainty were calculated for each sensor.

\subsubsection{Locations}

The locations of the temperature sensors including those from the PV integrator are shown in the previous array diagrams. The sensors are mounted on the backsheets of the modules, with each sensor centered under a cell. Four sensors are installed on one module in the center of each array and on each reference module at the weather station, positioned according to IEC 60891 [12] (see previous array diagrams). The rest of the sensors in the arrays and the additional thermocouples on the reference modules at the weather station are installed behind a center cell on separate modules.

The sensor locations are distributed in the array with the intent of best capturing temperature gradients in the array and best calculating a single representative array temperature. At the Canopy Array, nine temperature sensors plus one from the integrator are installed, spanning the full length and half-width of the center canopy. It is assumed that the other canopies will have similar temperature distributions. The integrator's temperature sensor is co-located on 
one of the same modules as a NIST temperature sensor, near the south end of the center canopy by the integrator's outdoor data acquisition enclosure.

At the Ground Array, nine temperature sensors plus one from the integrator are installed, spanning the full length and width of the northwest quarter of the array. It is assumed that the four quarters of the array will have similar temperature distributions. The integrator's temperature sensor is co-located on one of the same modules as a NIST temperature sensor, at the west end of the center shed by the integrator's outdoor data acquisition enclosure.

At the Roof Array, seven temperature sensors plus one from the integrator are installed, spanning the full length and width of the array. The integrator's temperature sensor is not co-located with a NIST temperature sensor at this array, and is located near the south end of the array by the integrator's outdoor data acquisition enclosure.

\subsubsection{Mounting and Alignment}

The temperature sensors are mounted to the module backsheet using Omegabond OB-101 thermally conductive epoxy and an Innotec 248DR, $57.2 \mathrm{~mm}$ (2.25 in.) diameter, $83 \mu \mathrm{m}$ (3.3 mil) thick round polyester adhesive film overlay, as shown in Figure 3-8. This method was derived as the combination of two of the best module back surface temperature measurement methods as determined by Smith, et al. [13], specifically the methods designated as positions $\mathrm{C}$ and $\mathrm{H}$. This combination allows accurate measurement of the surface temperature, minimally affects the surface temperature, results in a more precise bias from the true cell temperature, and provides reliably secure attachment to the surface. The best practices recommended by Smith, et al. were also followed when mounting the sensors, including minimizing the thickness of the epoxy under the sensor, minimizing the amount spread beyond the sides of the sensor, and using additional adhesive films and ties on the cable for strain relief to prevent the sensor from detaching. For the adhesive backed sensors, the thermally conductive epoxy is applied to the adhesive surface, first removing the adhesive covers. The temperature sensors were aligned under the center of the respective cells by distance measurements and visual means.

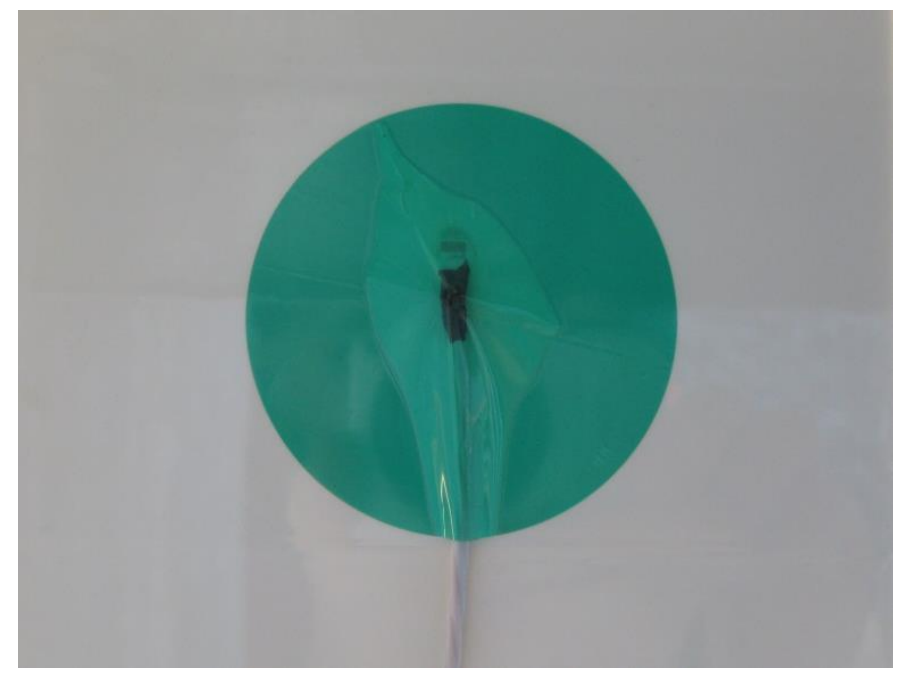

Figure 3-8 An RTD mounted on the back of a module using thermally conductive epoxy and an adhesive film overlay

The integrator's sensors were mounted by the integrator, adhering the adhesive surface directly to the module backsheet and overlaying with insulated foil tape, as shown in Figure 3-9. No thermally conductive epoxy was employed. 


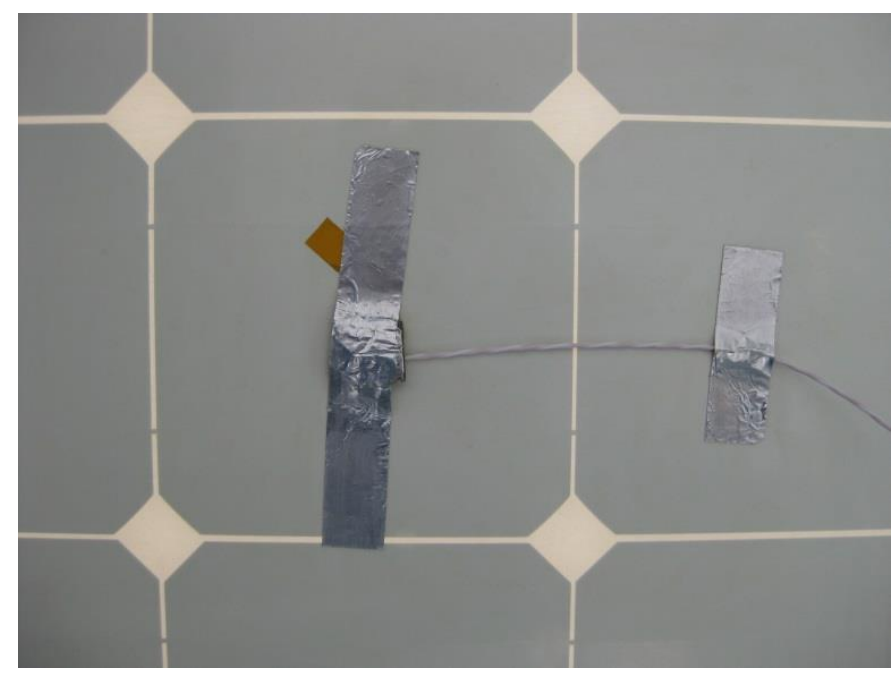

Figure 3-9 The integrator's module temperature sensor mounted on the back of a module at the Ground Array

\subsubsection{Wiring}

The module temperature sensors are wired directly to the data logger multiplexers using UV and moisture protected cable run through metal dedicated data conduit, separating them from power conductors that may generate EMI. The cables enter the conduit through cable glands at pull boxes or conduit access ports. The sensors at the Roof Array, however, initially pass through shorter sections of nonmetallic conduit. The sensors are wired using shielded cable grounded at one end on the data logger side to reduce EMI. The RTD cable has four wires and has the inner wire insulation (and outer jacket) made of PTFE (Teflon). PTFE has a much lower permittivity and subsequent capacitance than PVC and nearly all other wire insulation materials, resulting in faster settling times after excitation. The RTDs are connected to the extension cables using waterproof IP67 connectors. The TCs are connected to the extension cables using standard flat pin connectors housed in custom waterproof cable connector enclosures.

The integrator's temperature sensors are wired directly to their nearby outdoor data acquisition enclosures using no extension cables, entering through cable glands.

\subsection{Wind}

\subsubsection{Sensor}

The horizontal wind speed and direction is measured at each array using one Vaisala WMT52 heated ultrasonic wind sensor. An ultrasonic sensor was chosen instead of a traditional vane and cup or windmill anemometer because it is has a smaller physical profile, is easily heated and kept free of snow and ice, has no moving parts and therefore a higher reliability, and has a higher sensitivity because of the faster response time and virtually zero starting threshold (even very low wind speeds will be detected). The wind sensor is configured to sample readings at $4 \mathrm{~Hz}$ and average every $1 \mathrm{~s}$, and to perform maximum and minimum calculations instead of gust and lull. The wind sensor controls its level of heating as a function of the ambient and its internal temperatures. The wind sensors communicate over one wire pair using an RS485 serial ASCII protocol at 19200 bits per second (bps). Note that the PV integrator did not install any wind sensors. The sensors were calibrated at the factory and verified to be within specifications, and they have an unspecified yearly drift.

\subsubsection{Locations and Orientation}

The sensors are located next to the arrays in horizontal orientations in locations $56 \mathrm{~cm}$ to $150 \mathrm{~cm}(21.9$ in. to 59.0 in.) above and $83 \mathrm{~cm}$ to $160 \mathrm{~cm}$ (32.5 in. to $62.8 \mathrm{in}$.) to the north of the modules. The wind sensors at the Canopy (see Figure 3-1) and Ground Arrays (Figure 3-10) are north of the entire respective arrays while the sensor at the Roof Array (Figure 3-11) is near the middle of the array, north of the middle section of modules. These locations 
were chosen to measure the wind that is near to but out of the immediate boundary layer while minimally shading the modules, which does occur but is limited to tens of minutes at sunrise and sunset in the summertime. The sensor at the Roof Array is not north of the entire array like at the other arrays because it would shade the older horizontal array north of this array and it would likely not be as representative of the wind over the array due to its closer proximity to the 14 story (13 stories above array) building tower directly north of the array.

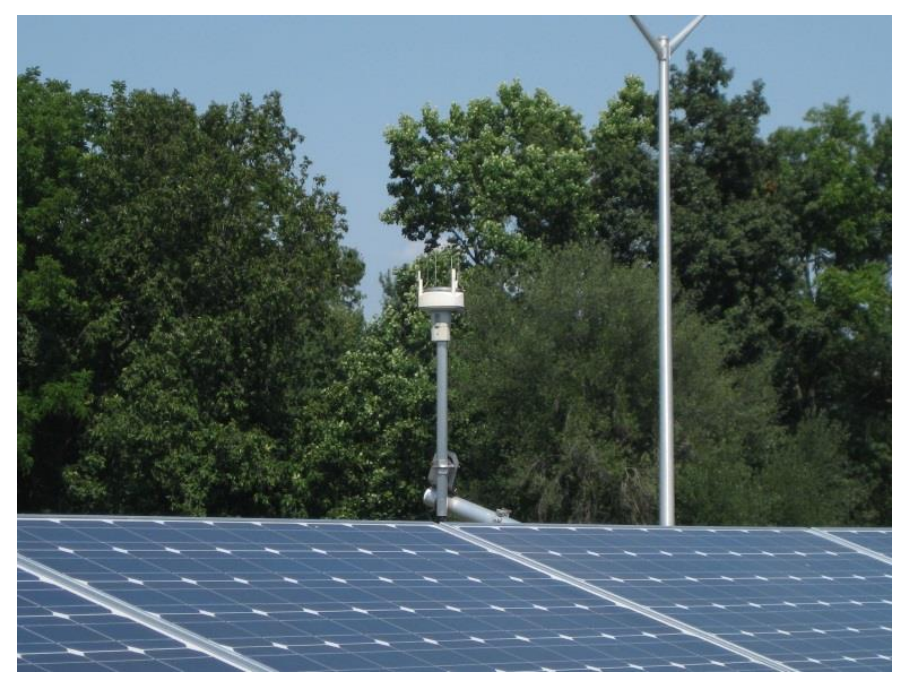

Figure 3-10 The wind sensor at the Ground Array

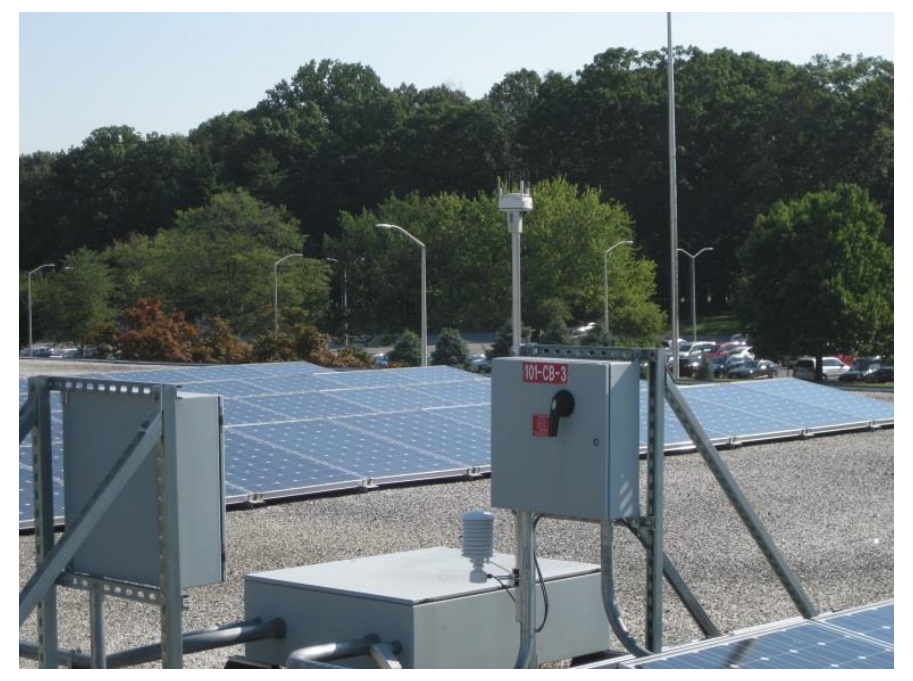

Figure 3-11 The wind sensor and outdoor ambient temperature sensor at the Roof Array

\subsubsection{Mounting and Alignment}

The wind sensors are mounted on top of vertical poles, aligned to true north using visual references and checked using a compass (adjusted for the local magnetic declination). The wind sensors at the Canopy and Ground Arrays are higher than any nearby sensor and structure so a Vaisala WSP150 surge protector, designed for this type of application, was installed near each wind sensor in-line with the power and data cable to suppress power surges caused by nearby lightning. Metal spikes designed for these specific sensors are installed on top of the sensor at each array to deter birds from perching on them and affecting the readings. 


\subsubsection{Wiring}

The wind sensors are wired to the surge protectors at the Canopy and Ground Arrays. These surge protectors and the wind sensor at the Roof Array are wired directly to the data logger serial communication modules. All cables are UV and moisture protected, and at the Canopy and Ground Arrays run through metal dedicated data conduit, separating them from power conductors that may generate high EMI. The cables enter the conduit through cable glands at pull boxes. The sensor at the Roof Array is located immediately adjacent to the data acquisition enclosure and enters a short nonmetallic conduit through a conduit access port. The sensors are wired using shielded cable grounded at one end on the data logger side to reduce EMI. These sensors communicate over one wire pair, with power for the sensor and the heater on separate wire pairs. To reduce power consumption, termination resistors are not wired in parallel at the ends of the RS485 communication wires to reduce signal reflections because they are not needed, as the cable lengths are less than $600 \mathrm{~m}(2000 \mathrm{ft})$ and the data rates are relatively low $(19200 \mathrm{bps})$. The surge protectors for the wind sensors are grounded to local earth ground using a short length of 8 American wire gauge (AWG) $\left(8.37 \mathrm{~mm}^{2}\right.$ ) wire. The wind sensor at the Roof Array is near higher building structures but is also locally grounded like the other two wind sensors to prevent and mitigate surges caused by nearby lightning.

\subsection{Electrical}

\subsubsection{Sensors}

The direct current (DC) voltage of the arrays is measured at each array using one Caddock 1776-C6815 voltage divider integrated circuit (IC) on a custom circuit board housed in a DIN rail mounted enclosure, as shown with the cover off in Figure 3-12. Voltage dividers were chosen instead of other types of DC voltage transducers or sensors because they are much more accurate and stable, with little long-term drift or sensitivity to their environment, and therefore need no periodic adjustments to their gain and offset. Voltage dividers do however need to be connected to very high input impedance ( 10 M $\Omega$ ) measurement devices to minimize current flow to the devices, which can affect the measurements.

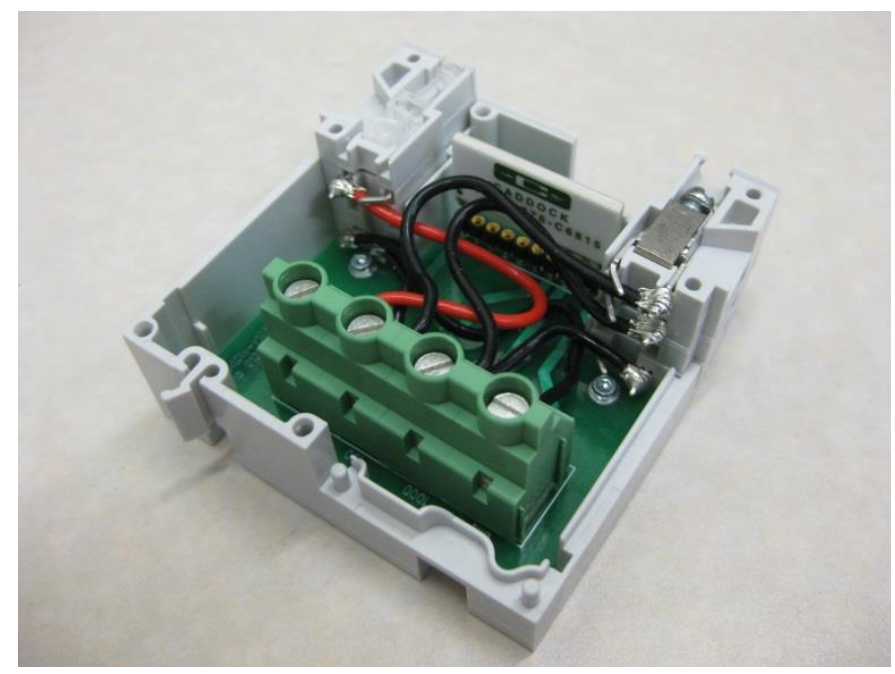

Figure 3-12 The custom voltage divider circuit for measuring the array DC voltage

The output circuit currents of the arrays are measured using seven Empro W-200-100 (0.5 m $\Omega$ ) current shunts at each of the Canopy and Ground Arrays and three Empro HA/LAB-120-100 (0.833 m $\Omega$ ) and one HA/LAB-90-100 $(1.111 \mathrm{~m} \Omega$ ) current shunt at the Roof Array. (These shunts are custom and have an HA style body and LAB style base). These shunts were specified to best match the current range of the output circuits and the voltage range of the isolating remote terminal units (RTUs) to which they are wired, and to be the most appropriate for the manner of their installation. Current shunts were chosen instead of current transformers (CTs) or Hall effect sensors because 
they are much more accurate and stable, with little long-term drift or sensitivity to their environment. Current shunts, however, are often more difficult to install and may need more precautions than the other sensor options.

Isolators need to be used with both the voltage dividers and current shunts to electrically separate them from the measurement circuits to prevent inadvertent secondary conductive paths from the array circuits to ground, which would suppress the inverters' ground fault detection. The voltage divider at each array is isolated with an Acromag TT337, which is a high-voltage isolator and analog output transmitter. This transmitter was chosen because of its high voltage isolation, high input impedance (15 M $\Omega$ ), low uncertainties, and small form factor. The transmitter is configured to sample readings at $13 \mathrm{~Hz}$ and employ various filters, including for rejecting $60 \mathrm{~Hz}$ noise. The transmitter outputs a $0 \mathrm{~V}$ to $5 \mathrm{~V}$ signal proportional to the input voltage signal.

The current shunts at each array are isolated with a Gantner Q.bloxx A104 RTU, which is a high-voltage isolator and 8-channel analog-to-digital converter (ADC). This RTU was chosen because of its high voltage isolation, small form factor, and very low uncertainties at the millivolt levels output from the shunts, due partly to it being specialized for measuring only millivolt signals, typically from thermocouples. The RTU samples readings at $100 \mathrm{~Hz}$ and averages every $10 \mathrm{~ms}$. None of the configurable RTU filters are employed as tests showed that the RTUs were more accurate and had a faster response time without them. The RTU communicates over one wire pair using the RS485 serial Modbus RTU protocol at 19200 bps. A combination ADC and isolator RTU was chosen to eliminate any EMI that would be picked up by the cable runs between the measurement location in the inverter or shunt enclosure and the data logger. This EMI could have a relatively large effect on the millivolt shunt readings. Use of the RTUs also resulted in less needed cables running back to the data loggers.

Various DC measurements are also performed by the inverters, as listed in Table 3-2. The inverters communicate these measurements as well as the inverter operating state and any fault codes over one wire pair using the RS485 serial Modbus RTU protocol at 9600 bps. Note that the PV integrator did not install any DC measuring sensors, but does communicate with the inverter.

Table 3-2 Inverter DC Measurements

\begin{tabular}{lcc}
\hline Measurement & $\begin{array}{c}\text { Canopy and } \\
\text { Ground Inverters }\end{array}$ & $\begin{array}{c}\text { Roof } \\
\text { Inverter }\end{array}$ \\
\hline PV voltage $^{1}$ & $\mathrm{X}$ & $\mathrm{X}$ \\
Input voltage $^{2}$ & $\mathrm{X}$ & $\mathrm{X}$ \\
Input current & $\mathrm{X}$ & $\mathrm{X}$ \\
Input power & $\mathrm{X}$ & $\mathrm{X}$ \\
Ground current & & $\mathrm{X}$ \\
Ground impedance & & $\mathrm{X}$ \\
\hline
\end{tabular}

${ }^{1}$ The voltage on the array side of the DC contactor

${ }^{2}$ The voltage on the load side of the DC contactor

\subsubsection{Calibrations}

The voltage dividers and isolators were calibrated in the laboratory and verified to be within specifications. The current shunts were calibrated at the factory to an accuracy of $\pm 0.10 \%$.

\subsubsection{Locations and Orientations}

The measurement components at the Canopy and Ground Arrays are located in the inverter DC combiner compartment, as shown in Figure 3-13. The voltage divider and isolators are together at the top of the compartment and the current shunts are horizontally oriented between the DC output circuit wires and the DC busbar. 


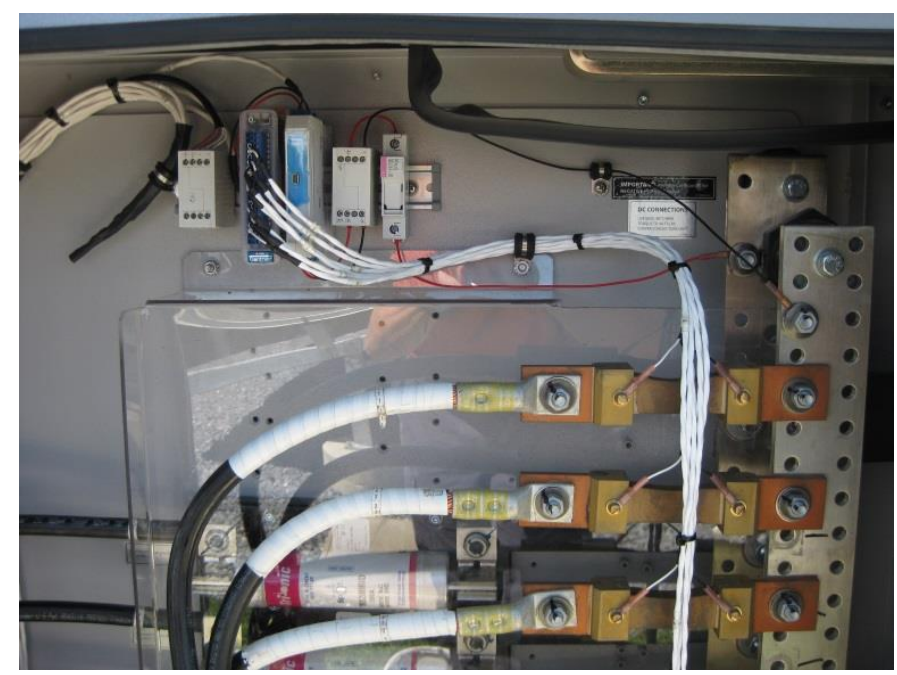

Figure 3-13 The inverter DC combiner compartment at the Ground Array with the installed DC measurement components, including the current shunts, and left-to-right on the upper DIN rail: the ambient temperature sensor, shunt RTU, analog transmitter, voltage divider, and fuse holder

The sensors at the Roof Array are located exterior to the inverter in an outdoor enclosure, as shown in Figure 3-14, approximately three-quarters of the wiring distance from the array to the inverter. The voltage divider and isolators are together at the top of the enclosure and the current shunts are horizontally oriented in-line with the DC output circuit wires. The measurements at the Roof Array were not made in the inverter because the manufacturer of that inverter had recently ceased operations and therefore the installation design could not be reviewed.

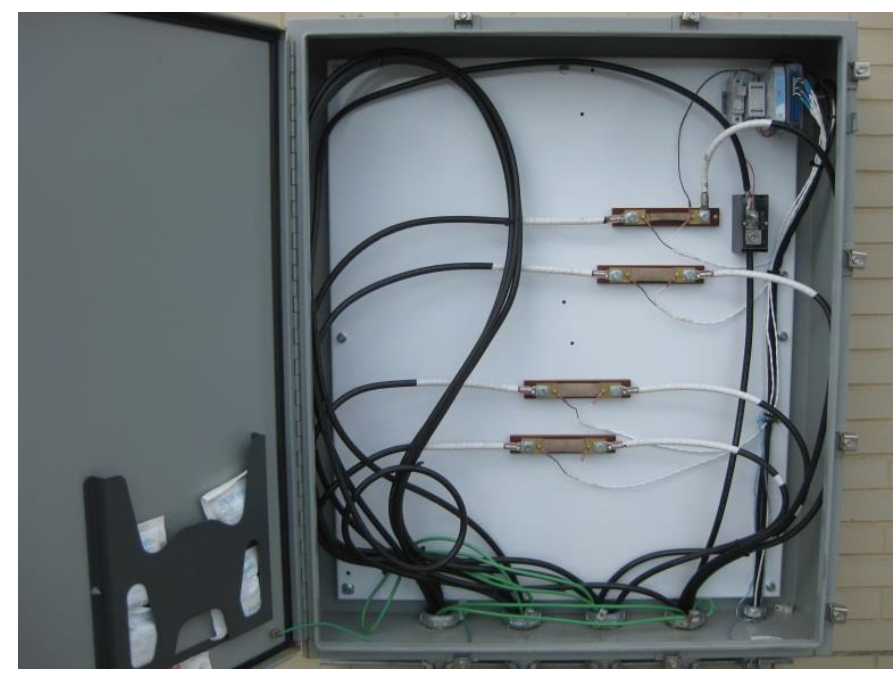

Figure 3-14 The outdoor DC measurement enclosure at the Roof Array, which includes the current shunts, and left-to-right on the upper DIN rail: the fuse holder, voltage divider, analog transmitter, and shunt RTU

\subsubsection{Mounting}

At the Canopy and Ground Arrays, the voltage divider and isolators are mounted to a DIN rail fastened to existing threaded holes in the back panel in the DC combiner compartment. Also mounted on the DIN rail are the inverter ambient temperature sensor in its enclosure (far left) and a fuse in a touch-safe holder (far right) for the DC voltage tap. The current shunts are fastened to the front of the negative busbar using the same hardware, torque 
specifications, and orientation for normally fastening the output circuit cables. The installation of the shunts does not cause the separation between the negative and positive busbars to be reduced.

At the Roof Array, the voltage divider and isolators are mounted to a DIN rail fastened with screws to the enclosure back panel. Also mounted on the DIN rail is a fuse in a touch-safe holder (far left) for the DC voltage tap (far right under DIN rail). The shunts are also fastened with screws directly to the enclosure back panel.

\subsubsection{Wiring}

At the Canopy and Ground Arrays, high temperature, $600 \mathrm{~V}$ rated wires are connected to both the positive and negative busbars using solder-filled ring terminals and the same hardware and torque specifications as that for the output circuit cables, or in this case the current shunts. The positive wire is connected to the $0.5 \mathrm{~A}$ fast-blow fuse in the touch-safe holder on the DIN rail, which is for disconnecting the voltage divider from the array if it fails and becomes shorted. The other side of the fuse holder and the wire from the negative busbar are connected to the voltage divider, which in turn is wired to its respective isolator. For the current measurements, the output circuit cables are connected to the other side of the shunts in a similar manner as fastening the shunts to the busbar, with the cables supporting all of their own weight due to their rigidity. High temperature, $600 \mathrm{~V}$ rated cables are connected to the sensing terminals of the current shunts using solder-filled ring terminals and wired to their respective channels on the isolating RTU.

At the Roof Array, a high-amp distribution block is connected in-line with one of the positive output circuit wires to provide a positive voltage sensing terminal; a sensing terminal on one of the shunts provides the negative sensing point. High temperature, $600 \mathrm{~V}$ rated wires are connected to both the positive and negative sensing terminals using solder-filled ring terminals. The positive wire is connected to the $0.5 \mathrm{~A}$ fast-blow fuse in the touch-safe holder on the DIN rail, which is also for disconnecting the voltage divider from the array if it fails and becomes shorted. The other side of the fuse holder and the wire from the negative terminal (on a shunt) are connected to the voltage divider, which in turn is wired to its respective isolator. For the current measurements, the negative current carrying wires are cut and fastened to both sides of the respective shunts using compression lugs. High temperature, $600 \mathrm{~V}$ rated cables are connected to the sensing terminals of the current shunts using solder-filled ring terminals and wired to their respective channels on the isolating RTU.

At each array, the voltage divider transmitter and isolating RTU are wired directly to a data logger multiplexer and a serial communication module, respectively. The inverter communication card is wired using Cat5 cable to a communication hub in the closest building. To reduce power consumption, termination resistors are not wired in parallel at the ends of the RS485 communication wires for the isolating RTUs and inverter cards because they are not needed to reduce signal reflections, as the cable lengths are less than $600 \mathrm{~m}(2000 \mathrm{ft})$ and the data rates are relatively low (19200 bps and $9600 \mathrm{bps}$, respectively). The cables are UV and moisture protected and run through metal dedicated data conduit, separating them from power conductors that may generate EMI. The cables are also shielded twisted-pair and grounded at one end on the data logger or indoor side to reduce and allow the EMI to be later rejected when differentially measured.

\subsection{AC Electrical}

\subsubsection{Sensors}

The alternating current (AC) voltage, current, and other metrics are measured at each array using one Schneider Electric Powerlogic ION8600 AC power meter. The meters use fused voltage taps (no potential transformers) and revenue grade bar-type CTs with a 200:5 ratio at the Canopy and Ground Arrays and a 100:5 ratio at the Roof Array, both of otherwise unknown specifications. Both the meter and the CTs were selected and installed by the PV integrator. Various AC measurements are also performed by the inverters, with both the inverter and power meter AC measurements listed in Table 3-3. The inverters communicate these measurements as well as the inverter operating state and any fault codes over one wire pair using the RS485 serial Modbus RTU protocol, as described 
before, and the AC power meters communicate over Ethernet using the Modbus TCP/IP protocol. Note that the PV integrator also communicates with the inverter and $\mathrm{AC}$ power meter at each array.

Table 3-3 Inverter and Power Meter AC Measurements

\begin{tabular}{|c|c|c|c|}
\hline Measurement & $\begin{array}{c}\text { Canopy and } \\
\text { Ground Inverters }\end{array}$ & $\begin{array}{c}\text { Roof } \\
\text { Inverter }\end{array}$ & $\begin{array}{l}\text { Power } \\
\text { Meter }\end{array}$ \\
\hline Line voltage $A, B, C$ & $\mathrm{X}$ & $X$ & $X$ \\
\hline Line current $A, B, C$ & $\mathrm{X}$ & $\mathrm{X}$ & $\mathrm{X}$ \\
\hline Neutral current & & $X$ & \\
\hline Output real power & $\mathrm{X}$ & $\mathrm{X}$ & $\mathrm{X}$ \\
\hline Output reactive power & & $\mathrm{X}$ & $X$ \\
\hline Output apparent power & & $\mathrm{X}$ & $\mathrm{X}$ \\
\hline Power factor & & $\mathrm{X}$ & $\mathrm{X}$ \\
\hline Total real energy & $\mathrm{X}$ & $\mathrm{X}$ & $X^{1}$ \\
\hline Total reactive energy & & & $X^{1}$ \\
\hline Line frequency & $\mathrm{X}$ & $\mathrm{X}$ & $X^{2}$ \\
\hline Phase reversal & & & $\mathrm{X}$ \\
\hline Total harmonic distortion & & & $\mathrm{X}^{3}$ \\
\hline $\begin{array}{l}{ }^{1} \text { includes separate receive } \\
{ }^{2} \text { includes minimum and } n \\
{ }^{3} \text { maximum on each line }\end{array}$ & $\begin{array}{l}\text { nd delivered } \\
\text { mum }\end{array}$ & & \\
\hline
\end{tabular}

The AC power meters are installed in the closest building to each array near the building's switchgear, with the meter at the Ground Array shown in Figure 3-15. The CTs are housed in a junction box near the switchgear, and the fused voltage taps are in the same junction box at the Roof Array and in one of the switchgear's power distribution boards at the Canopy and Ground Arrays, with the fuses housed in a separate dedicated enclosure near the AC power meter.

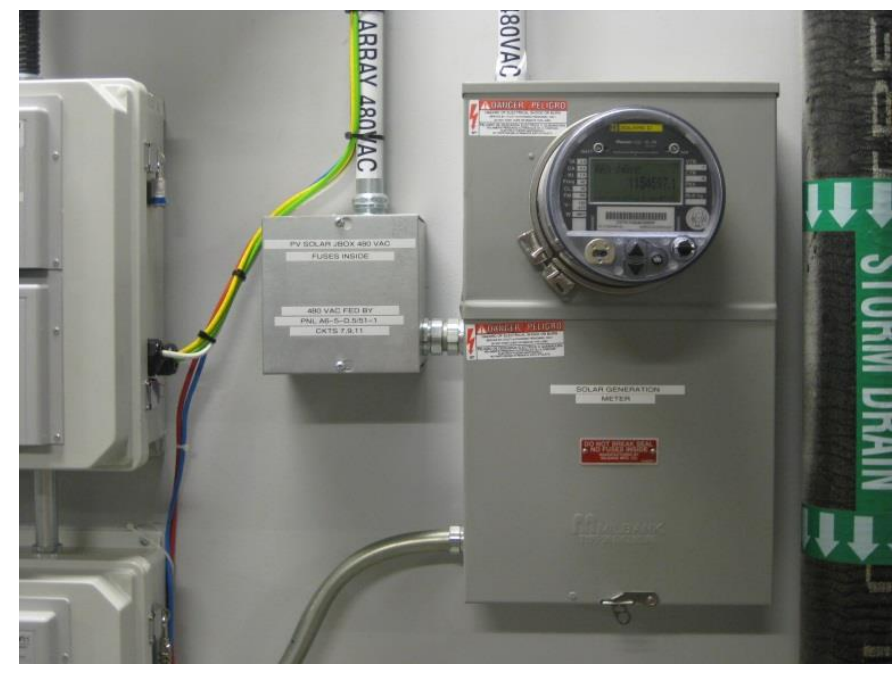

Figure 3-15 The AC power meter at the Ground Array (formerly branded by Square D), also showing the separate dedicated enclosure for the voltage tap fuses 


\subsubsection{Wiring}

The inverters are connected to the 480 VAC, three-phase campus grid via a four-wire Y connection with the neutral grounded. The power meters are connected to meter sockets wired to the buildings' switchgear. The voltage taps are connected through $2 \mathrm{~A}$ fuses and the CTs are wired to the meters using approximately $6 \mathrm{~m}$ to $9 \mathrm{~m}$ (20 ft to $30 \mathrm{ft}$ ) leads. These leads are relatively long and their effect on the CT burdens and subsequent accuracy should be considered. Each power meter is connected to the NIST network with a Cat5e cable, and each inverter communication card, as explained before, is wired using Cat5 cable (twisted-pair) to a communication hub in the closest building. The inverter communication cables are UV and moisture protected and run through metal dedicated data conduit, separating them from power conductors that may generate EMI. The inverter cables are also shielded and grounded at one end on the indoor side to reduce EMI.

\section{Data Acquisition and Control}

\subsection{Data loggers}

\subsubsection{Components}

The data logger at each array is a Campbell Scientific CR1000-ST, shown in Figure 4-1 in the upper left of the Canopy Array outdoor data acquisition enclosure. The data acquisition enclosures at the Ground and Roof Arrays are very similar and have identical components.

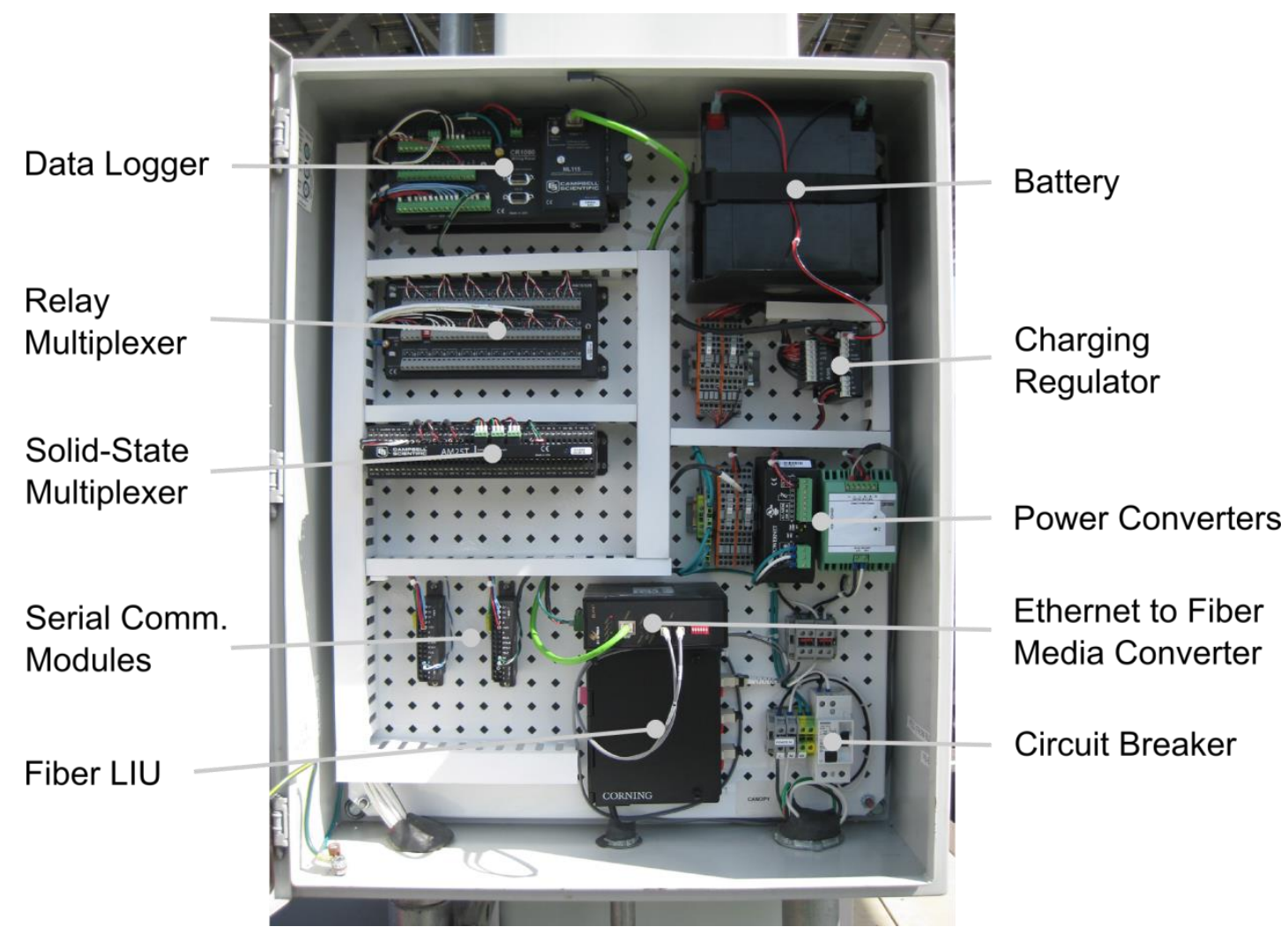

Figure 4-1 The data acquisition enclosure at the Canopy Array showing the data logger, measurement and communication peripherals, battery backup, and power converters and distribution blocks 
This data logger was chosen because it has:

- good measurement accuracy

- adequate processing power

- high reliability for extended periods in outdoor environmental conditions

- the ability to interface with a large variety of peripherals

- a small form factor

- relatively low power draws and therefore needs only a small battery backup for extended power outages

The analog voltage and current signals are multiplexed using one Campbell Scientific AM25T solid-state multiplexer, with the current carrying wires first connected to Campbell Scientific CURS100 100 ohm current shunts to convert the current signals to voltage signals. The RTDs are multiplexed using one Campbell Scientific AM16/32B-ST relay multiplexer. The serial devices are each connected to separate Campbell Scientific SDM-SIO1 serial communication modules.

Solid-state multiplexers are used because of their faster switching times and greater longevity than relay multiplexers, which are needed for measuring numerous channels at a one-second sample rate over an extended duration. Relay multiplexers are used for the RTD measurements instead of solid-state multiplexers because the solid-state multiplexers cannot pass the currents needed to excite the RTDs. This restriction does limit the RTD sample rate to greater than one-second, but this rate is acceptable because the module temperatures change at a slower rate than the irradiance and array DC voltage. The separate serial communication modules are used instead of the serial communication channels on the data logger because there were not enough available channels.

The relay multiplexer is connected to the data logger through a Campbell Scientific 4 WPB100 $100 \Omega$ four-wire halfbridge terminal input module. The bridge employs a high-accuracy $( \pm 0.01 \%)$, low temperature dependence $(<8$ $\mathrm{ppm} /{ }^{\circ} \mathrm{C}$ ) shunt to measure the current through the RTD, generated by the excitation voltage supplied by the data logger. A current limiting resistor is used in series with the shunt to allow for higher excitation voltages at the data logger, minimizing the relative noise in the excitation, while limiting the current and subsequent self-heating in the sensing resistor (RTD). Self-heating, which results in a measurement bias error, is caused by the excitation current passing through the sensor resistor.

A Campbell Scientific NL115 is connected to the data logger's peripheral port and provides 10BASE-T Ethernet communications and a CompactFlash card slot interface for storing measurements. An industrial quality 2 GB Synchrotech CFV-2GB-TSI-3524 card is used, which like the data logger, can operate with high reliability for extended periods in outdoor environmental conditions.

The integrator's RTU at each array is an Advantech ADAM-4015 RTD input module, shown in Figure 4-2 with a terminal block in its outdoor data acquisition enclosure at the Ground Array. This RTU is specialized for measuring RTDs, but the ones employed by the integrator are customized by the manufacturer to also measure analog voltages, including the one from the integrator's pyranometer. The RTU samples readings at $10 \mathrm{~Hz}$, integrating each for $50 \mathrm{~ms}$ (three $60 \mathrm{~Hz}$ cycles), and does not average the readings. The RTU at each array is indirectly connected to the integrator's indoor data logger, which is an industrial computer of unknown specifications, communicating over one wire pair using the RS485 serial Modbus RTU protocol at 9600 bps. 


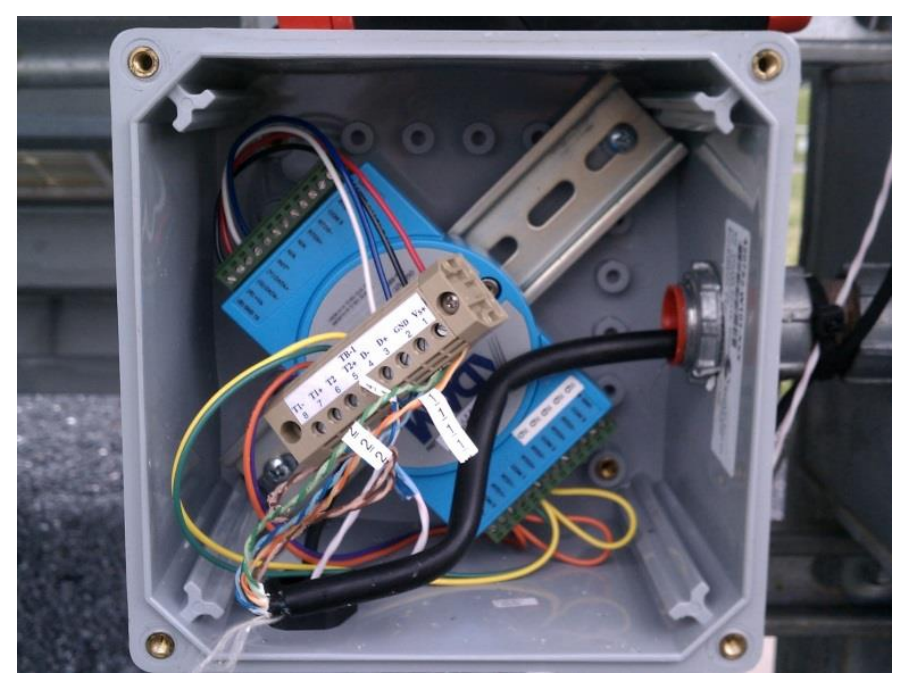

Figure 4-2 The integrator's RTU and a terminal block in their outdoor enclosure at the Ground Array

\subsubsection{Locations and Housing}

Each data acquisition enclosure is located near the respective array in an easily accessible location that does not shade the array. Each enclosure is NEMA 4 rated and locked to control access, with an additional sensor installed to monitor when the door is open (at which time the data logger sends out an email alert). The humidity in the enclosure is regulated by sealing the conduit openings with duct seal compound and replacing desiccant packets on an as needed basis, with the humidity level monitored using a humidity indicator card. The enclosure at the Roof Array is in a horizontal orientation to not shade the array, and is inside of another larger enclosure to better protect against water ingress. The integrator's outdoor RTU enclosures are also weather resistant and located near the array; however, the enclosure at the Canopy array is located at the south end of the center canopy near the top of the canopy and is only accessible with a ladder or lift.

\subsubsection{Wiring and Power}

All wiring inside of the enclosures is done with low capacitance, high temperature PTFE insulated stranded wires with insulated ferrules crimped on their ends. Ferrule-terminated wires make troubleshooting and reworking easier and provide a more secure, lower contact resistance connection to the terminals. Jumper wires are connected between the low sides of the pyranometers' differential inputs and the respective ground terminals to keep the pyranometers, the only electrically floating sensors in these DASs, from floating above the ground potential and out of the data logger's common mode range, which would decrease the accuracy of the measurements. The jumpers also keep the pyranometers from potentially floating out of the measurable range entirely.

The Ethernet communication module on the data logger connects via a Cat6 Ethernet patch cable to an Etherwan EL1141 hardened 10/100BASE-TX Ethernet to 100BASE-FX fiber media converter. The media converter is connected to a fiber light interface unit (LIU) using a fiber patch cable, where the LIU is a protective enclosure for splitting and adding connectors to individual optical fibers. Fiber optic communication was chosen for the data loggers to eliminate any EMI and reduce the potential for ground loops and power surges back to the data logger. The distance between the data loggers and the network access point in the nearby buildings is also near to or over the distance limit for Cat $5 / 6$ cable $(100 \mathrm{~m} \mathrm{[330} \mathrm{ft])} \mathrm{which} \mathrm{could} \mathrm{have} \mathrm{caused} \mathrm{slow} \mathrm{or} \mathrm{unreliable} \mathrm{communications.}$

The data logger is battery-backed using a Genesis NP24-12 $12 \mathrm{~V}, 24 \mathrm{~A} \cdot \mathrm{h}(288 \mathrm{~W} \cdot \mathrm{h})$ sealed rechargeable lead acid battery connected to a Campbell Scientific CH200 charging regulator. This regulator charges the battery and switches between line and battery power, providing an uninterrupted power supply (UPS) to the data logger and all other peripherals in the enclosure except the Ethernet to fiber media converter. The UPS at each array will provide at 
least 2.8 days of power to the DAS when there is no external power feeding the enclosure, even during high power draw conditions (e.g., while heating the wind sensor in winter). A breakdown of the DAS energy draws is shown in Figure 4-3.

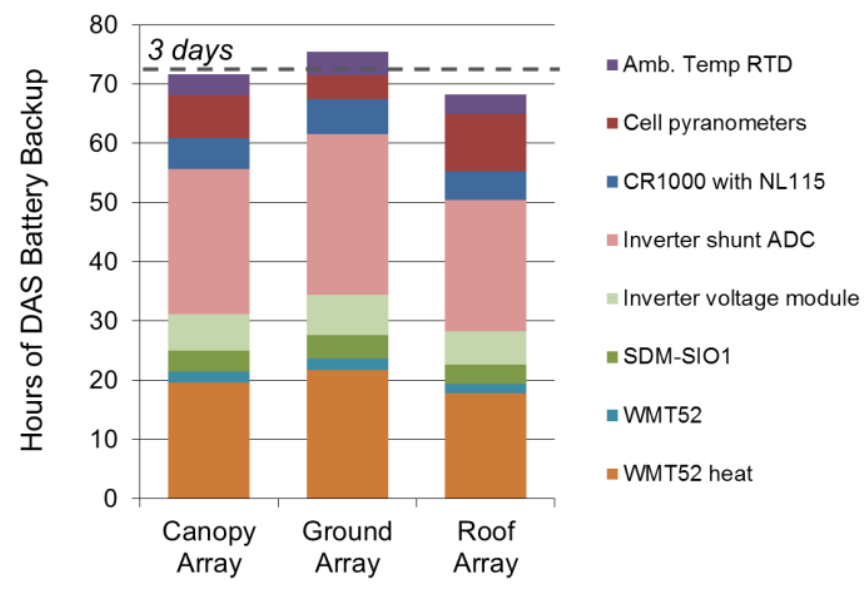

Figure 4-3 Breakdown of the DAS energy draws and UPS backups

Power from the UPS is distributed to the data logger, peripherals, and an array of terminal blocks for the different sensors via a Campbell Scientific A105 terminal expansion adapter on the charging regulator. The power from the non-battery-backed power supply is distributed to a different array of terminal blocks, for currently just the Ethernet to fiber media converter. The line inputs of the charging regulators for the UPSs at the Canopy and Roof arrays are each connected to $120 \mathrm{VAC}$ to 24 VDC power converters, while the terminal blocks for the non-battery-backed Ethernet to fiber media converters are connected to 120 VAC to 12 VDC power converters. These two power converters are connected to $120 \mathrm{VAC}$ feeding those enclosures via terminal blocks and a single AC circuit breaker. The charging regulator for the UPS at the Ground Array and the media converter are connected via terminal blocks and a single AC circuit breaker to 24 VDC feeding that enclosure.

The data acquisition enclosure components at each array are grounded to a central point on the enclosure. Grounding in a "star-point" configuration minimizes the potential differences between the devices and therefore reduces any currents through the devices during a power surge event. The central point of the "star" is connected via the enclosure to the conduit which is locally grounded. The conduit was chosen instead of the ground wires fed from the nearby buildings because it provides a lower resistance path to ground and will not have an electrical choke effect when there is a sudden, high current surge from a nearby lightning strike, which occurs for a surge carrying wire inside of a ferrous conduit. The importance of proper grounding in the interest of equipment longevity cannot be overemphasized.

Three conduits connect to each data acquisition enclosure, one carrying the AC or DC power wires or cable, one carrying the fiber communication cable, and one carrying the sensor data cables. Excess lengths of the data cables for potential future reworks (approximately $3 \mathrm{~m} \mathrm{[10} \mathrm{ft])} \mathrm{are} \mathrm{stored} \mathrm{in} \mathrm{a} \mathrm{nearby} \mathrm{pull} \mathrm{box} \mathrm{connected} \mathrm{to} \mathrm{the} \mathrm{data} \mathrm{conduit}$ at the Canopy and Ground Arrays and in the outer enclosure at the Roof Array.

The integrator's RTU is wired to the nearest building using Cat5 cable, communicating over one twisted-pair and powered using two other twisted-pairs. At the Canopy Array, however, the RTU is powered by a NIST non-batterybacked power supply in the outdoor NIST data acquisition enclosure. The data wires for this RTU are also connected to a Moxa ISD-1230 RS485 surge protector next to the RTU in the integrator's outdoor enclosure because it has been very susceptible to failure, especially during storms. To reduce power consumption, termination resistors 
are not wired in parallel at the ends of the RS485 communication wires because they are not needed to reduce signal reflections, as the cable lengths are less than $600 \mathrm{~m}$ (2000 ft) and the data rates are relatively low $(9600 \mathrm{bps})$.

\subsubsection{Communications}

The communication hubs for the data acquisition systems are at an indoor location in the nearest building to each array. Two locked enclosures, one for the NIST equipment and one for the integrator's data logger and RTU power supply, are installed in the switchgear mechanical room near the AC power meter, as shown in Figure 4-4 at the Ground Array.

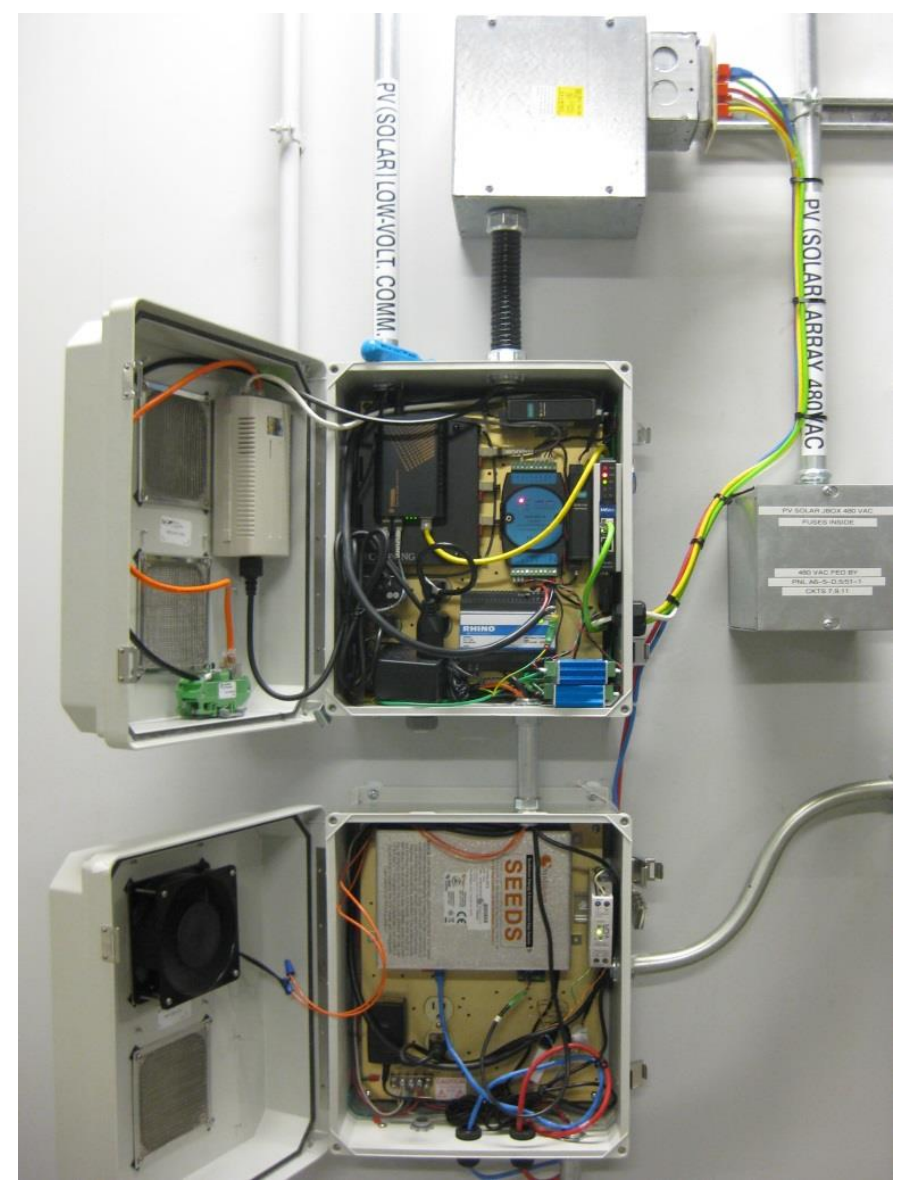

Figure 4-4 The indoor communication hubs at the Ground Array for the NIST (top) and integrator (bottom) equipment

Near or inside the NIST enclosures are NIST network jacks with connections to the internal private network for the NIST data loggers and to the public firewalled network for the integrator's data loggers and all other equipment accessed by both NIST and the integrator, including the AC power meters. When located outside of the NIST enclosure, the network patch cables are locked to the jacks to prevent unauthorized disconnection. A complete anonymized diagram of the communications network is shown in Appendix F, with a simplified diagram of the local network at each array shown in Figure 4-5. 


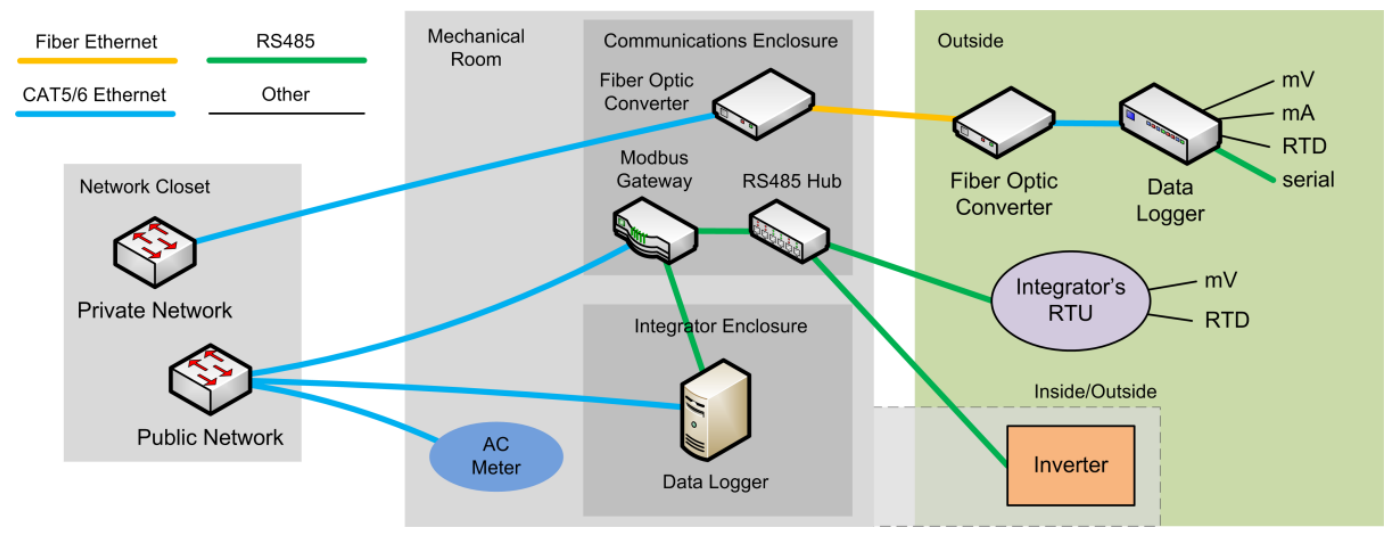

Figure 4-5 Diagram of local network at each array

The fiber optic cable from the outdoor data logger terminates in the NIST enclosure at a fiber LIU, which connects to an Etherwan EL100 10/100BASE-TX Ethernet to 100BASE-FX fiber media converter. (At the Canopy Array, these devices are located in a network closet on a different floor). The media converter connects to a network jack on the internal private NIST network with a Cat6 patch cable. The Cat5 cables from the inverter and the integrator's RTU at each array terminate at separate Moxa ISD-1230 RS485 surge protectors in the NIST enclosure. These, along with the other equipment in the enclosure, are grounded using $10 \mathrm{AWG}\left(5.26 \mathrm{~mm}^{2}\right)$ wire in another star-point configuration to a central point in the enclosure that is connected to the building ground.

The outputs from the surge protectors are wired to a CommFront HUB-485-4 RS485 hub. The single input on the hub is wired along with the serial communication port on the integrator's data logger to separate serial ports on a Moxa MGate MB3270 serial-to-Ethernet Modbus gateway, both through additional, smaller SerialComm ISO-485-P surge protectors. This gateway translates and coordinates communications between the inverter and integrator's RTU and both the NIST data logger (Ethernet connection) and the integrator's data logger (serial connection). The gateway connects to a network jack on the public firewalled NIST network with a Cat6 patch cable. The NIST data loggers communicate over the NIST network with the inverters and RTUs through the gateways, using the Modbus TCP/IP protocol over Ethernet, which is translated by the gateways into the RS485 serial Modbus RTU protocol, and vice versa.

The NIST indoor communication enclosure at the Ground Array also contains a 24 VDC power supply for the outdoor data logger and a Power over Ethernet (PoE) midspan for the Ground Array camera. The NIST enclosure at the Roof Array contains an extra smaller surge protector for connecting the RS485 hub to RTUs measuring module temperatures sensors on the older horizontal PV array. 


\subsubsection{Configuration}

\subsubsection{Sampling Rates and Parallel Processing}

The data loggers are programmed using the Campbell Scientific language CRBASIC. The programs measure all of the sensors every $1 \mathrm{~s}$, except for the RTDs which are measured every $10 \mathrm{~s}$. The slower RTD sampling rate is due to the slower relay multiplexers to which the RTDs are connected, but is not a restriction nonetheless because the module temperatures the RTDs are measuring are not changing appreciably faster than every $10 \mathrm{~s}$. It takes longer than $1 \mathrm{~s}$ to measure, and poll and receive data from the sensors and instruments if done sequentially, so the program is run in "pipeline" mode which effectively executes some of the measurement steps in parallel.

\subsubsection{Time Synchronization}

In order to maintain time synchronization within $1 \mathrm{~s}$ between data loggers, the data loggers are instructed every morning just after midnight to synchronize with a local internet time server. This synchronization keeps the data loggers within $0.5 \mathrm{~s}$ of each other at all times. The data loggers are configured to always use local standard time (LST) to eliminate issues arising from the switch to and from daylight saving time (DST) and to allow easier comparisons and calculations.

\subsubsection{Channel Ranges}

The input voltage ranges for each measurement channel are explicitly chosen and fixed; auto-range is not used to eliminate the initial measurement needed to set the range, resulting in a shorter sampling time. The range determined by auto-range may also not be accurate for the irradiance and electrical measurements as they can fluctuate rapidly.

\subsubsection{Self-Calibration}

The data logger is instructed to periodically self-calibrate to compensate for aging-induced and operating temperature-induced (Seebeck effect) drift. Voltage offsets are measured on each channel when the signal source is internally disconnected, using an internal voltage standard as a reference for all channels.

\subsubsection{Measurement Techniques}

Various techniques are employed for every measurement to more accurately measure the sensed value. The voltage signals, both direct from the sensor and those from a shunt when measuring current signals, are measured differentially instead of single-ended with respect to the data logger ground. This approach eliminates any voltage reference offsets and rejects capacitively coupled common-mode noise.

Although considered, the thermopile pyranometers, the only electrically floating sensors in these DASs, are not pulled to ground before each measurement to null any common-mode voltage. Rather, jumper wires are connected between the low sides of the differential inputs for the pyranometers and the respective ground terminals to keep the pyranometers grounded, as previously described. These data loggers combine nulling the common-mode voltage with open input detection, commonly used for thermocouples, into one function and neither can be individually implemented. The open input detection, which biases the high side of the differential input for the pyranometer above the channel measurement range while grounding the low side, would not allow the pyranometer output enough time to stabilize before the measurement. No measurement channels in the DASs employ the common-mode nulling and open input detection function.

The settling times, the delay after the channel terminals are internally connected to the input amplifier and before the measurement is started, were chosen to be $10 \mathrm{~ms}$ for the pyranometers and $3 \mathrm{~ms}$ for other analog signals. The longer settling time for the pyranometers allows further reduction of voltage transients caused by channel switching, as they would have a larger relative magnitude compared to the pyranometers' much smaller voltage signals. Due to the larger number of sensors at the Roof Array, only the essential pyranometers in the southeast corner of the array and in the center of the older horizontal array are allowed to settle for $10 \mathrm{~ms}$, with the rest settling for $3 \mathrm{~ms}$, to allow for all sensors to be sampled every $1 \mathrm{~s}$. 
The voltage signals are integrated for exactly $16.67 \mathrm{~ms}$. This integration time, the period of a $60 \mathrm{~Hz}$ waveform, rejects $60 \mathrm{~Hz}$ frequency components in the signal by cancelling them out. This noise is induced from nearby AC power sources, which operate at $60 \mathrm{~Hz}$ in the USA. The signals for the nonessential pyranometers at the Roof Array are integrated for $250 \mu \mathrm{s}$ instead of $16.67 \mathrm{~ms}$, also to allow for all sensors to be sampled every $1 \mathrm{~s}$.

Each differential voltage measurement is performed twice, with the second time after the channel terminals are internally reverse-connected to the input amplifier. The two measurements are subtracted and divided by two to cancel any voltage offsets in the measurement circuitry, as well as any common-mode gain errors. Note that before each measurement the signal is allowed time to settle, which doubles the total settling time per measurement.

There is not enough available time in the $1 \mathrm{~s}$ scan period to employ all of the aforementioned techniques when measuring the four-wire RTDs, so tests were performed to identify those most beneficial in this application. The tests determined that a settling time of $3 \mathrm{~ms}$ was adequate and revealed that $60 \mathrm{~Hz}$ integration reduces significantly more uncertainty than reversing the inputs and reversing the excitation, combined. Reversing the excitation is similar to reversing the inputs, but does so for the excitation and works to cancel any voltage offsets before and in the measurement circuitry (reversing the input cancels the offset in the measurement circuitry as well as the common-mode gain errors). Note that these two techniques each double the total settling time and combining both quadruples it. If there was a longer sampling period then all three techniques would have been employed, even though the benefits of the two reversals are relatively small in this application.

The excitation for the RTDs is optimized by maximizing the measurement resolution of the voltage across the sensing resistor (RTD) while keeping the self-heating error, caused by the excitation current passing through the sensing resistor, below an acceptable level. Self-heating errors for $100 \Omega$ RTDs like the ones in these DASs are less than $0.001{ }^{\circ} \mathrm{C}\left(0.0018^{\circ} \mathrm{F}\right)$ in still air when the voltage drop across the sensing resistor is less than approximately 25 $\mathrm{mV}(6 \mu \mathrm{W})$ [14]. The optimal excitation voltage is therefore what results in a maximum sensor voltage of $25 \mathrm{mV}$, which occurs at the highest expected temperature, chosen conservatively to be $90{ }^{\circ} \mathrm{C}\left(194{ }^{\circ} \mathrm{F}\right)$. This corresponds to a maximum resistance of $135 \Omega$. The optimal excitation voltage is calculated for the half-bridge and current-limiting resistor in Figure 4-6 using Equation (1), neglecting the negligible lead resistances. The equation is calculated using values of the measurement bridge resistors at the low end of their respective tolerance ranges, resulting in a higher current and subsequently higher RTD voltage. If the tolerances are not accounted for, this potentially higher RTD voltage could be greater than the selected measurement range. 


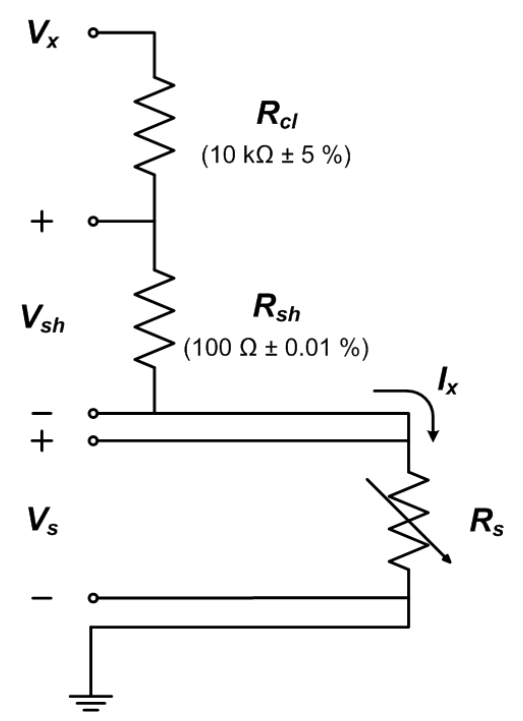

Figure 4-6 Half-bridge for measuring RTDs

$$
V_{x}=\frac{V_{s, \text { max }}}{R_{s, \text { max }}}\left(R_{c l, \text { min }}+R_{s h, \text { min }}+R_{s, \text { max }}\right)
$$

where:

$V_{x}=$ excitation voltage

$V_{s}=$ sensing voltage

$R_{s}=$ sensing resistor $(\mathrm{RTD})$

$R_{c l}=$ current limiting resistor

$R_{s h}=$ completion (shunt) resistor

$V_{s h}=$ shunt voltage

$I_{x}=$ excitation current

The optimal excitation, calculated to be $1.8 \mathrm{~V}$, is only kept on during the measurement to further reduce the selfheating errors. The measurement equation for the half-bridge, when reduced, becomes the ratiometric relation $R_{s}=R_{s h} \cdot\left(V_{s} / V_{s h}\right)$. The temperature of the RTD is then determined from the resistance using the inverse of the Callendar-Van Dusen equation according to the ASTM E1137-04 [15] standard.

Timeouts for the serial and Ethernet communicating instruments, the time after polling the instrument waiting for a reply, were carefully chosen to be the maximum time the instrument normally takes to respond to a request. A flag in the data logger programs can be manually set while the program is running to stop polling individual instruments in the case where they are temporarily unresponsive, which has occurred for the integrator's RTUs and the inverters. Setting this flag can speed up the program and avoid missed measurements while the data logger would normally be waiting the full timeout period for a response.

\subsubsection{Control}

The data loggers regulate the power to the inverter shunt RTUs and the wind sensor heaters when external power to the data acquisition enclosures is off and the data loggers are operating on battery power. These two devices consume the most power and are regulated to allow the DASs to operate for approximately three days on battery 
power. Power to the inverter shunt RTUs is turned off at night between 20:30 and 04:00 LST. Power to the wind sensor heater is turned on during the first five minutes of each hour and turned off at all other times.

The data logger at the Roof Array, due to its high utilization, drops its communications every few days and needs a power reset to restore it. One of the data loggers that is part of the weather station remotely toggles the power to the Roof data logger via a relay every other day at 01:00 LST or when the data logger is unresponsive. The relay is controlled over the public network through the RS485 hub at the Roof Array.

\subsubsection{Data storage and processing}

Measurements are stored on the memory card as either 16-bit floating point, 32-bit floating point, or 32-bit signed integer data types according to the needed range and precision of the individual measurements. This selective allocation conserves storage space and increases processing speeds in the data logger and server. All measurements are saved every one-second, including the RTD measurements, resulting in nine duplicate RTD measurements saved every 10-second sample period. All measurements are also either averaged or the minimum or maximum calculated for each minute, whichever more appropriate, and saved. The one-minute values are calculated from the samples taken between $1 \mathrm{~s}$ and $60 \mathrm{~s}$, inclusive, preceding the recorded minute time. The wind measurements are processed according to EPA guidelines [16] to produce the mean horizontal wind speed, the unit vector mean wind direction, and the standard deviation of wind direction calculated using the Yamartino algorithm.

The 2 GB of storage can store 82 days to 131 days of measurements depending on the array for times when the communications are down. The storage is configured as ring memory, where the oldest data is overwritten when the memory card is full.

\subsection{Reference Modules}

Reference modules, one for each orientation at each array, are installed in the same orientations at the weather station, as shown in Figure 4-7. These reference modules provide baseline measurements without the significant wiring, mismatch, soiling, snow, shading, and other losses of the modules in the arrays. These reference modules also provide data on their aging, and their true average cell temperature and absorbed/effective irradiance from their measured I-V curves, which can be correlated with the measured backsheet surface temperature and POA irradiance, respectively.

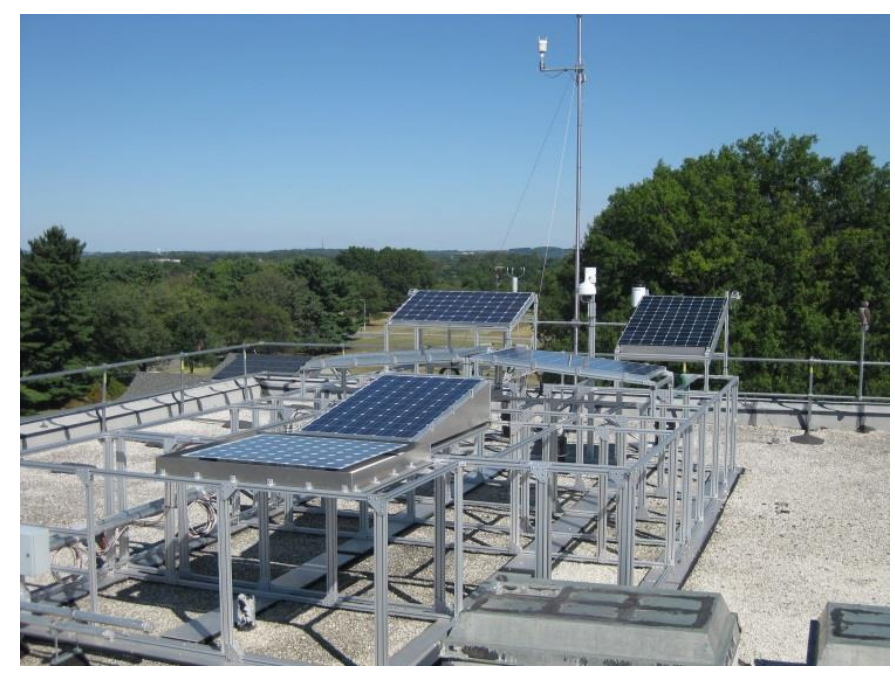

Figure 4-7 The reference modules installed at the weather station

There are two modules for the Canopy Array (facing left and right), one module each for the Ground Array (back left) and Roof Array (second from front), one module for the older horizontal array near the Roof Array (front), and 
one module for the array on NIST's Net-Zero Energy Residential Test Facility (NZERTF) (back right). These reference modules (except the one for the older horizontal array) are from the same production batches as those installed at each array. The modules are arranged according to a CAD model made in SketchUp [17], which calculated less than 45 minutes of any mutual or external shading on the modules at sunrise and sunset on the summer solstice and less than 5 minutes on the winter solstice, the two extremes of the year. Flashing is installed around the modules for the older horizontal array, Roof Array, and NZERTF array to simulate the effect of the respective installations on the module temperatures; the modules in the Canopy and Ground Arrays have open air circulation on their back sides and therefore have no flashing installed around their reference modules.

The backsheet surface temperatures of each module are measured using one Omega CO1-T-72 thermocouple mounted behind a center cell and either four Omega SA1-RTD-4W-80 RTDs for the Canopy, Ground, Roof Array modules or four additional Omega CO1-T-72 thermocouples for the older horizontal and NZERTF array modules, matching the sensor type at each array. The set of four temperature sensors are mounted behind one center and three peripheral cells, as described in section 3.4. The POA irradiance is measured for each module using an IMT Solar Si-420TC flat-plate silicon irradiance sensor, as described in section 3.2.

The modules, thermocouples, and irradiance sensors are connected to a Daystar Multi-Tracer 5 (MT5) I-V curve tracer with maximum power tracker and load system, as shown in Figure 4-8. (The set of four temperature sensors on each module are connected to a data logger multiplexer for the weather station, sampled every $10 \mathrm{~s}$ and saved every $1 \mathrm{~s}$, and averaged and saved every $1 \mathrm{~min}$.) The modules are wired directly to the system using 10 AWG (5.26 $\mathrm{mm}^{2}$ ) UV and moisture protected PV cable run through metal dedicated conduit. The sensors are wired as described in sections 3.2.5 and 3.4.5.

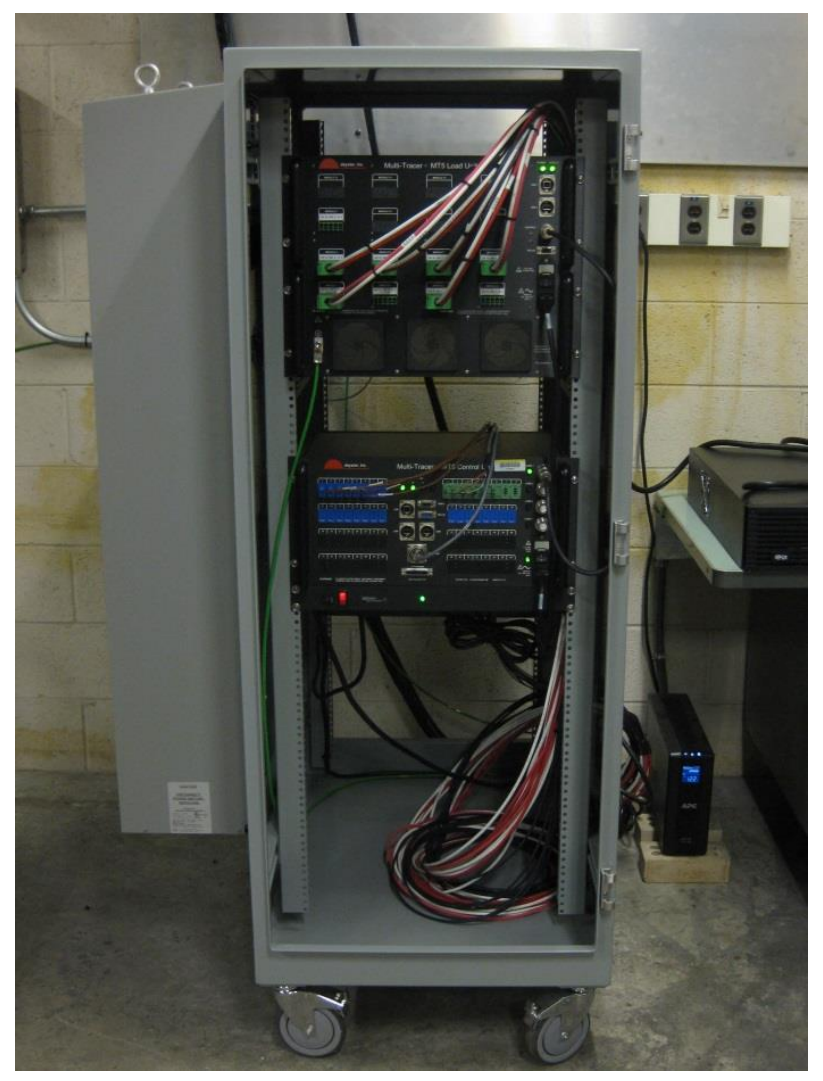

Figure 4-8 The I-V curve tracer with maximum power tracker and load 
The I-V tracer and maximum power tracking system performs an I-V trace for each module every minute, integrating every current and voltage reading for $100 \mu \mathrm{s}$. The curves are saved along with measurements of the respective thermocouple and irradiance sensor before and after each trace. At all other times, the system maximum power tracks each module, measuring the maximum power voltage and current and the corresponding thermocouple and irradiance sensor, sampling every one second and averaging and saving every minute. All measurements are saved to internal memory. The MT5 system does not adjust its clock for DST, which allows for easier comparison with the measured data from the data loggers, which also do not adjust for DST. The system was calibrated at the factory and verified to be within specifications.

\subsection{Cameras}

Images of each array are taken using an Axis Q6032-E pan-tilt-zoom (PTZ) network camera located at each array, with the camera for the Canopy Array shown in Figure 4-9. The images taken by the cameras are used to capture the shading, snow, rain, and frost, and any other obstructions or damage to the arrays.

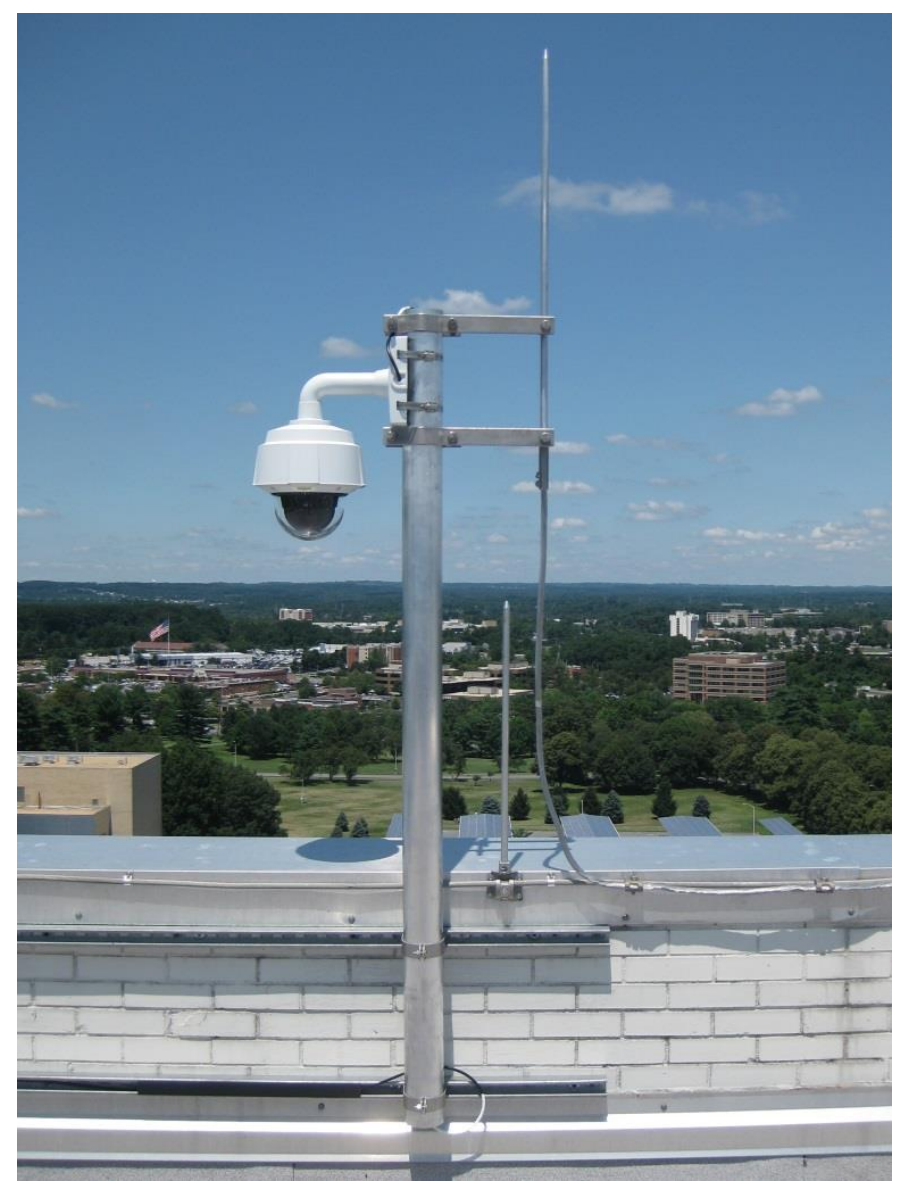

Figure 4-9 The PTZ camera that records images of the Canopy Array

The cameras are configured for constant white balance, auto exposure, and to use an IR cut filter during the day but not at night to increase sensitivity. The cameras, like the data loggers, are configured to not adjust their clocks for DST for easier comparison with the measured data. The cameras take $704 \times 480$ resolution images, which are saved as uncompressed JPEG images on an internal 32 GB SanDisk Extreme SD card. Each camera is programmed to take images of the entire array and of close-up sections at a constant zoom for detailed analysis and stitching together into a single higher resolution image. The cameras take images every five minutes during the day (04:00 to 20:00 LST) and every hour all day. 
The array cameras communicate over the NIST private network and are powered using Power over Ethernet (PoE). A surge protector is housed in an outdoor enclosure, and the midspan, for combining the power and Ethernet, and any necessary network switch and power supply are housed in an indoor enclosure, with the enclosure for the Canopy and Roof Array cameras shown in Figure 4-10.

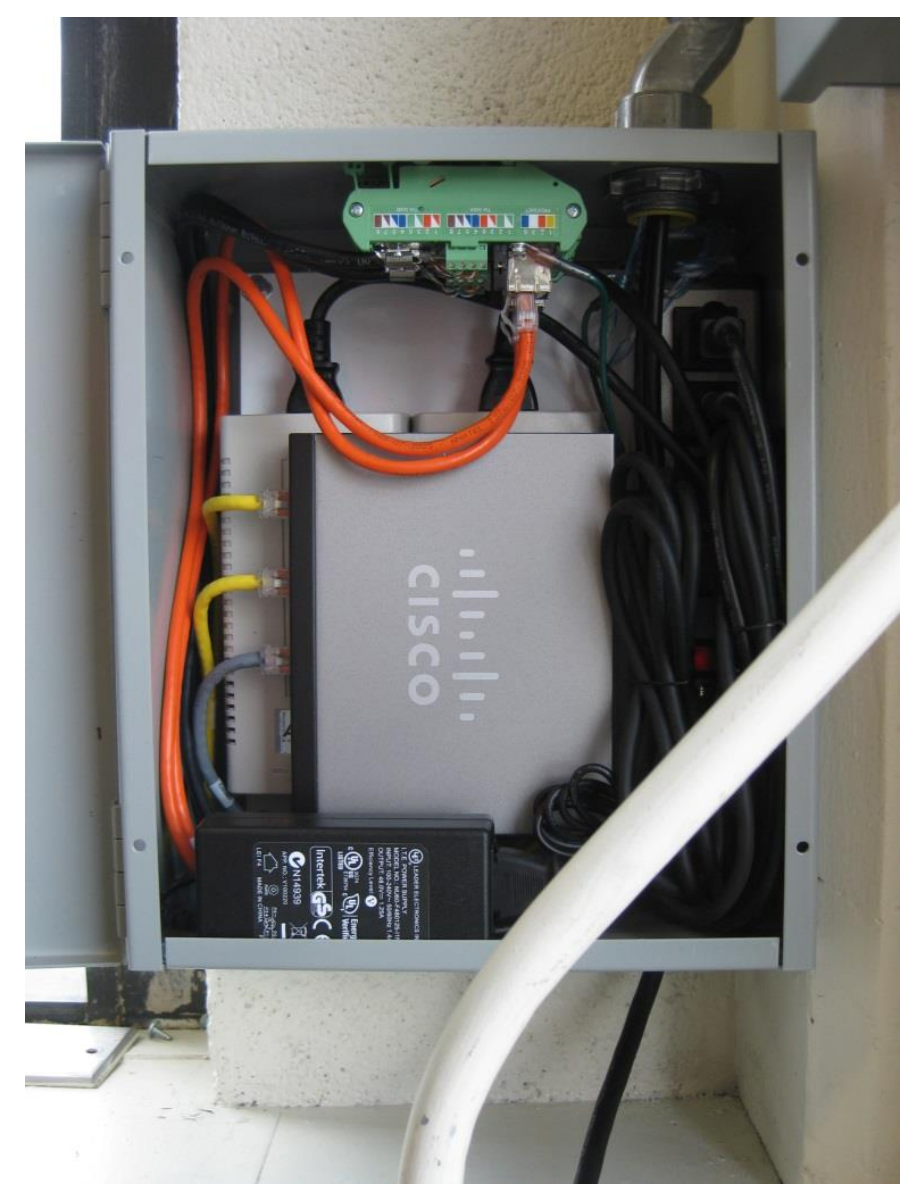

Figure 4-10 The enclosure for the Canopy and Roof Array camera midspans and network switch

There is also a Campbell Scientific CC5MPX camera at the weather station that takes images of the reference modules. This camera does not adjust for DST and takes $2592 \times 1944$ resolution images saved as uncompressed JPEG images on an internal 32 GB SanDisk Extreme SD card. No other settings are configurable. The camera is programmed to take a fixed zoom image every five minutes during the day (04:00 to 20:00 LST) and every hour all day. This camera communicates over the NIST private network and is powered using a separate cable.

\section{Data Archiving and Monitoring}

Campbell Scientific LoggerNet Admin is used to manage the network of data loggers. It is installed on a network server running Windows Server 2008 R2. Loggernet Admin runs as a service, running whether or not a user is logged in and starts immediately after the server restarts. Loggernet is configured to import data from the data loggers every minute, leaving a copy on the data loggers as a backup to be later overwritten. The data are saved on the server as Campbell Scientific TOA5 formatted plain text files, one for each of the 12 defined data logger tables from the Canopy, Ground, and Roof Array data loggers, including the one-minute aggregated tables but not including the file of the temperature measurements of the reference modules from the weather station data logger. 
The data files are imported to a MySQL database every minute by Vista Data Vision (VDV) Enterprise by Vista Engineering, also installed on the server. VDV is configured to send email alerts when data values are outside of defined ranges and when the data files are not being updated. Custom dashboards for each array with plots of select measurements are updated by VDV every minute and provide an overview of the system health. These dashboards are displayed in a web interface hosted by the server, with the main data dashboard for the Ground Array shown in Figure 5-1. In addition to the dashboards, custom plots of various types, tables, logs of alarms, completeness of the database, and a viewer for the hourly camera images of each array are also provided in the web interface. This web interface is currently only available inside the NIST firewall, but a public data portal with the ability to download data will be made available. In the meantime, interested modelers and analysts who would like to use these data in collaboration on new research can contact the author.

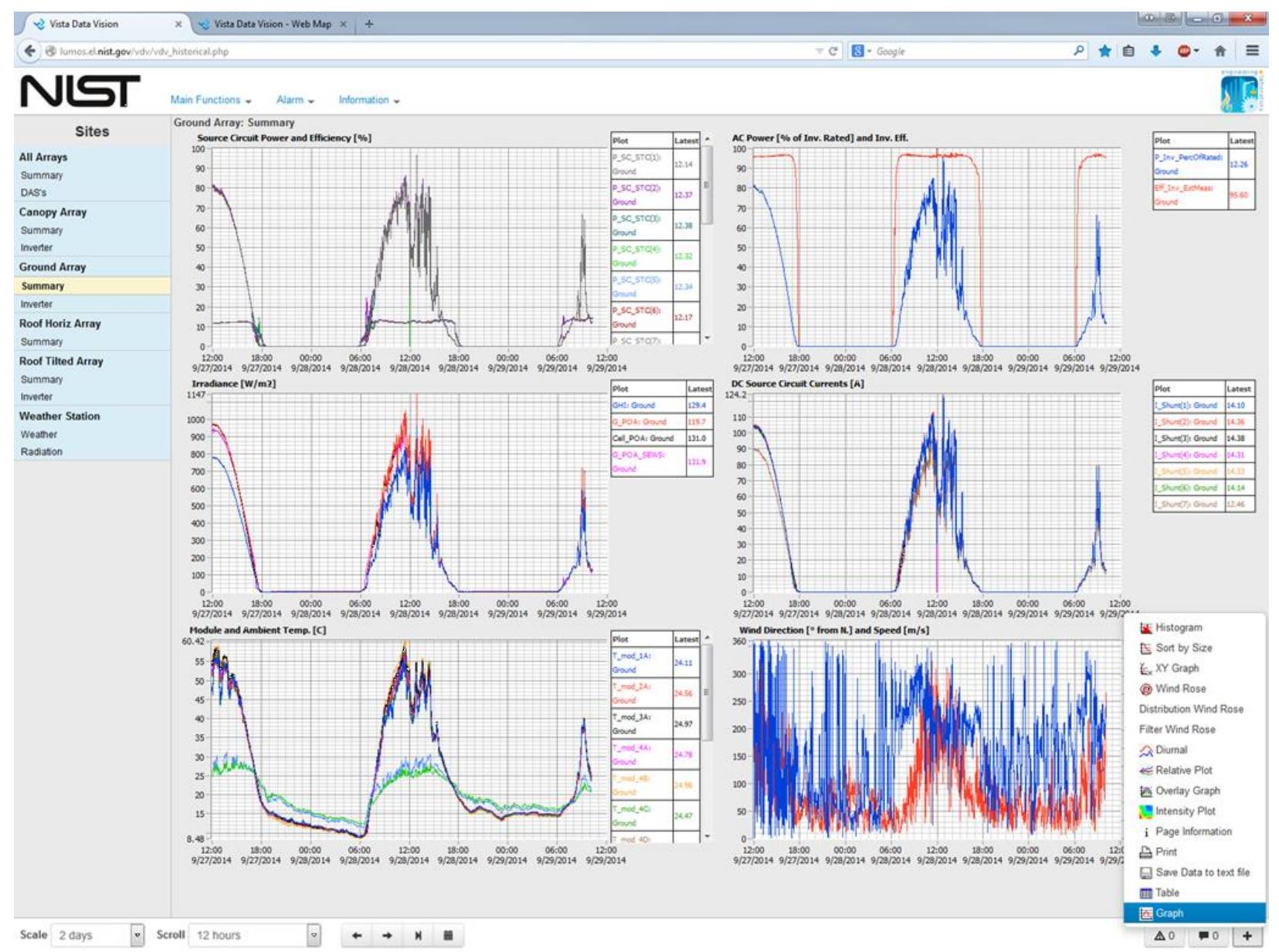

Figure 5-1 The main data dashboard for the Ground Array

Data from the I-V curve tracer and maximum power tracking system and images from the cameras are copied to the server every 30 minutes by an FTP client on the server run as a scheduled task. A custom script, also run as a scheduled task, monitors and sends alerts when data files from the I-V curve tracer and maximum power tracking system are not being transferred to the server. VDV monitors and sends alerts when new images from each camera are not being transferred. All data and images on the server, including data from the data loggers, are continually backed up to offsite cloud storage. 


\section{Uncertainty}

Uncertainties for the collected data are not listed because a complete uncertainty analysis is outside the scope of this report, but one will be performed for each measurement and presented in a forthcoming paper. Sensor and instrument-level uncertainties are not given as they are only part of the system-level values, and therefore can be misleading. Furthermore, they do not account for the error between the measurand, the quantity of interest, and the realized quantity, the quantity measurable by the sensor.

\section{Maintenance}

The data dashboards for each array are checked every weekday for any apparent problems in the DASs. The irradiance sensors at the Ground and Roof Arrays are cleaned every other day, minus weekends, using cleanroom wipes moistened with a $6 \%$ isopropyl/94 \% deionized water mixture and dried with optical tissue. Any ice buildup is first melted using an ethanol solution of the same concentration. One of the flat-plate irradiance sensors in the pair measuring the soiling at the Roof Array is never cleaned. The irradiance sensors at the Canopy Array are cleaned only two to three times a year due to difficulty in gaining access to the elevated instruments, but a solution is being implemented that will allow regular cleaning. A log is kept of the dates and times when the sensors at the different arrays are cleaned.

The data files on the server grow indefinitely, so once a week a custom script is run that pauses the data importation from the data loggers and runs the Campbell Scientific program File Format Convert that splits the files into separate daily files for easier archiving and use.

Thermopile pyranometers are replaced every 12 to 18 months with newly calibrated pyranometers from NREL. A $\log$ is kept of these instrument replacements, which also contains all other maintenance including when sensors, instruments, and devices fail and are replaced and when the arrays are offline.

\section{Acknowledgements}

The author wishes to thank all those who contributed time and effort planning, constructing, and implementing the infrastructure needed for the data acquisition systems described in this report. They include Bill Robson and John Selby of Legatus 6, Christoph Heinzer of Advanced Energy, Carrie Kelly of NIST's Office of Facilities and Property Management, and Mike Zelinsky of SunEdison. Special thanks to Brian Dougherty of NIST's Engineering Laboratory's (EL's) Energy and Environment Division for logistical, construction, and maintenance support. Thanks to Luis Luyo, also of EL's Energy and Environment Division, for constructing the infrastructure for the reference modules, and to Jeffrey Sze for early testing of the systems. Thank you also to Ryan Smith of Pordis, LLC, then at NREL, for early instrument selection advice and design resources.

\section{References}

[1] K. Lynn, SunShot, (2011). http://www.solar.energy.gov/pdfs/doe_lynn_pv_validation_2011_aug.pdf (Accessed on Sept. 11, 2015)

[2] J. Granata, PV performance and reliability validation capabilities at Sandia National Laboratories and the National Renewable Energy Laboratory, http://energy.gov/sites/prod/files/2014/01/f7/pv_manufacturing_workshop_2011_march_granata.pdf (Accessed on Sep. 11, 2015)

[3] J. Newmiller, Validation information for PV power system project review, (2011). http://www.solar.energy.gov/pdfs/dnv newmiller_pv validation_2011_aug.pdf (Accessed on Sep. 11, 2015)

[4] Sandia National Laboratories, PV validation and bankability workshop - August 31, 2011 - Survey Results, (2011). http://energy.gov/sites/prod/files/2014/01/f7/pv_vb_surveyresults.pdf (Accessed Sep. 23, 2015)

[5] Brookhaven National Laboratory, Northeast solar energy research center (NSERC) - A multi-purpose research facility on the BNL campus, (2013). https://www.bnl.gov/energy/files/nserc/NSERCbro3.pdf (Accessed on Sep. 11, 2015) 
[6] Brookhaven National Laboratory, Overview of BNL's Solar Energy Research Plans, (2011). http://www.bnl.gov/energy/files/nserc/BNL_Solar_Research_Overview_and_NSERC_Plans with_Input.pdf (Accessed on Sep. 9, 2014)

[7] Sandia National Laboratories, Vermont regional test center, (2014). https://rtc.sandia.gov/wpcontent/uploads/2014/08/7-VT-RTC_SAND2014-4204P.pdf (Accessed on Sep. 11, 2014)

[8] M. Boyd, Analytical model for solar irradiance near a planar vertical diffuse reflector - Formulation, validation, and simulations, Sol. Energy 91 79-92 (2013).

[9] I. Reda, D. Myers, and T. Stoffel, Uncertainty estimate for the outdoor calibration of solar pyranometers: a metrologist perspective, NCSLI Meas. 3 (4), 58-66 (2008).

[10] Omega Engineering, Temperature handbook and encyclopedia, (2010).

[11] ASTM, Standard Test Method for Calibration of Thermocouples By Comparison Techniques, ASTM International, (2007).

[12] IEC, Photovoltaic devices - Procedures for temperature and irradiance corrections to measured I-V characteristics, International Electrotechnical Commission (IEC), Geneva, Switzerland(2009).

[13] R.M. Smith, S. Kurtz, and B. Sekulic, Back-of-module temperature measurement methods, SolarPro 90-104 (2011).

[14] Campbell Scientific, CR1000 Measurement and Control System, (2013). https://s.campbellsci.com/documents/us/manuals/cr1000.pdf (Accessed Sep. 23, 2015)

[15] ASTM, Standard Specification for Industrial Platinum Resistance Thermometers, ASTM International, (2008).

[16] EPA, Meteorological Measurements, Quality Assurance Handbook for Air Pollution Measurement Systems, (2008).

[17] SketchUp Pro, Trimble Navigation Limited, Sunnyvale, California USA(2012). 
Appendix A. Oblique Images of the Arrays

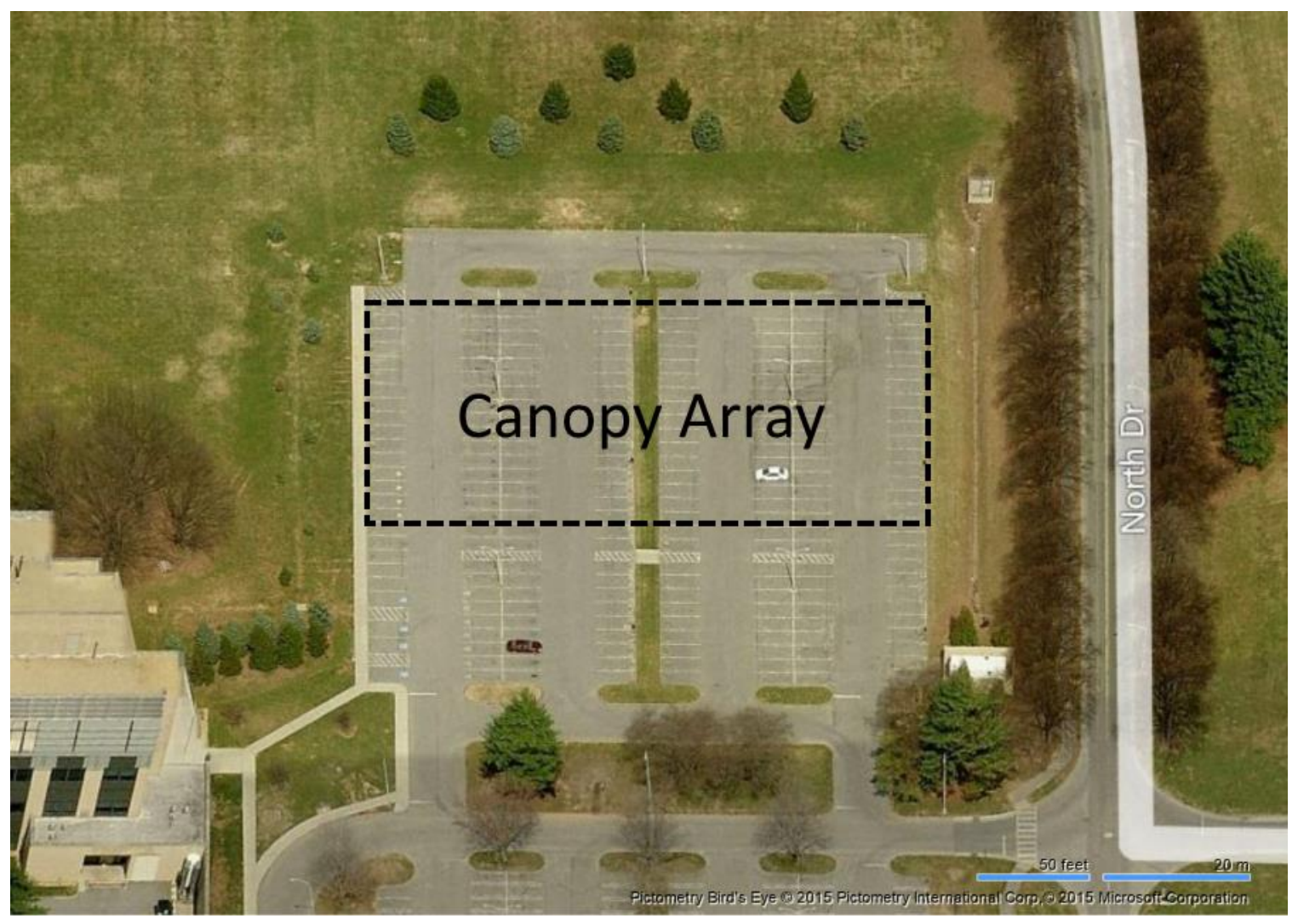

Figure A-1 Oblique Aerial View of the Canopy Array Site 
Appendix A. Oblique Images of the Arrays



Figure A-2 Oblique Aerial View of the Ground Array Site 
Appendix A. Oblique Images of the Arrays

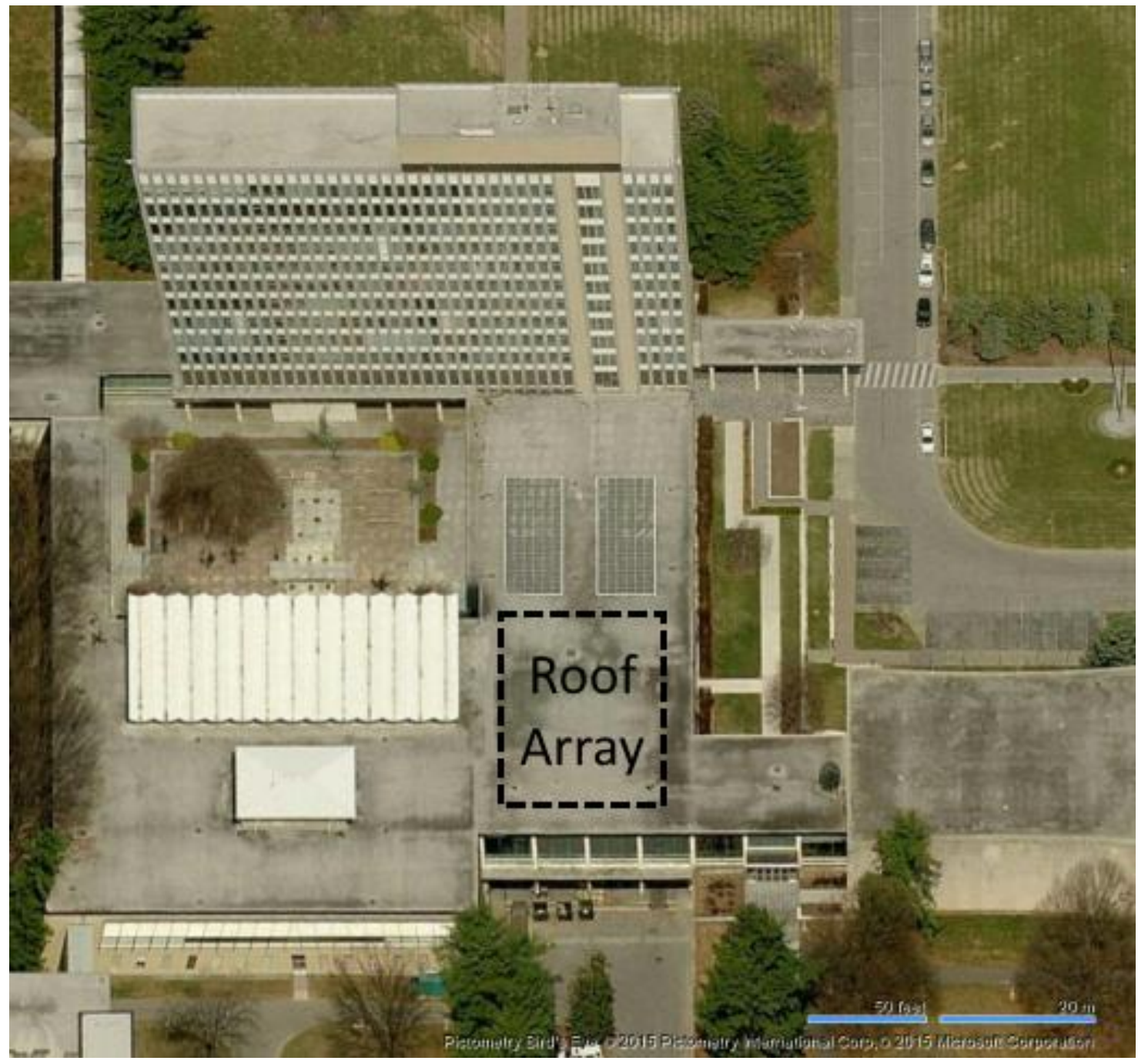

Figure A-3 Oblique Aerial View of the Roof Array site 
Appendix B. Manufacturer Data Sheets

\section{WATT}

NU-U235F2

NEC 2008 Compliant

Module output cables: 12 AWG PV Wire

\begin{tabular}{|c|c|c|}
\hline \multicolumn{3}{|c|}{ ELECTRICAL CHARACTERISTICS } \\
\hline \multicolumn{2}{|l|}{ Maximum Power (Pmax)* } & $235 \mathrm{~W}$ \\
\hline \multicolumn{2}{|l|}{ Tolerance of Pmax } & $+10 \% /-5 \%$ \\
\hline \multicolumn{2}{|l|}{ Type of Cell } & Monocrystalline silicon \\
\hline \multicolumn{2}{|l|}{ Cell Configuration } & 60 in series \\
\hline \multicolumn{2}{|l|}{ Open Circuit Voltage (Voc) } & $37.0 \mathrm{~V}$ \\
\hline \multicolumn{2}{|l|}{ Maximum Power Voltage (Vpm) } & $30.0 \mathrm{~V}$ \\
\hline \multicolumn{2}{|l|}{ Short Circuit Current (Isc) } & $8.60 \mathrm{~A}$ \\
\hline \multicolumn{2}{|l|}{ Maximum Power Current (Ipm) } & $7.84 \mathrm{~A}$ \\
\hline \multicolumn{2}{|l|}{ Module Efficiency (\%) } & $14.4 \%$ \\
\hline \multicolumn{2}{|l|}{ Maximum System (DC) Voltage } & $600 \mathrm{~V}$ \\
\hline \multicolumn{2}{|l|}{ Series Fuse Rating } & $15 \mathrm{~A}$ \\
\hline \multicolumn{2}{|l|}{ NOCT } & $47.5^{\circ} \mathrm{C}$ \\
\hline \multicolumn{2}{|l|}{ Temperature Coefficient (Pmax) } & $-0.485 \% /{ }^{\circ} \mathrm{C}$ \\
\hline \multicolumn{2}{|l|}{ Temperature Coefficient (Voc) } & $-0.351 \% /{ }^{\circ} \mathrm{C}$ \\
\hline \multicolumn{2}{|l|}{ Temperature Coefficient (Isc) } & $0.053 \% /{ }^{\circ} \mathrm{C}$ \\
\hline \multicolumn{3}{|c|}{$\begin{array}{l}\text { "Illumination of } 1 \mathrm{~kW} / \mathrm{m}^{2}(1 \mathrm{sun} \text { ) at spectral distribution of AM } 1.5 \text { (ASTM E892 } \\
\text { global spectral irradiance) at a cell temperature of } 25^{\circ} \mathrm{C} \text {. }\end{array}$} \\
\hline \multicolumn{3}{|c|}{ MECHANICAL CHARACTERISTICS } \\
\hline Dimensions ( $\mathrm{A} \times \mathrm{B} \times \mathrm{C}$ below) & \multicolumn{2}{|c|}{$39.1 " \times 64.6 " \times 1.8 " / 994 \times 1640 \times 46 \mathrm{~mm}$} \\
\hline Cable Length (G) & \multicolumn{2}{|c|}{$43.3^{\prime \prime} / 1100 \mathrm{~mm}$} \\
\hline Output Interconnect Cable** & \multicolumn{2}{|c|}{12 AWG with MC4 Locking Connector } \\
\hline Weight & \multicolumn{2}{|c|}{$41.9 \mathrm{lbs} / 19.0 \mathrm{~kg}$} \\
\hline Max Load & \multicolumn{2}{|c|}{50 psf (2400 Pascals) } \\
\hline Operating Temperature (cell) & \multicolumn{2}{|c|}{-40 to $194^{\circ} \mathrm{F} /-40$ to $90^{\circ} \mathrm{C}$} \\
\hline \multicolumn{3}{|c|}{$\begin{array}{l}\text { "*A safety lock clip (Multi Contact part number PV-SSH4) may be required in } \\
\text { readily accessible locations per NEC } 2008690.33 \text { (C) } \\
\text { "*PV Wire per UL Subject } 4703\end{array}$} \\
\hline \multicolumn{3}{|l|}{ QUALIFICATIONS } \\
\hline UL Listed & \multicolumn{2}{|c|}{ UL 1703} \\
\hline Fire Rating & \multicolumn{2}{|c|}{ Class C } \\
\hline
\end{tabular}

\section{WARRANTY}

25-year limited warranty on power output

Contact Sharp for complete warranty information

Design and specifications are subject to change without notice.

Sharp is a registered trademark of Sharp Corporation. All other trademarks are property of their respective owners. Contact Sharp to obtain the latest prod
any Sharp device. Cover photo: Solar Installation by SPG Solar.

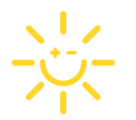

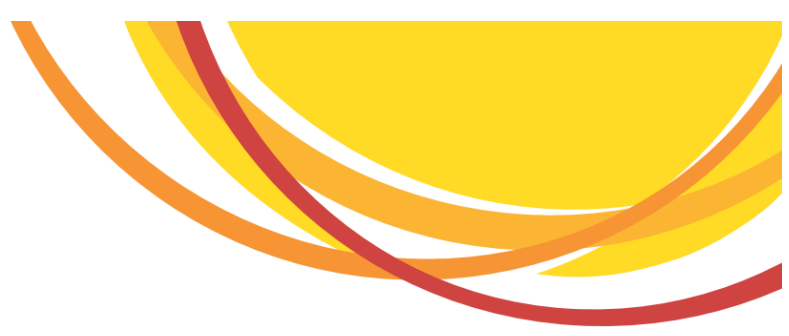

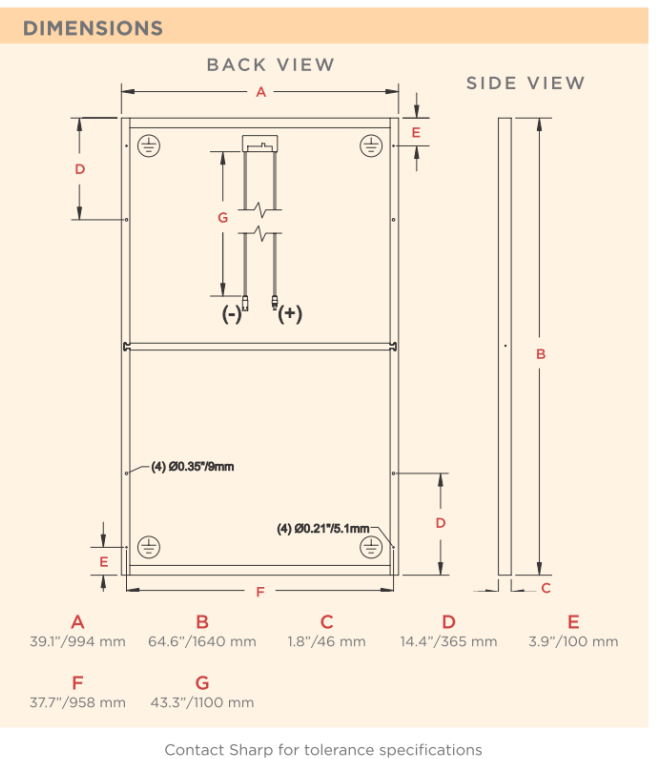

Contact Sharp for tolerance specifications

\section{"BUY AMERICAN"}

Sharp solar modules are manufactured in the United States and Japan, and qualify as "American" goods under the "Buy American" clause of the American Recovery and Reinvestment Act (ARRA).

\section{SHARP}

@ 2010 Sharp Electronics Corporation. All rights reserved.
SHARP ELECTRONICS CORPORATION

5901 Bolsa Avenue, Huntington Beach, CA 92647

1-800-SOLAR-06•Email: sharpsolar@sharpusa.com

www.sharpusa.com/solar

Figure B-1 Manufacturer Datasheet for the PV Module at All Three Arrays 


\section{Appendix B. Manufacturer Data Sheets}
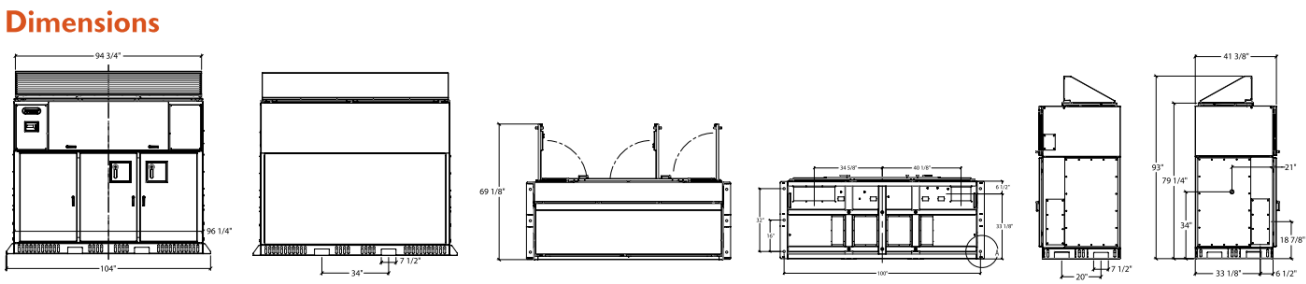

\section{Specifications}

\begin{tabular}{|c|c|c|}
\hline Model & PVP260kW & PVP260kW-LV \\
\hline \multicolumn{3}{|l|}{ Electrical Specifications } \\
\hline Continuous Output Power (kW) & $260 \mathrm{~kW}$ & $260 \mathrm{~kW}$ \\
\hline Weighted CEC Efficiency (\%) & 97.0\% & $96.5 \%$ \\
\hline Maximum DC Input Voltage (Voc) & 600 & 600 \\
\hline DC Peak Power Tracking Range (V) & $295-595$ & 265-595 \\
\hline DC Imp Nominal Current $(A)$ & 925 & 1030 \\
\hline ACNominal Voltage (V) & $480 \mathrm{Y}$ & $480 Y$ \\
\hline AC Operating Range (V) & $423-528$ & $423-528$ \\
\hline AC Frequency Range $(\mathrm{Hz})$ & $59.3-60.5$ & $59.3-60.5$ \\
\hline AC Maximum Continuous Current (A) & 316 & 316 \\
\hline Standby Losses (W) & 67 & 67 \\
\hline Harmonic Distortion (\%THD) & $<3 \%$ & $<3 \%$ \\
\hline Power Factor & $>.99$ & $>.99$ \\
\hline \multicolumn{3}{|l|}{ Mechanical Specifications } \\
\hline Enclosure & NEMA 4 & NEMA 4 \\
\hline Construction & $\begin{array}{l}\text { Powder Coated Steel } \\
\text { Optional Stainless Steel }\end{array}$ & $\begin{array}{l}\text { Powder Coated Steel } \\
\text { Optional Stainless Steel }\end{array}$ \\
\hline Mounting & Pad Mount & Pad Mount \\
\hline Weight(lbs) & 5.000 & 5.000 \\
\hline Cooling & Forced Convection & Forced Convection \\
\hline $\begin{array}{l}\text { Operating Ambient Temperature Range } \\
\left({ }^{\circ} \mathrm{C}\right)\end{array}$ & -30 to 50 & -30 to 50 \\
\hline $\begin{array}{l}\text { Standby/Storage Ambient Temperature } \\
\text { Range }\left({ }^{\circ} \mathrm{C}\right)\end{array}$ & -40 to 60 & -40 to 60 \\
\hline $\begin{array}{l}\text { Noise Emission } \\
\text { (typical at full load) }\end{array}$ & $<65 \mathrm{dBA} \odot 8 \mathrm{ft}$ & $<65 \mathrm{dBA} @ 8 \mathrm{ft}$ \\
\hline Agency Approvals & $\begin{array}{l}\text { UL 1741, IEEES19, IEEE929, IEEE1547, } \\
\text { CSA 107.1-1 } \\
\text { FCC Class A for conducted and radiated }\end{array}$ & \\
\hline
\end{tabular}

Options

- Integrated fused sub-array

combiner with options

from 4 to 20 fuses and 70

to 400 Amps

- Fused subcombiners with

monitoring: $8 \times 200 \mathrm{~A}, 16$

$\times 100 \mathrm{~A}$

- Integrated revenue grade

meter

- Integrated data

monitoring solutions

- $24 \mathrm{~V}$ auxiliary power

supply

- Stainless Steel Enclosure

- 20-year extended

warranty

Advanced power

Controls:

- Power factor

- Curtailment

- Controlled ramp rate

- Remote enable/disable

Performance Monitoring

Increase uptime and reduce maintenance costs with integrated performance monitoring hardware that enables

connectivity to a variety of software solutions from industry leading monitoring partners. The tight integration between

Advanced Energy and our monitoring partners creates a superior service and support experience while seamlessly

delivering meaningful data. Factory integration and testing of our $\mathrm{UL}$ listed monitoring solution ensures high reliability

and significantly reduces field installation costs.

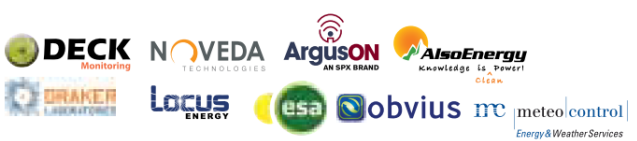

Figure B-2 Manufacturer Datasheet for the Inverter at the Canopy and Ground Arrays 


\section{PowerGate Plus 75 kW UL}

Streamlined Design

With all components encased in

a single, space-saving enclosure,

PowerGate Plus PV inverters are easy

to install, operate and maintain.

Rugged Construction

- Engineered for outdoor environments

-Wide thermal operating range: from

$-4^{\circ} \mathrm{F}$ to $+122^{\circ} \mathrm{F}\left(-20^{\circ} \mathrm{C}\right.$ to $\left.+50^{\circ} \mathrm{C}\right)$

without derating

- Solar shield attached to exterior of enclosure dissipate solar radiation,

reduce heat buildup

- Single cooling fan

- Single cabinet with small footprint

- Modular components make

service efficient

- Convenient access to all components

- Customizable large in-floor cable gland plates make installation of DC and $A C$ cables easy

- Integrated DC two-pole disconnect switch isolates the inverter, with the xetection and Interruption) circual, from the photovoltaic power system

allow inspection and maintenance

Proven Reliability

Rugged and reliable, PowerGate Plus

PV inverters are engineered from the

ground up to meet the demands of

large-scale installations.

Safety

- UBC seismic Zone 4 compliant

- Built-in DC and AC disconnect

switches

- Protective covers over exposed

power connections

Output Transforme

- Provides galvanic isolation

- Matches the output voltage of the PV inverter to the grid
Easy Maintenance

\begin{tabular}{|c|c|c|c|c|}
\hline \multicolumn{2}{|c|}{ PowerGate Plus 75 kW Specifications } & \multicolumn{3}{|c|}{ UL/CSA } \\
\hline \multicolumn{5}{|l|}{ Input Parameters } \\
\hline \multicolumn{2}{|l|}{ Input Voltage Range } & \multicolumn{3}{|c|}{$315-600$ VDC } \\
\hline \multicolumn{2}{|l|}{ Maximum Array Input Voltage } & \multicolumn{3}{|c|}{$600 \mathrm{VDC}$} \\
\hline \multicolumn{2}{|c|}{ Maximum Operating Input Current ${ }^{1}$} & \multicolumn{3}{|c|}{248 ADC } \\
\hline \multirow[t]{2}{*}{ PV Array Configuration } & $\begin{array}{l}\text { Negative } \\
\text { Ground }\end{array}$ & \multicolumn{3}{|c|}{$\bullet$} \\
\hline & $\begin{array}{l}\text { Positive } \\
\text { Ground }\end{array}$ & \multicolumn{3}{|c|}{$\bullet$} \\
\hline \multicolumn{5}{|l|}{ DC Input Combiner Options } \\
\hline Combiner Bus Bar Inputs & $\bullet$ & \multicolumn{3}{|c|}{6} \\
\hline Number of Inputs and Fuses & $\circ$ & \multicolumn{3}{|c|}{$\begin{array}{l}5 \times 100 A \\
6 \times 80 A\end{array}$} \\
\hline \multicolumn{5}{|l|}{ Transformer } \\
\hline Integrated Transformer ${ }^{2}$ & & \multicolumn{3}{|c|}{ Yes } \\
\hline \multicolumn{5}{|l|}{ Efficiency } \\
\hline \multicolumn{2}{|l|}{ Maximum $^{3}$} & $96.6 \%$ & $96.6 \%$ & $96.7 \%$ \\
\hline CEC & & \multicolumn{2}{|r|}{$96 \%$} & \\
\hline \multicolumn{5}{|l|}{ Output Parameters } \\
\hline \multicolumn{2}{|l|}{ Nominal Power } & \multicolumn{3}{|c|}{$75 \mathrm{~kW}$} \\
\hline \multicolumn{2}{|l|}{ Nominal Output Voltage } & 208 VAC & 240 VAC & $480 \mathrm{VAC}$ \\
\hline \multicolumn{2}{|c|}{ Output Voltage Range, [-12\%/10\%] } & 183-229 VAC & 211-264 VAC & 422-526 VAC \\
\hline \multicolumn{2}{|l|}{ Maximum Output Current/Phase } & $208 \mathrm{~A}$ & $181 \mathrm{~A}$ & $91 \mathrm{~A}$ \\
\hline \multicolumn{2}{|c|}{$\begin{array}{l}\text { Standby Consumptions (tare losses } \\
\text { including control power and aux.) }\end{array}$} & $65 \mathrm{~W}$ & $72 \mathrm{~W}$ & $70 \mathrm{~W}$ \\
\hline \multicolumn{2}{|c|}{ Nominal Output Frequency, 3-Phase } & \multicolumn{3}{|c|}{$60 \mathrm{~Hz}$} \\
\hline \multicolumn{2}{|l|}{ Maximum Harmonic Distortion } & \multicolumn{3}{|c|}{$<3 \% \mathrm{THD}$} \\
\hline Power Factor, Full Load & & & $>99 \%$ & \\
\hline Dynamic Power Factor Contro & & & $+/-0.8$ & \\
\hline Power Curtailment & & & $0-100 \%, 1 \%$ steps & \\
\hline Environment & & & & \\
\hline $\begin{array}{l}\text { Operating Temperature Range } \\
\text { (Nominal Power) }\end{array}$ & & $-4^{\circ} \mathrm{F}$ & $\begin{array}{l}+122^{\circ} \mathrm{F}\left(-20^{\circ} \mathrm{C} \text { to }\right. \\
\text { pt. }-40^{\circ} \mathrm{C} \text { to }+50^{\circ} \\
\end{array}$ & $\left.50^{\circ} \mathrm{C}\right)$ \\
\hline Storage Temperature Range & & $-22^{\circ} \mathrm{F}$ & $+158^{\circ} \mathrm{F}\left(-30^{\circ} \mathrm{Ctc}\right.$ & $\left.70^{\circ} \mathrm{C}\right)$ \\
\hline Cooling & & & Forced Air & \\
\hline Noise Level (Distance of $3 \mathrm{~m}$ ) & & & $<65 \mathrm{~dB}(\mathrm{~A})$ & \\
\hline Relative Humidity (Non-Conde & sing) & & up to $90 \%$ & \\
\hline
\end{tabular}

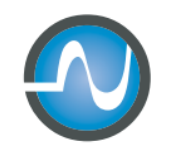

Satcon

Utility-Ready Solar Inverters

Figure B-3 Manufacturer Datasheet for the Inverter at the Roof Array 


\section{Appendix C. Copper Wire Gauges and Lengths}

Table C-1 Copper Wire Gauges and Lengths

\begin{tabular}{lccc}
\hline & Canopy & Ground & Roof \\
\hline Modules & & & \\
Lead Cross-Sectional Area $\left[\mathrm{mm}^{2}\right]$ & 3.31 & 3.31 & 3.31 \\
Individual Lead Length $[\mathrm{m}]$ & 1.1 & 1.1 & 1.1 \\
& & & \\
Modules to Combiner Box & & & \\
Conductor Cross-Sectional Area $\left[\mathrm{mm}^{2}\right]$ & 5.26 & 5.26 & 5.26 \\
Approximate Average Distance, One-Way $[\mathrm{m}]$ & 85 & 95 & 52
\end{tabular}

\section{Combiner Box to Inverter DC Combiner \\ Compartment}

$\begin{array}{lccc}\text { Conductor Cross-Sectional Area }\left[\mathrm{mm}^{2}\right] & 142 * & 127 & 53.5 \\ \text { Approximate Average Distance, One-Way [m] } & 60 & 79 & 167\end{array}$

\section{Inverter DC Combiner Compartment to \\ Inverter Power Module Assembly \\ Compartment}

Conductor Cross-Sectional Area $\left[\mathrm{mm}^{2}\right]$

$613 \quad 613 \quad 242$

Approximate Average Distance, One-Way [m]

$4 \quad 4$

\begin{tabular}{|lccc|}
\hline Inverter to Building Switchgear & & & \\
\hline Conductor Cross-Sectional Area $\left[\mathrm{mm}^{2}\right]$ & 253 & 253 & 42.4 \\
\hline Number of Wires per Phase & 1 & 2 & 1 \\
\hline Total Conductor Cross-Sectional Area $\left[\mathrm{mm}^{2}\right]$ & 253 & 507 & 42.4 \\
\hline Approximate Average Distance, One-Way [m] & 172 & 79 & 14 \\
\hline
\end{tabular}

* Weighted average of $127 \mathrm{~mm}^{2}$ and $177 \mathrm{~mm}^{2}$ conductors 
Appendix D. Diagrams of the Arrays

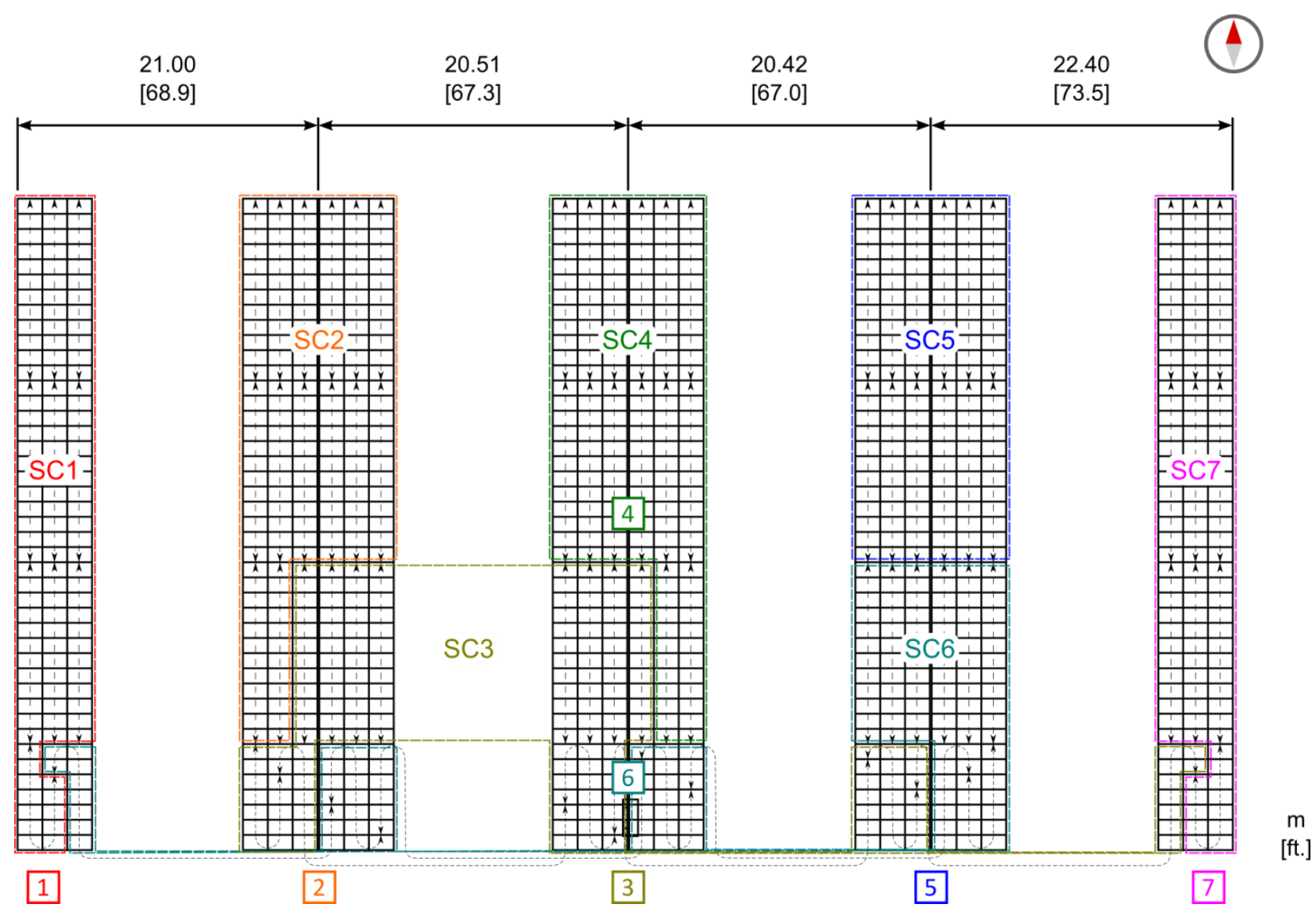

Figure D-1 Diagram of the Canopy Array Strings and Pertinent Array Dimensions 


\section{Appendix D. Diagrams of the Arrays}

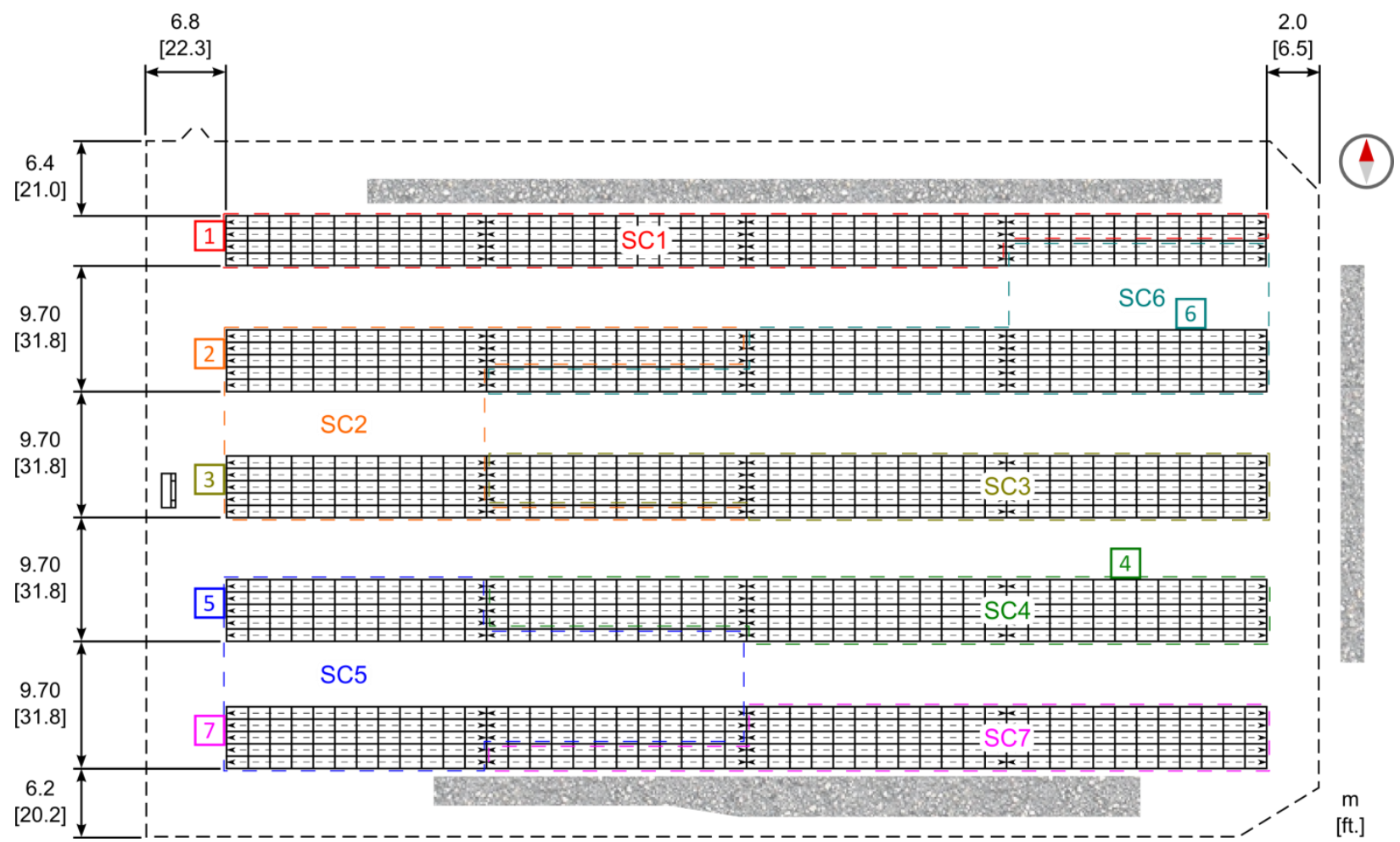

Figure D-2 Diagram of the Ground Array Strings and Pertinent Array and Fence Dimensions 
Appendix D. Diagrams of the Arrays

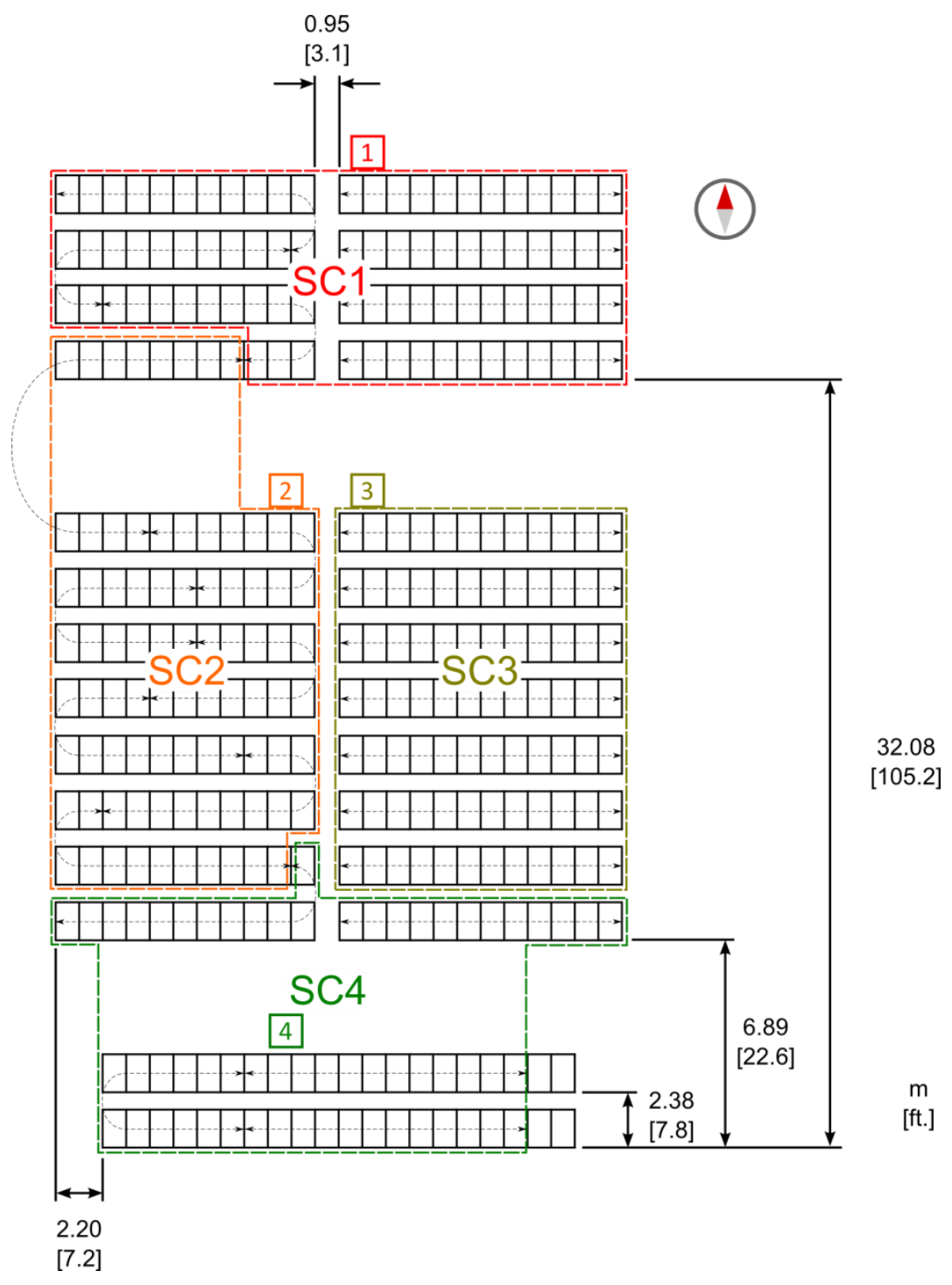

Figure D-3 Diagram of the Roof Array Strings and Pertinent Array Dimensions 


\section{Appendix E. The Saved Data Values From Each Array}

Table E-1 The Saved Data Values From Each Array

\begin{tabular}{|c|c|c|c|c|}
\hline Variable Name & Units & Description & $\begin{array}{l}\text { One-Minute } \\
\text { Average/ } \\
\text { Min/Max }\end{array}$ & $\begin{array}{l}\text { Canopy }(\mathbf{C}) / \\
\text { Ground (G)/ } \\
\operatorname{Roof}(\mathbf{R})\end{array}$ \\
\hline AmbTemp_C & $\mathrm{C}$ & Outdoor ambient temperature & Average & $\mathrm{C} / \mathrm{G} / \mathrm{R}$ \\
\hline Battery_A & A & Current to DAS battery, neg. = discharging & Average & $\mathrm{C} / \mathrm{G} / \mathrm{R}$ \\
\hline Battery_V & $\mathrm{V}$ & Charge voltage of DAS battery & Min & $\mathrm{C} / \mathrm{G} / \mathrm{R}$ \\
\hline ChgSource & - & $\begin{array}{l}\text { Charging regulator power source } \\
0=\text { none } \\
1=\text { solar terminals } \\
2=\text { continuous terminals }\end{array}$ & Min & $\mathrm{C} / \mathrm{G} / \mathrm{R}$ \\
\hline ChgState & - & $\begin{array}{l}\text { State of charging regulator; } \\
-1=\text { regulator fault } \\
0=\text { no charge } \\
1=\text { current limited charging } \\
2=\text { cycle charging } \\
3=\text { float charging } \\
4=\text { battery test }\end{array}$ & Min & $\mathrm{C} / \mathrm{G} / \mathrm{R}$ \\
\hline CkBatt & - & $\begin{array}{l}\text { Status of DAS battery; } \\
0=\text { normal } \\
1=\text { check battery }\end{array}$ & Max & $\mathrm{C} / \mathrm{G} / \mathrm{R}$ \\
\hline CR1000Temp_C & $\mathrm{C}$ & $\begin{array}{l}\text { Temperature of the data logger front } \\
\text { terminal panel }\end{array}$ & Average & $\mathrm{C} / \mathrm{G} / \mathrm{R}$ \\
\hline DoorOpen & - & $\begin{array}{l}\text { Door sensor for DAS enclosure; } \\
-1=\text { open, } 0=\text { closed }\end{array}$ & Min & $\mathrm{C} / \mathrm{G} / \mathrm{R}$ \\
\hline DPCBFaults & - & $\begin{array}{l}\text { Inverter digital power control board fault } \\
\text { code }\end{array}$ & $\operatorname{Max}$ & $\mathrm{R}$ \\
\hline GeneralFaults1 & - & Inverter general fault code, group 1 & Max & $\mathrm{R}$ \\
\hline GeneralFaults2 & - & Inverter general fault code, group 2 & Max & $\mathrm{R}$ \\
\hline HardwareFaults & - & Inverter hardware fault code & Max & $\mathrm{R}$ \\
\hline InvDriveFault & - & Inverter drive fault code & Max & $\mathrm{C} / \mathrm{G}$ \\
\hline InverterFaults & - & Inverter inverter fault code & Max & $\mathrm{R}$ \\
\hline InvEtoday_kWh & $\mathrm{kWh}$ & $\begin{array}{l}\text { AC total real energy from current day, } \\
\text { meas. by inverter }\end{array}$ & Max & $\mathrm{R}$ \\
\hline InvEtot_kWh & $\mathrm{kWh}$ & $\begin{array}{l}\text { AC total accumulated real energy, meas. by } \\
\text { inverter }\end{array}$ & Max & $\mathrm{C} / \mathrm{G} / \mathrm{R}$ \\
\hline InvEtot_kWh & $\mathrm{kWh}$ & $\begin{array}{l}\text { AC total accumulated real energy, meas. by } \\
\text { inverter }\end{array}$ & Max & $\mathrm{R}$ \\
\hline InvEyesterday_kWh & $\mathrm{kWh}$ & $\begin{array}{l}\text { AC total real energy from previous day, } \\
\text { meas. by inverter }\end{array}$ & Max & $\mathrm{R}$ \\
\hline InvFreq & $\mathrm{Hz}$ & $\mathrm{AC}$ frequency, meas. by inverter & Average & $\mathrm{C} / \mathrm{G} / \mathrm{R}$ \\
\hline InvGndImped_kOhm & $\mathrm{k} \Omega$ & Inverter ground impedance & Average & $\mathrm{R}$ \\
\hline
\end{tabular}




\begin{tabular}{|c|c|c|c|c|}
\hline InvGridFault & - & Inverter grid fault code & Max & $\mathrm{C} / \mathrm{G}$ \\
\hline InvIa & A & Line current, phase A, meas. by inverter & Average & $\mathrm{C} / \mathrm{G} / \mathrm{R}$ \\
\hline InvIabcAvg & A & Average AC line current, meas. by inverter & Average & $\mathrm{R}$ \\
\hline InvIb & A & Line current, phase B, meas. by inverter & Average & $\mathrm{C} / \mathrm{G} / \mathrm{R}$ \\
\hline InvIc & $\mathrm{A}$ & Line current, phase $\mathrm{C}$, meas. by inverter & Average & $\mathrm{C} / \mathrm{G} / \mathrm{R}$ \\
\hline InvIDCin & A & Inverter DC input current, meas. by inverter & Average & $\mathrm{C} / \mathrm{G} / \mathrm{R}$ \\
\hline InvIGnd & A & Inverter DC ground current & Average & $\mathrm{R}$ \\
\hline InvINeutral & A & AC neutral current, meas. by inverter & Average & $\mathrm{R}$ \\
\hline InvIUnbal & $\%$ & $\begin{array}{l}\text { AC line current unbalance, meas. by } \\
\text { inverter }\end{array}$ & Average & $\mathrm{R}$ \\
\hline InvMainFault & - & Inverter main fault code & Max & $\mathrm{C} / \mathrm{G}$ \\
\hline InvOpState & - & Inverter operating status/state & Average & $\mathrm{R}$ \\
\hline InvOpStatus & - & Inverter operating status/state & Average & $\mathrm{C} / \mathrm{G}$ \\
\hline InvPAC_kW & $\mathrm{kW}$ & AC real power, meas. by inverter & Average & $\mathrm{C} / \mathrm{G} / \mathrm{R}$ \\
\hline InvPDC_kW & $\mathrm{kW}$ & Inverter DC input power, meas. by inverter & Average & $\mathrm{C} / \mathrm{G} / \mathrm{R}$ \\
\hline InvPF & - & AC power factor, meas. by inverter & Average & $\mathrm{R}$ \\
\hline InvPVMStatus & - & Inverter PV monitoring status code & $\operatorname{Max}$ & $\mathrm{C} / \mathrm{G}$ \\
\hline InvSystemFault & - & Inverter system fault code & Max & $\mathrm{C} / \mathrm{G}$ \\
\hline InvSystemWarn & - & Inverter system warning code & $\operatorname{Max}$ & $\mathrm{C} / \mathrm{G}$ \\
\hline InvTempFault & - & Inverter temperature fault code & Max & $\mathrm{C} / \mathrm{G}$ \\
\hline InvTempHeatsink_C & $\mathrm{C}$ & Inverter heatsink temperature & Average & $\mathrm{R}$ \\
\hline InvTempInternalAir_C & $\mathrm{C}$ & $\begin{array}{l}\text { Ambient temperature inside inverter general } \\
\text { enclosure }\end{array}$ & Average & $\mathrm{R}$ \\
\hline InvTempInverterAir_C & $\mathrm{C}$ & $\begin{array}{l}\text { Ambient temperature inside inverter } \\
\text { inverter enclosure }\end{array}$ & Average & $\mathrm{R}$ \\
\hline InvVa & $\mathrm{V}$ & Line voltage, phase A, meas. by inverter & Average & $\mathrm{C} / \mathrm{G} / \mathrm{R}$ \\
\hline InvVA_kVA & $\mathrm{kVA}$ & $\mathrm{AC}$ apparent power, meas. by inverter & Average & $\mathrm{R}$ \\
\hline InvVabcAvg & V & Average AC line voltage, meas. by inverter & Average & $\mathrm{R}$ \\
\hline InvVAR_kVAR & kVAR & $\mathrm{AC}$ reactive power, meas. by inverter & Average & $\mathrm{R}$ \\
\hline $\mathrm{InvVb}$ & $\mathrm{V}$ & Line voltage, phase $\mathrm{B}$, meas. by inverter & Average & $\mathrm{C} / \mathrm{G} / \mathrm{R}$ \\
\hline $\mathrm{InvVc}$ & $\mathrm{V}$ & Line voltage, phase $\mathrm{C}$, meas. by inverter & Average & $\mathrm{C} / \mathrm{G} / \mathrm{R}$ \\
\hline InvVDCin & $\mathrm{V}$ & $\begin{array}{l}\text { Inverter DC input voltage on load side of } \\
\text { DC contactor, meas. by inverter }\end{array}$ & Average & $\mathrm{C} / \mathrm{G} / \mathrm{R}$ \\
\hline InvVDVoltage_V & $\mathrm{V}$ & $\begin{array}{l}\text { Array DC voltage on DC busbars, measured } \\
\text { using voltage divider }\end{array}$ & Average & $\mathrm{C} / \mathrm{G} / \mathrm{R}$ \\
\hline InvVoltageFault & - & Inverter voltage fault code & Max & $\mathrm{C} / \mathrm{G}$ \\
\hline InvVPVin & $\mathrm{V}$ & $\begin{array}{l}\text { Array DC voltage on line }(\mathrm{PV}) \text { side of DC } \\
\text { contactor, meas. by inverter }\end{array}$ & Average & $\mathrm{C} / \mathrm{G} / \mathrm{R}$ \\
\hline
\end{tabular}




\begin{tabular}{|c|c|c|c|c|}
\hline InvVUnbal & $\%$ & $\begin{array}{l}\text { AC line voltage unbalance, meas. by } \\
\text { inverter }\end{array}$ & Average & $\mathrm{R}$ \\
\hline Load_A & A & $\begin{array}{l}\text { Current supplied to load (DAS) from } \\
\text { charging regulator }\end{array}$ & Average & $\mathrm{C} / \mathrm{G} / \mathrm{R}$ \\
\hline NumActiveFaults & - & Inverter number of active faults & Max & $\mathrm{R}$ \\
\hline PwrMtrEdel_kVARh & $\mathrm{kVARh}$ & $\begin{array}{l}\text { AC total accumulated reactive energy to } \\
\text { (used by) inverter, meas. by AC meter }\end{array}$ & Max & $\mathrm{C} / \mathrm{G} / \mathrm{R}$ \\
\hline PwrMtrEdel_kWh & $\mathrm{kWh}$ & $\begin{array}{l}\text { AC total accumulated real energy to (used } \\
\text { by) inverter, meas. by AC meter }\end{array}$ & $\operatorname{Max}$ & $\mathrm{C} / \mathrm{G} / \mathrm{R}$ \\
\hline PwrMtrErec_kVARh & $\mathrm{kVARh}$ & $\begin{array}{l}\text { AC total accumulated reactive energy from } \\
\text { (generated by) inverter, meas. by AC meter }\end{array}$ & Max & $\mathrm{C} / \mathrm{G} / \mathrm{R}$ \\
\hline PwrMtrErec_kWh & $\mathrm{kWh}$ & $\begin{array}{l}\text { AC total accumulated real energy from } \\
\text { (generated by) inverter, meas. by AC meter }\end{array}$ & Max & $\mathrm{C} / \mathrm{G} / \mathrm{R}$ \\
\hline PwrMtrFreq & $\mathrm{Hz}$ & $\mathrm{AC}$ frequency, meas. by $\mathrm{AC}$ meter & Average & $\mathrm{C} / \mathrm{G} / \mathrm{R}$ \\
\hline PwrMtrFreqMax & $\mathrm{Hz}$ & Max. AC frequency, meas. by $\mathrm{AC}$ meter & $\operatorname{Max}$ & $\mathrm{C} / \mathrm{G} / \mathrm{R}$ \\
\hline PwrMtrFreqMin & $\mathrm{Hz}$ & Min. AC frequency, meas. by $\mathrm{AC}$ meter & Min & $\mathrm{C} / \mathrm{G} / \mathrm{R}$ \\
\hline PwrMtrIa & A & Line current, phase A, meas. by AC meter & Average & $\mathrm{C} / \mathrm{G} / \mathrm{R}$ \\
\hline PwrMtrIb & A & Line current, phase $\mathrm{B}$, meas. by $\mathrm{AC}$ meter & Average & $\mathrm{C} / \mathrm{G} / \mathrm{R}$ \\
\hline PwrMtrIc & A & Line current, phase $\mathrm{C}$, meas. by $\mathrm{AC}$ meter & Average & $\mathrm{C} / \mathrm{G} / \mathrm{R}$ \\
\hline PwrMtrP_kVA & $\mathrm{kVA}$ & $\mathrm{AC}$ apparent power, meas. by $\mathrm{AC}$ meter & Average & $\mathrm{C} / \mathrm{G} / \mathrm{R}$ \\
\hline PwrMtrP_kVAR & kVAR & $\mathrm{AC}$ reactive power, meas. by $\mathrm{AC}$ meter & Average & $\mathrm{C} / \mathrm{G} / \mathrm{R}$ \\
\hline PwrMtrP_kW & $\mathrm{kW}$ & $\mathrm{AC}$ real power, meas. by $\mathrm{AC}$ meter & Average & $\mathrm{C} / \mathrm{G} / \mathrm{R}$ \\
\hline PwrMtrPF & - & $\mathrm{AC}$ power factor, meas. by $\mathrm{AC}$ meter & Average & $\mathrm{C} / \mathrm{G} / \mathrm{R}$ \\
\hline PwrMtrPhaseRev & $\mathrm{Hz}$ & AC phase reversal, meas. by AC meter & Average & $\mathrm{C} / \mathrm{G} / \mathrm{R}$ \\
\hline PwrMtrVa & $\mathrm{V}$ & Line voltage, phase $\mathrm{A}$, meas. by $\mathrm{AC}$ meter & Average & $\mathrm{C} / \mathrm{G} / \mathrm{R}$ \\
\hline PwrMtrVaTHDMax & $\%$ & $\begin{array}{l}\text { AC max. total harmonic distortion in phase } \\
\text { A, meas. by AC meter }\end{array}$ & Max & $\mathrm{C} / \mathrm{G} / \mathrm{R}$ \\
\hline PwrMtrVb & $\mathrm{V}$ & Line voltage, phase $\mathrm{B}$, meas. by $\mathrm{AC}$ meter & Average & $\mathrm{C} / \mathrm{G} / \mathrm{R}$ \\
\hline PwrMtrVbTHDMax & $\%$ & $\begin{array}{l}\text { AC max. total harmonic distortion in phase } \\
\mathrm{B} \text {, meas. by AC meter }\end{array}$ & Max & $\mathrm{C} / \mathrm{G} / \mathrm{R}$ \\
\hline PwrMtrVc & $\mathrm{V}$ & Line voltage, phase $\mathrm{C}$, meas. by $\mathrm{AC}$ meter & Average & $\mathrm{C} / \mathrm{G} / \mathrm{R}$ \\
\hline PwrMtrVcTHDMax & $\%$ & $\begin{array}{l}\text { AC max. total harmonic distortion in phase } \\
\mathrm{C} \text {, meas. by AC meter }\end{array}$ & Max & $\mathrm{C} / \mathrm{G} / \mathrm{R}$ \\
\hline Pyra1_mV & $\mathrm{mV}$ & $\begin{array}{l}\text { Millivolt output from pyranometer; } \\
\text { Canopy: POA, west-tilted } \\
\text { Ground: GHI } \\
\text { Roof: GHI, southwest }\end{array}$ & Average & $\mathrm{C} / \mathrm{G} / \mathrm{R}$ \\
\hline Pyra2_mV & $\mathrm{mV}$ & $\begin{array}{l}\text { Millivolt output from pyranometer; } \\
\text { Canopy: GHI } \\
\text { Ground: POA } \\
\text { Roof: GHI, southeast }\end{array}$ & Average & $\mathrm{C} / \mathrm{G} / \mathrm{R}$ \\
\hline
\end{tabular}




\begin{tabular}{|c|c|c|c|c|}
\hline Pyra3_mV & $\mathrm{mV}$ & $\begin{array}{l}\text { Millivolt output from pyranometer; } \\
\text { Canopy: POA, east-tilted } \\
\text { Roof: } \quad \text { POA, southeast }\end{array}$ & Average & $\mathrm{C} / \mathrm{R}$ \\
\hline Pyra4_mV & $\mathrm{mV}$ & $\begin{array}{l}\text { Millivolt output from pyranometer; } \\
\text { Roof: } \quad \text { GHI, northwest }\end{array}$ & Average & $\mathrm{R}$ \\
\hline Pyra5_mV & $\mathrm{mV}$ & $\begin{array}{l}\text { Millivolt output from pyranometer; } \\
\text { Roof: GHI, northeast }\end{array}$ & Average & $\mathrm{R}$ \\
\hline Pyra6_mV & $\mathrm{mV}$ & $\begin{array}{l}\text { Millivolt output from pyranometer; } \\
\text { Roof: } \quad \text { GHI, center of older horiz. array }\end{array}$ & Average & $\mathrm{R}$ \\
\hline Pyra7_mV & $\mathrm{mV}$ & $\begin{array}{l}\text { Millivolt output from pyranometer; } \\
\text { Roof: } \quad \text { GHI, northwest of older horiz. } \\
\text { array }\end{array}$ & Average & $\mathrm{R}$ \\
\hline Pyra8_mV & $\mathrm{mV}$ & $\begin{array}{l}\text { Millivolt output from pyranometer; } \\
\text { Roof: } \quad \text { GHI, northeast of older horiz. } \\
\quad \text { array }\end{array}$ & Average & $\mathrm{R}$ \\
\hline Qloss_Ah & $A \cdot h$ & Charge deficit of DAS battery & Max & $\mathrm{C} / \mathrm{G} / \mathrm{R}$ \\
\hline RefCell1_Wm2 & $\mathrm{W} / \mathrm{m}^{2}$ & $\begin{array}{l}\text { Irradiance from flat-plate silicon sensor; } \\
\text { Canopy: POA, west-tilted } \\
\text { Ground: POA } \\
\text { Roof: } \quad \text { POA, southeast }\end{array}$ & Average & $\mathrm{C} / \mathrm{G} / \mathrm{R}$ \\
\hline RefCell2_Wm2 & $\mathrm{W} / \mathrm{m}^{2}$ & $\begin{array}{l}\text { Irradiance from flat-plate silicon sensor; } \\
\text { Canopy: POA, east-tilted } \\
\text { Roof: } \quad \text { GHI, center of older horiz. array, } \\
\quad \text { east, cleaned }\end{array}$ & Average & $\mathrm{C} / \mathrm{R}$ \\
\hline RefCell3_Wm2 & $\mathrm{W} / \mathrm{m}^{2}$ & $\begin{array}{l}\text { Irradiance from flat-plate silicon sensor; } \\
\text { Roof: } \quad \text { GHI, center of older horiz. array, } \\
\text { west, uncleaned }\end{array}$ & Average & $\mathrm{R}$ \\
\hline RTD_C(1) & $\mathrm{C}$ & $\begin{array}{l}\text { Temperature of module backsheet; } \\
\text { Canopy: east-tilted southwest module } \\
\text { Ground: } \\
\text { Roof: } \\
\begin{array}{l}\text { south sub-array, south-center } \\
\text { module }\end{array}\end{array}$ & Average & $\mathrm{C} / \mathrm{G} / \mathrm{R}$ \\
\hline RTD_C(10) & $\mathrm{C}$ & Ambient temperature inside inverter & Average & $\mathrm{C} / \mathrm{G} /$ \\
\hline RTD_C(2) & $\mathrm{C}$ & $\begin{array}{l}\text { Temperature of module backsheet; } \\
\text { Canopy: east-tilted southeast module } \\
\text { Ground: center shed, center module of } \\
\text { west half } \\
\text { Roof: } \quad \begin{array}{l}\text { center-east sub array, center-east } \\
\text { module }\end{array}\end{array}$ & Average & $\mathrm{C} / \mathrm{G} / \mathrm{R}$ \\
\hline RTD_C(3) & $\mathrm{C}$ & $\begin{array}{l}\text { Temperature of module backsheet; } \\
\text { Canopy: west-tilted center-east module } \\
\text { Ground: center shed, center-bottom } \\
\text { module } \\
\text { Roof: } \quad \begin{array}{l}\text { center-east sub array, center } \\
\text { module, center }\end{array}\end{array}$ & Average & $\mathrm{C} / \mathrm{G} / \mathrm{R}$ \\
\hline
\end{tabular}




\begin{tabular}{|c|c|c|c|c|}
\hline RTD_C(4) & $\mathrm{C}$ & $\begin{array}{l}\text { Temperature of module backsheet; } \\
\text { Canopy: east-tilted center-west module, } \\
\text { center } \\
\text { Ground: center shed, center module, center } \\
\text { Roof: } \quad \begin{array}{l}\text { center-east sub array, center } \\
\text { module, northwest }\end{array}\end{array}$ & Average & $\mathrm{C} / \mathrm{G} / \mathrm{R}$ \\
\hline RTD_C(5) & $\mathrm{C}$ & $\begin{array}{l}\text { Temperature of module backsheet; } \\
\text { Canopy: east-tilted center-west module, } \\
\text { southwest } \\
\text { Ground: } \begin{array}{l}\text { center shed, center module, } \\
\text { southwest }\end{array} \\
\text { Roof: } \quad \begin{array}{l}\text { center-east sub array, center } \\
\text { module, south-center }\end{array}\end{array}$ & Average & $\mathrm{C} / \mathrm{G} / \mathrm{R}$ \\
\hline RTD_C(6) & $\mathrm{C}$ & $\begin{array}{l}\text { Temperature of module backsheet; } \\
\text { Canopy: east-tilted center-west module, } \\
\text { center-east } \\
\text { Ground: } \begin{array}{l}\text { center shed, center module, } \\
\text { center-east }\end{array} \\
\text { Roof: } \begin{array}{l}\text { center-east sub array, center } \\
\text { module, center-east }\end{array}\end{array}$ & Average & $\mathrm{C} / \mathrm{G} / \mathrm{R}$ \\
\hline RTD_C(7) & $\mathrm{C}$ & $\begin{array}{l}\text { Temperature of module backsheet; } \\
\text { Canopy: east-tilted center-west module, } \\
\text { north-center } \\
\text { Ground: } \\
\text { center shed, center module, north- } \\
\text { center }\end{array}$ & Average & $\mathrm{C} / \mathrm{G} / \mathrm{R}$ \\
\hline RTD_C(8) & $\mathrm{C}$ & $\begin{array}{l}\text { Temperature of module backsheet; } \\
\text { Canopy: east-tilted center-east module } \\
\text { Ground: center shed, center-top module }\end{array}$ & Average & $\mathrm{C} / \mathrm{G} /$ \\
\hline RTD_C(9) & $\mathrm{C}$ & $\begin{array}{l}\text { Temperature of module backsheet; } \\
\text { Canopy: east-tilted northwest module } \\
\text { Ground: north shed, center module }\end{array}$ & Average & $\mathrm{C} / \mathrm{G} /$ \\
\hline SEWSAmbientTemp_C & $\mathrm{C}$ & $\begin{array}{l}\text { Outdoor ambient temperature from } \\
\text { integrator's sensor }\end{array}$ & Average & $\mathrm{C} / \mathrm{G} / \mathrm{R}$ \\
\hline SEWSModuleTemp_C & $\mathrm{C}$ & $\begin{array}{l}\text { Module temperature from integrator's } \\
\text { sensor }\end{array}$ & Average & $\mathrm{C} / \mathrm{G} / \mathrm{R}$ \\
\hline SEWSPOAIrrad_Wm2 & $\mathrm{W} / \mathrm{m}^{2}$ & $\begin{array}{l}\text { POA irradiance from integrator's domed } \\
\text { diffused silicon-cell pyranometer }\end{array}$ & Average & $\mathrm{C} / \mathrm{G} / \mathrm{R}$ \\
\hline ShuntCurrent_A(1) & A & Output circuit current from combiner box 1 & Average & $\mathrm{C} / \mathrm{G} / \mathrm{R}$ \\
\hline ShuntCurrent_A(2) & A & Output circuit current from combiner box 2 & Average & $\mathrm{C} / \mathrm{G} / \mathrm{R}$ \\
\hline ShuntCurrent_A(3) & A & Output circuit current from combiner box 3 & Average & $\mathrm{C} / \mathrm{G} / \mathrm{R}$ \\
\hline ShuntCurrent_A(4) & A & Output circuit current from combiner box 4 & Average & $\mathrm{C} / \mathrm{G} / \mathrm{R}$ \\
\hline ShuntCurrent_A(5) & A & Output circuit current from combiner box 5 & Average & $\mathrm{C} / \mathrm{G}$ \\
\hline ShuntCurrent_A(6) & A & Output circuit current from combiner box 6 & Average & $\mathrm{C} / \mathrm{G}$ \\
\hline ShuntCurrent_A(7) & A & Output circuit current from combiner box 7 & Average & $\mathrm{C} / \mathrm{G}$ \\
\hline
\end{tabular}




\begin{tabular}{|c|c|c|c|c|}
\hline ShuntEtot_kWh_Avg(1) & $\mathrm{kWh}$ & $\begin{array}{l}\text { Output circuit total accumulated energy } \\
\text { from combiner box } 1 \text {, meas. using shunts } \\
\text { and voltage divider* }\end{array}$ & - & $\mathrm{C} / \mathrm{G} / \mathrm{R}$ \\
\hline ShuntEtot_kWh_Avg(2) & $\mathrm{kWh}$ & $\begin{array}{l}\text { Output circuit total accumulated energy } \\
\text { from combiner box } 2 \text {, meas. using shunts } \\
\text { and voltage divider* }\end{array}$ & - & $\mathrm{C} / \mathrm{G} / \mathrm{R}$ \\
\hline ShuntEtot_kWh_Avg(3) & $\mathrm{kWh}$ & $\begin{array}{l}\text { Output circuit total accumulated energy } \\
\text { from combiner box } 3 \text {, meas. using shunts } \\
\text { and voltage divider* }\end{array}$ & - & $\mathrm{C} / \mathrm{G} / \mathrm{R}$ \\
\hline ShuntEtot_kWh_Avg(4) & $\mathrm{kWh}$ & $\begin{array}{l}\text { Output circuit total accumulated energy } \\
\text { from combiner box } 4 \text {, meas. using shunts } \\
\text { and voltage divider* }\end{array}$ & - & $\mathrm{C} / \mathrm{G} / \mathrm{R}$ \\
\hline ShuntEtot_kWh_Avg(5) & $\mathrm{kWh}$ & $\begin{array}{l}\text { Output circuit total accumulated energy } \\
\text { from combiner box } 5 \text {, meas. using shunts } \\
\text { and voltage divider* }\end{array}$ & - & $\mathrm{C} / \mathrm{G}$ \\
\hline ShuntEtot_kWh_Avg(6) & $\mathrm{kWh}$ & $\begin{array}{l}\text { Output circuit total accumulated energy } \\
\text { from combiner box } 6 \text {, meas. using shunts } \\
\text { and voltage divider* }\end{array}$ & - & $\mathrm{C} / \mathrm{G}$ \\
\hline ShuntEtot_kWh_Avg(7) & $\mathrm{kWh}$ & $\begin{array}{l}\text { Output circuit total accumulated energy } \\
\text { from combiner box } 7 \text {, meas. using shunts } \\
\text { and voltage divider* }\end{array}$ & - & $\mathrm{C} / \mathrm{G}$ \\
\hline ShuntPDC_kW_Avg(1) & $\mathrm{kW}$ & $\begin{array}{l}\text { Output circuit power from combiner box } 1 \text {, } \\
\text { meas. using shunts and voltage divider* }\end{array}$ & - & $\mathrm{C} / \mathrm{G} / \mathrm{R}$ \\
\hline ShuntPDC_kW_Avg(2) & $\mathrm{kW}$ & $\begin{array}{l}\text { Output circuit power from combiner box } 2 \text {, } \\
\text { meas. using shunts and voltage divider* }\end{array}$ & - & $\mathrm{C} / \mathrm{G} / \mathrm{R}$ \\
\hline ShuntPDC_kW_Avg(3) & $\mathrm{kW}$ & $\begin{array}{l}\text { Output circuit power from combiner box } 3 \text {, } \\
\text { meas. using shunts and voltage divider* }\end{array}$ & - & $\mathrm{C} / \mathrm{G} / \mathrm{R}$ \\
\hline ShuntPDC_kW_Avg(4) & $\mathrm{kW}$ & $\begin{array}{l}\text { Output circuit power from combiner box } 4 \text {, } \\
\text { meas. using shunts and voltage divider* }\end{array}$ & - & $\mathrm{C} / \mathrm{G} / \mathrm{R}$ \\
\hline ShuntPDC_kW_Avg(5) & $\mathrm{kW}$ & $\begin{array}{l}\text { Output circuit power from combiner box } 5 \text {, } \\
\text { meas. using shunts and voltage divider* }\end{array}$ & - & $\mathrm{C} / \mathrm{G}$ \\
\hline ShuntPDC_kW_Avg(6) & $\mathrm{kW}$ & $\begin{array}{l}\text { Output circuit power from combiner box } 6 \text {, } \\
\text { meas. using shunts and voltage divider* }\end{array}$ & - & $\mathrm{C} / \mathrm{G}$ \\
\hline ShuntPDC_kW_Avg(7) & $\mathrm{kW}$ & $\begin{array}{l}\text { Output circuit power from combiner box } 7 \text {, } \\
\text { meas. using shunts and voltage divider* }\end{array}$ & - & $\mathrm{C} / \mathrm{G}$ \\
\hline TemperatureFaults & - & Inverter temperature fault code & Max & $\mathrm{R}$ \\
\hline TIMESTAMP & LST & Date and time & Max & $\mathrm{C} / \mathrm{G} / \mathrm{R}$ \\
\hline Warnings & - & Inverter system warning code & Max & $\mathrm{R}$ \\
\hline WindDir_deg & $\circ$ & Wind direction, clockwise from north & - & $\mathrm{C} / \mathrm{G} / \mathrm{R}$ \\
\hline WindDirAve_deg & $\circ$ & Unit vector mean wind direction* & - & $\mathrm{C} / \mathrm{G} / \mathrm{R}$ \\
\hline WindDirStdDev_deg & $\circ$ & Standard deviation of the wind direction* & - & $\mathrm{C} / \mathrm{G} / \mathrm{R}$ \\
\hline
\end{tabular}




\begin{tabular}{|c|c|c|c|c|}
\hline WindHeatStateID & - & $\begin{array}{l}1=\text { heating disabled } \\
2=\text { enabled, not heating } \\
3=50 \% \text { heating } \\
4=100 \% \text { heating } \\
5=\text { error }\end{array}$ & Average & $\mathrm{C} / \mathrm{G} / \mathrm{R}$ \\
\hline WindRef_V & $\mathrm{V}$ & Internal reference voltage in wind sensor & Min & $\mathrm{C} / \mathrm{G} / \mathrm{R}$ \\
\hline WindSpeed_ms & $\mathrm{m} / \mathrm{s}$ & Wind speed & Max & $\mathrm{C} / \mathrm{G} / \mathrm{R}$ \\
\hline WindSpeedAve_ms & $\mathrm{m} / \mathrm{s}$ & Mean horizontal wind speed* & - & $\mathrm{C} / \mathrm{G} / \mathrm{R}$ \\
\hline WindValid & - & $\begin{array}{l}\text { Wind sensor data validity } \\
-1=\text { wind data is valid } \\
0=\text { wind data is invalid }\end{array}$ & Average & $\mathrm{C} / \mathrm{G} / \mathrm{R}$ \\
\hline
\end{tabular}

Note: All measurements are sampled every $1 \mathrm{~s}$ except the RTDs, which are sampled every 10 seconds. All measurements are saved every $1 \mathrm{~s}$, except those marked with a "**".

* Calculated from saved $1 \mathrm{~s}$ samples; only the $1 \mathrm{~min}$ aggregate data are saved 


\section{Appendix F. Anonymized Diagram of the Data Acquisition Systems' Communications Network}

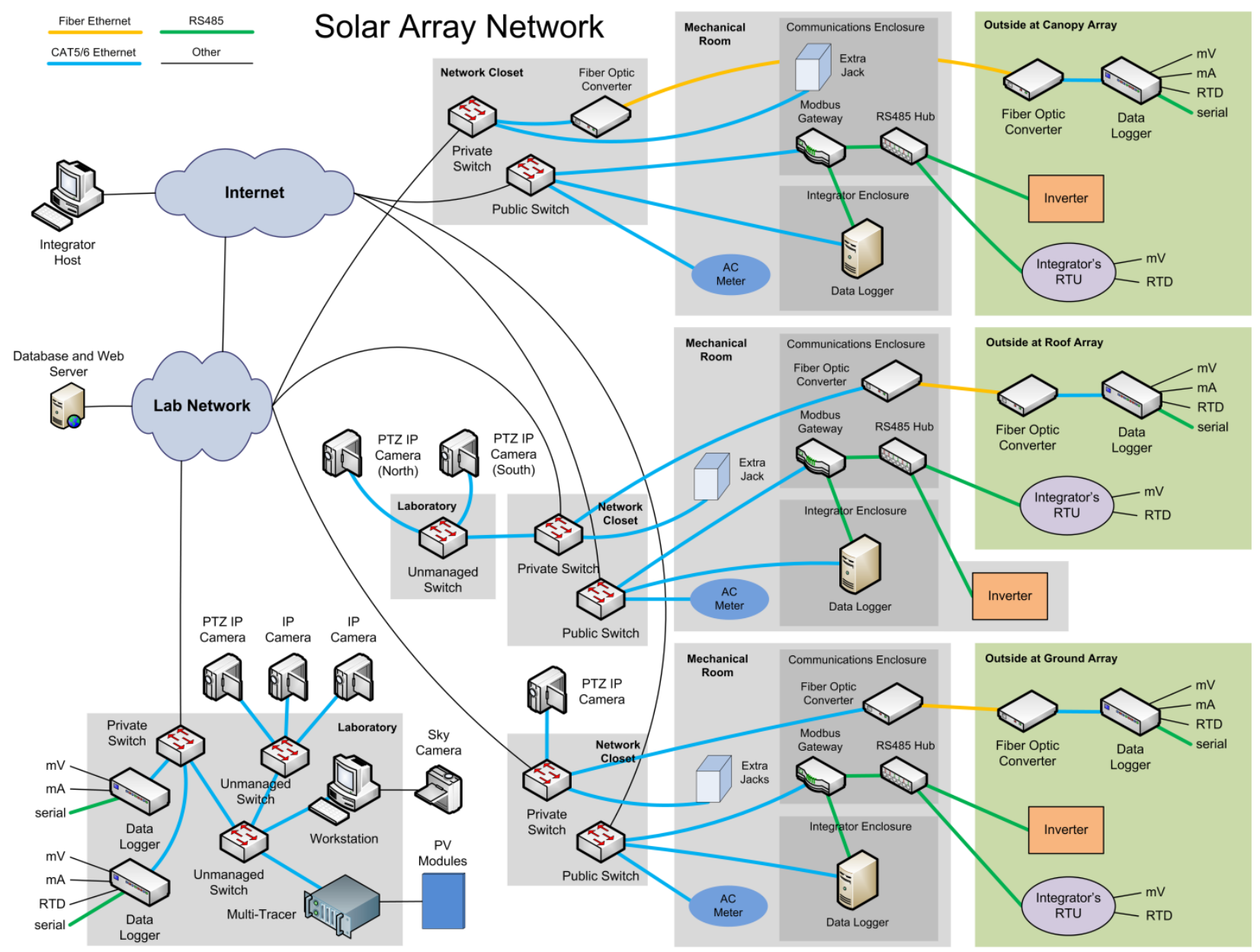

Figure F-1 Anonymized Diagram of the Data Acquisition Systems' Communications Network 